WP 43_13

\author{
Patrick Kline \\ University of California, Berkeley, USA
}

Enrico Moretti

University of California, Berkeley, USA

The Rimini Centre for Economic Analysis (RCEA), Italy

\title{
LOCAL ECONOMIC DEVELOPMENT, AgGLOMERATION ECONOMIES AND THE BIG PUSH: 100 YEARS OF EVIDENCE FROM THE TENNESSEE VALLEY AUTHORITY
}

Copyright belongs to the author. Small sections of the text, not exceeding three paragraphs, can be used provided proper acknowledgement is given.

The Rimini Centre for Economic Analysis (RCEA) was established in March 2007. RCEA is a private, nonprofit organization dedicated to independent research in Applied and Theoretical Economics and related fields. RCEA organizes seminars and workshops, sponsors a general interest journal The Review of Economic Analysis, and organizes a biennial conference: The Rimini Conference in Economics and Finance (RCEF) . The RCEA has a Canadian branch: The Rimini Centre for Economic Analysis in Canada (RCEACanada). Scientific work contributed by the RCEA Scholars is published in the RCEA Working Papers and Professional Report series.

The views expressed in this paper are those of the authors. No responsibility for them should be attributed to the Rimini Centre for Economic Analysis. 


\title{
LOCAL ECONOMIC DEVELOPMENT, AGGLOMERATION ECONOMIES AND THE BIG PUSH: 100 YEARS OF EVIDENCE FROM THE TENNESSEE VALLEY AUTHORITY*
}

\author{
Patrick Kline and Enrico Moretti
}

\begin{abstract}
We study the long run effects of one of the most ambitious regional development programs in U.S. history: the Tennessee Valley Authority (TVA). Using as controls authorities that were proposed but never approved by Congress, we find that the TVA led to large gains in agricultural employment that were eventually reversed when the program's subsidies ended. Gains in manufacturing employment, by contrast, continued to intensify well after federal transfers had lapsed - a pattern consistent with the presence of agglomeration economies in manufacturing. Because manufacturing paid higher wages than agriculture, this shift raised aggregate income in the TVA region for an extended period of time. Economists have long cautioned that the local gains created by place based policies may be offset by losses elsewhere. We develop a structured approach to assessing the TVA's aggregate consequences that is applicable to other place based policies. In our model, the TVA affects the national economy both directly through infrastructure improvements and indirectly through agglomeration economies. The model's estimates suggest that the TVA's direct investments yielded a significant increase in national manufacturing productivity, with benefits exceeding the program's costs. However, the program's indirect effects appear to have been limited: agglomeration gains in the TVA region were offset by losses in the rest of the country. Spillovers in manufacturing appear to be the rare example of a localized market failure that cancels out in the aggregate.
\end{abstract}

JEL Codes: R11, J20, N92, O40

${ }^{*}$ We thank the referees, two editors, Daron Acemoglu, Raj Chetty, Janet Currie, Donald Davis, Yuriy Gorodnichenko, Chang-Tai Hsieh, Rick Hornbeck, Costas Meghir, Evan Rawley, Stephen Redding, Chris Udry and seminar participants at Berkeley, Columbia, UC Davis, the Econometric Society Summer Meetings, Harvard, Humboldt, LSE, Maryland, Michigan, the NBER Summer Institute, Paris Sciences Po, Pompeu Fabra, Princeton, Stanford, Tinbergen, Yale, Wharton, Wisconsin, UBC, and UCLA for useful comments. We thank Olivier Deschenes and Alan Barreca for providing us with some of the data. We gratefully acknowledge the Berkeley Center for Equitable Growth for funding support. We thank Michel Serafinelli, Valentina Paredes, Juan Pablo Atal, Edson Severnini and Owen Zidar for excellent research assistance. Corresponding author: Patrick Kline, Department of Economics, University of California, 530 Evans Hall \#3880 Berkeley, CA 94720-3880; email: pkline@berkeley.edu. 


\section{Introduction}

Like most countries, the United States exhibits vast differences in income across cities and regions. After adjusting for skill composition, average wages in the highest and lowest paying U.S. metropolitan areas differ by nearly a factor of three (Moretti, 2011). Such disparities have prompted governments to create a variety of place based economic development policies aimed at reducing regional inequality. These programs, which target public resources towards disadvantaged geographic areas rather than towards disadvantaged individuals, are widespread. In the U.S., it is estimated that federal and local governments spend roughly $\$ 95$ billion per year on such programs, significantly more than Unemployment Insurance in a typical year. ${ }^{1}$

In many cases, place based policies seek to attract manufacturing plants to a specific jurisdiction. Such programs have arguably become the de-facto industrial policy in the United States, and are also widespread in Europe and Asia. A fundamental concern often raised by economists is that spatially targeted policies may simply shift economic activity from one locality to another, with little impact on the aggregate level of output. In such a case, the benefits enjoyed by the target locality may come at the expense of other (possibly quite distant) areas. Echoing this concern, Glaeser and Gottlieb (2008) conclude in a recent review that "any government spatial policy is as likely to reduce as to increase welfare." Likewise, a recent analysis by the New York Times describes such policies as a "zero sum game" among American communities (Story, 2013).

In this paper, we evaluate one of the most ambitious place based economic development policies in the history of the United States: the Tennessee Valley Authority (TVA). Charged by President Roosevelt with "touching and giving life to all forms of human concerns" the program was intended to modernize the economy of the Tennessee Valley region via a series of large scale infrastructure investments including electricity generating dams and an extensive network of new roads, canals, and flood control systems.

The TVA makes for a particularly interesting case study for at least two reasons. First, because of its large size and ambitious goals, the TVA program is perhaps the best example of a "big push" development strategy in the history of the United States. Such strategies are predicated on the notion that economic development exhibits threshold effects, so that large enough public investments in a severely underdeveloped region may generate huge increases in productivity and welfare (Rosenstein-Rodan, 1943; Murphy, Shleifer, and Vishny, 1989; Azariadis and Stachurski, 2005). An important channel through which this process might occur when output is traded on national markets involves agglomeration forces, particularly productive spillovers between workers and firms, which have received a growing amount of theoretical and empirical attention in the literature (Ellison and Glaeser, 1999; Rosenthal and Strange, 2004; Greenstone, Hornbeck and

\footnotetext{
${ }^{1}$ The federal government spends about $\$ 15$ billion annually (GAO, 2012). Story (2013) estimates that state and local governments spend at least $\$ 80$ billion annually. In addition to the direct provision of subsidies, states often compete on income and corporate taxes and labor and environmental regulations. Bartik (1991) provides a comprehensive taxonomy of place based policies.
} 
Moretti, 2010). At the time of the TVA's inception in 1933, its service region was among the poorest, least developed, areas in the nation. If the program's large localized investments in public infrastructure failed to yield a sustained boost in local productivity, it is hard to imagine what programs might have succeeded.

Second, the timing of federal investments in the TVA provide an opportunity to examine whether a lapsed development policy may have persistent effects. At the program's peak in the period 19501955 , the annual federal subsidy to the region amounted to $\$ 750$ for the typical household (roughly $10 \%$ of household income). By 1960 however, that figure had become negligible, as Congress made the TVA a fiscally self-sustaining entity. Big push models of development typically suggest the positive effects of an initial subsidy on the local economy may be long lasting provided the initial investment is large enough. The TVA provides us with an opportunity to scrutinize this prediction empirically. In doing so, we contribute to a growing literature on the persistence and uniqueness of spatial equilibria (Davis and Weinstein, 2002, 2008; Redding, Sturm, and Wolf, 2011).

Our analysis proceeds in two steps: we first conduct a reduced form evaluation of the TVA's local impacts. We then use a more structured approach to assess the program's national impacts.

The first part of the paper uses a rich panel data set of counties to conduct an evaluation of the dynamic effects of the TVA on the regional economy in the seventy year period following the program's inception. The manufacturing and agricultural sectors are analyzed separately, as there is a long standing presumption in the literature that manufacturing exhibits agglomeration economies but little reason to expect such effects in agriculture (Hornbeck and Naidu, 2012). To identify regional counterfactuals, we exploit the fact that in the years following the program's inception, Congress considered creating six additional regional authorities modeled upon the TVA. Due to political infighting, these additional authorities were never approved. We use the counties covered by authorities that were proposed but never implemented as controls for TVA counties with similar observable characteristics. Two other controls groups with similar characteristics are also considered. Placebo tests indicate that our covariates are successful at balancing economic trends in TVA and control counties in the two decades before the program began.

We find that between 1930 and 1960 - the period during which federal transfers were greatest the TVA generated gains in both agricultural and manufacturing employment. However, between 1960 and 2000 - during which time federal transfers were scaled down - the gains in agriculture were completely reversed, while the gains in manufacturing employment continued to intensify. Thus, forty years after TVA became financially self-sufficient, manufacturing employment in the region was still growing at a significantly faster pace than the comparison group. Because the manufacturing sector paid higher wages than agriculture, this shift raised aggregate income in the TVA region for an extended period of time.

A key question for policy purposes is whether the local gains associated with the TVA came at the expense of other parts of the country. In the second part of the paper, we seek to quantify 
the impact of the TVA on national welfare. This exercise is complicated by the difficulty of constructing a credible counterfactual for the entire nation. Put simply, we don't observe the entire U.S. economy in the absence of the TVA. We address this problem by developing an equilibrium model to structure our empirical analysis. Methodologically, our approach has the advantage of being extremely tractable and is easily adapted to the evaluation of other placed based policies.

In the model, the TVA affects the national economy in two ways. First, the TVA directly raises labor productivity due to the improvement in public infrastructure. With mobile workers, these localized productivity gains will yield national labor market impacts. Second, the program may have an indirect effect through agglomeration economies, if they exist. This second channel allows for the possibility - highlighted by the big push literature - that the effects of a one-time localized public investment might become self sustaining due to agglomeration economies. In our setting, agglomeration economies are technological externalities that arise through social interactions and learning (Moretti, 2004) or thick market effects (Marshall, 1890). ${ }^{2}$ Building on Glaeser and Gottleib (2008), the model clarifies the conditions under which place based policies can affect aggregate output. Reallocating economic activity from one region of the country to another results in a long run increase in total output only when the elasticity of agglomeration with respect to economic density is greater in the receiving region.

We develop a dynamic panel approach to estimating both the direct and indirect productivity effects of the TVA. The model parameters governing agglomeration are identified using restrictions on the timing and serial dependence of unobserved productivity shocks. Corroborating these restrictions, the estimated model yields predictions quantitatively consistent with the results of our reduced form program evaluation of the TVA's dynamic effects.

We find that the TVA's direct productivity effects were substantial. The investments in productive infrastructure resulted in a large increase in local manufacturing productivity, which in turn led to a $0.3 \%$ increase in national manufacturing productivity. By contrast, the indirect effects of the TVA on manufacturing productivity were limited. While we do find strong evidence of localized agglomeration economies in the manufacturing sector, our empirical analysis clearly points to a constant agglomeration elasticity. When the elasticity of agglomeration is the same everywhere in the country, spatially reallocating economic activity has no aggregate effects, as the benefits in the areas that gain activity are identical to the costs in areas that lose it. Thus, we estimate that the spillovers in the TVA region were fully offset by the losses in the rest of the country. Spillovers in manufacturing appear to be the rare example of a localized market failure that "cancels out" in the aggregate. Notably, this finding casts doubt on the traditional big push rationale for spatially progressive subsidies.

\footnotetext{
${ }^{2}$ The big push literature has traditionally focused on models with demand externalities, whereby income growth in an area causes increases in the demand for local goods and services and stimulates entry of firms with better technologies, ultimately resulting in higher aggregate productivity (Rosenstein-Rodan, 1943; Murphy, Shleifer, and Vishny, 1989).
} 
Using our model estimates to conduct a cost-benefit analysis, we find the net present value of the TVA program's long run benefits and costs to be $\$ 22 \mathrm{~B}$ and $\$ 17.3 \mathrm{~B}$, respectively. This positive rate of return to the TVA's federal investments is entirely explained by the direct productivity effects of the program's infrastructure investments. We caution, however, that our calculation of net benefits depends on conditions that are likely specific to the inception of the TVA program.

The remainder of the paper is organized as follows. Section II describes the program. Section III provides estimates of the impact of the TVA on the region's economy. Section IV develops our spatial equilibrium model. Section V estimate the model's parameters and the program effects on the national economy. Section VI concludes.

\section{The Tennessee Valley Authority Program}

\section{II.A. Brief History}

The TVA is a federally owned corporation created by Congress on May 18, 1933 with the passage of the Tennessee Valley Authority Act. At the time of its inception, the Authority's primary objective was to invest in, and rapidly modernize, the Tennessee Valley's economy. The TVA service area, pictured in Figure I, includes 163 counties spanning several states, including virtually all of Tennessee, and substantial portions of Kentucky, Alabama, and Mississippi. The federal effort to modernize the TVA region's economy entailed one of the largest place based development programs in U.S. history. Large investments were made in public infrastructure projects including a series of hydroelectric dams, a 650-mile navigation canal, and an extensive road network, with additional money flowing to the construction of new schools and flood control systems. ${ }^{3}$

Probably the most salient changes prompted by the TVA came from the electricity generated by the Authority's dams. Electricity was intended to attract manufacturing industries to what was a heavily agricultural region. While, in principle, electricity could have been exported outside the region, the Authority primarily sold to municipal power authorities and cooperatives inside its service area at reduced rates.

Between 1934 and 2000, federal appropriations for the TVA totaled approximately $\$ 20$ billion (2000 dollars). The size of these transfers varied significantly across decades. A time series of federal transfers to the Authority is shown in Figure II. Only a small fraction of total federal appropriations were actually used in the program's first seven years. The bulk of federal investment occurred over the period 1940-1958, during which time approximately $73 \%$ of federal transfers took place. This manifested in a correspondingly frenzied pace of TVA activity over this interval. Construction of the navigation canal began in 1939, and was completed in 1945, while most of the roads were built during the 1940s and 1950s. With the onset of World War II, construction of the dams became a national

\footnotetext{
${ }^{3}$ Funds were also spent on a hodgepodge of smaller programs including malaria prevention, soil erosion mitigation programs, educational programs, health clinics, the distribution of cheap fertilizers to farmers, reforestation and forest fire control, and provision of federal expertise for local economic development.
} 
priority due to the increased demand for aluminum; by 1942, 12 dams were under construction. By the end of the war, the Authority had become the largest single supplier of electricity in the country. Peak transfers occurred over the period 1950-1955, during which time the federal government was transferring approximately $\$ 150$ to each resident in each year in the form of subsidies to TVA. Since, at the time, the typical household in TVA counties had 5 members, the per household transfer was roughly $\$ 750$ per year, or about $10 \%$ of average household income.

In 1959, Congress passed legislation making the TVA power generation system self-financing. From that year on, federal subsidies declined sharply. Figure II shows that the magnitude of the overall federal transfer dropped significantly in the late 1950's -both in absolute and percapita terms-and remained low in the following four decades. Currently, TVA no longer receives a substantial net federal transfer.

\section{II.B. Selection into the TVA and Summary Statistics}

In order to understand the sorts of selection bias that might plague an evaluation of the TVA, it is important to understand how the geographic scope of the program was determined. Arthur E. Morgan (the Authority's first chairman) and other contemporary sources list several criteria that were used to determine the TVA service region (Morgan, 1934; Barbour, 1937; Boyce, 2004; Kimble, 1933; Menhinick, and Durisch, 1953; Satterfield, 1947). These criteria prioritized counties which (i) were heavily rural and required additional electric power; (ii) experienced severe flooding and/or had misguided land use; (iii) experienced heavy deficits; (iv) lacked public facilities such as libraries, health services and schools; (v) were willing to receive technical and advisory assistance from the TVA; (vi) had planning agencies and enabling legislation and agreed to experiment with new fertilizers; and (vii) were within reasonable transmission distance of power plants. ${ }^{4}$

Based on these criteria, it is reasonable to expect TVA counties to have been less developed than other parts of the country. The data generally confirm this impression. Our data come from a county-level panel covering the years 1900 to 2000 which we constructed using both microdata and published tables from the Population Census, the Manufacturing Census and the Agricultural Census. We also use topographic variables collected by Fishback, Haines, and Kantor (2011). The quality of some of the key variables is not ideal. Details on data construction and quality issues are provided in the Appendix.

In Table I we compare the average mean county characteristics in 1930 (i.e. before the start of the program) for TVA counties (column 1), all non-TVA counties (column 2), and non-TVA counties in the South (column 3). Based on 1930 levels, TVA counties appear to have had worse economic outcomes than other U.S. counties and other Southern counties. In particular, in 1930 the economies of TVA counties were significantly more dependent on agriculture and had a significantly smaller

\footnotetext{
${ }^{4}$ The list of counties to be included in the service region was first drafted by geographers at the Division of Land Planning and Housing based on the above criteria and later approved by the TVA Board of Directors
} 
manufacturing base, as measured by the share of workers in the two sectors. Manufacturing wages, housing values and agricultural land values were all lower, pointing to lower local productivity. TVA counties also tended to be less urbanized, had lower literacy rates and, in contrast with the rest of the country, had virtually no foreign immigrants. The lower fraction of households with a radio likely reflects both the lower local income level and the lack of electricity. TVA counties had a higher fraction of white residents than the rest of the South. The lower panel of Table I reports the average 10-year percentage changes between 1920 and 1930 for our covariates and suggests that the TVA region also exhibited somewhat different trends over the 1920s than the rest of the country.

Overall, Table I confirms that the Tennessee Valley was, at the time of the Authority's inception, an economically lagging region, both relative to the rest of the nation and, to a lesser extent, the South. This backwardness in levels coincides with some trend differences consistent with simple models of regional convergence (e.g. Barro and Sala-i-Martin, 1991). In particular, the TVA region exhibited greater growth in manufacturing share than the rest of the country accompanied by a faster rate of retrenchment in agriculture, issues which we are careful to address in the next section's empirical evaluation of TVA's long run impact.

\section{II.C. Proposed Authorities}

From the beginning, TVA was supposed to be the first of many regional Authorities. In a 1933 message to Congress urging passage of the Tennessee Valley Authority legislation, President Roosevelt stated that: "If we are successful here we can march on, step by step, in a like development of other great natural territorial units within our borders." In the next few years, reports of the alleged success of the TVA moved many members of Congress and regional leaders - especially Senator George W. Norris of Nebraska - to support the creation of additional Authorities in other parts of the United States. This effort culminated in the introduction by Senator Morris on June 3, 1937 of a Senate bill that envisioned the creation of seven new Authorities, one for each region of the country.

At the time, the bill was considered likely to pass. ${ }^{5}$ But a split within the FDR administration on the exact nature of the power to be granted to the Authorities led to delays, postponements and the ultimate failure of the bill. ${ }^{6}$ The push for new authorities, suspended by the onset of

\footnotetext{
${ }^{5}$ In his detailed account of the events, Leuchtenburg (1952) notes that "throughout the spring of 1937, newspaper dispatches left little reason to conclude anything but that Roosevelt and Norris were one in attempting to extend the TVA pattern to several other regions" and that Congress appeared generally supportive.

${ }^{6}$ Specifically, Leuchtenburg (1952) reports that Agriculture Secretary Henry Wallace and War Secretary Harry Woodring objected to the plan. Wallace and Woodring told Roosevelt that they would approve of regional planning authorities only if they were limited to a planning role. In addition, planners in Roosevelt's advisory National Resources Committee opposed features of the Norris bill that conflicted with their own proposals, which they never introduced as legislation. Power companies and Senator Copeland of New York opposed power production by valley authorities. Roosevelt asked his staff to redraft Norris's bill with the watered-down planning features that Wallace and Woodring had suggested. Senator Joseph J. Mansfield, chair of the House Rivers and Harbors Committee, introduced a competing watered down bill with a different set of provisions. Ultimately, the Norris bill and the Mansfield bills failed to overcome opposition.
} 
World War II, gathered new momentum towards the end of the war. In 1945, ten bills proposing the establishment of "valley authorities" comparable to the Tennessee Valley Authority were before Congress. Contemporary accounts suggest that approval was again considered likely. ${ }^{7}$ But none of the bills mustered enough support for final approval and they were ultimately dropped.

In our empirical analysis, we use these failed attempts to create additional Authorities to construct a set of counterfactual regions. These authorities offer a credible counterfactual because they were modeled on TVA, and were therefore likely to be economically similar by design. The proposed authorities had a reasonable ex-ante chance of getting implemented but ultimately failed due to largely exogenous political reasons. Thus, economic changes in these regions may be informative of the changes that might have occurred to the TVA regional economy had TVA not been implemented.

A limitation is that while the proposed legislation identified the general geographical scope of the regional authorities, it did not specify exactly which counties were going to belong to each authority. This requires us to make some assumptions on their exact geographical definition. We end up using six Authorities: an Atlantic Seaboard Authority, a Great Lakes-Ohio Valley Authority, Missouri Valley Authority, Arkansas Valley Authority, Columbia Authority, and a Western authority. They include 828 counties in 25 states. In the Appendix, we provide details on the algorithm used to impute their borders and a map of the regions.

Column 4 in Table I presents summary statistics for counties belonging to the proposed authorities. Since the proposed authorities were chosen with criteria similar to TVA, they have pre-program characteristics generally closer to the TVA counties than the average U.S. county. Among the key variables of interest, a comparison of columns 1 and 4 reveals that $7.5 \%$ and $7.7 \%$ of workers are employed in manufacturing in 1930 in the proposed authorities and in the TVA region, respectively. The corresponding figure for the average U.S. county outside the TVA region is significantly higher at $9 \%$. In the case of agricultural employment share, the means in TVA, proposed authorities, and the non-TVA U.S. are $61 \%, 51 \%$ and $45 \%$, respectively. More importantly, the change over time in the manufacturing share between 1920 and 1930 in the proposed authorities and in the TVA is respectively $-.010 \%$ and $-018 \%$, vs. a nationwide change of $-0.035 \%$. However, trends in population, employment, and housing units in the counterfactual authorities differ somewhat from trends in the TVA.

\section{The Effects of the TVA on the Local Economy}

The literature evaluating the effects of place based economic development policies has typically focused on credibly identifying short run effects on job creation and investment. Establishing that

\footnotetext{
${ }^{7}$ For example, Clark (1946) observes that "it seems almost a certainty that within a few years the regional authority idea which has received so much publicity as a result of the success of the TVA will be given further impetus by the enactment of additional valley authority laws."
} 
subsidies which target an area raise contemporaneous employment is a useful first step. However, the contemporaneous effects of these policies are likely to provide an incomplete assessment of the costs and benefits of such an intervention. Our interests center on estimating the long run effects of the TVA. In particular, we wish to learn what happened to the TVA regional economy after the federal subsidies associated with the program lapsed.

The existing evidence on the long run effects of location based policies is scant, which may be one of the reasons why such programs tend to be so controversial. Critics argue that these policies are a waste of public money, while officials of localities that receive transfers are often supportive. In 1984, the influential urban thinker Jane Jacobs published a scathing critique of the Authority - and, by extension, of many similar programs - with an unambiguous title: "Why TVA Failed." However, systematic empirical evidence on the long run effects of the TVA program on economic activity is limited.

\section{III.A. Econometric Model}

To identify the long run effect of TVA on local economies, we compare the economic performance of TVA counties with the performance of counties with similar pre-program characteristics located: (i) in the rest of the country; (ii) in the rest of the South; (iii) in the proposed Authorities. We control for pre-program differences between TVA counties and controls using Oaxaca-Blinder regressions. This is, we first fit regression models to the non-TVA counties of the form:

$$
y_{i t}-y_{i t-1}=\alpha+\beta X_{i}+\left(\epsilon_{i t}-\epsilon_{i t-1}\right)
$$

where $y_{i t}-y_{i t-1}$ is the change in the relevant dependent variable between year $t-1$ and $t$ for county $i$ and $X_{i}$ is a vector of preprogram characteristics. We then use the vector $\hat{\beta}$ of estimated coefficients to predict the counterfactual mean for the treated counties. Our vector of covariates includes a rich set of 38 economic, social, demographic and geographical variables measured in 1930 and in $1920 .{ }^{8}$ These covariates control not only for differences in levels between TVA and non-TVA counties before the program, but also for differences in trends. Because it is possible that counties outside but near TVA are directly affected by the program, we drop from the sample all non-TVA counties that border the TVA region. ${ }^{9}$

\footnotetext{
${ }^{8}$ In particular, controls incude a quadratic in 1920 and $1930 \log$ population and interactions; 1920 and 1930 urban share; 1920 and 1930 log employment; a quadratic in 1920 and 1930 agricultural employment share; a quadratic in 1920 and 1930 manufacturing employment share; 1920 and 1930 log wages in manufacturing; 1920 and 1930 log wages in trade (retail + wholesale); dummies for 1920 and 1930 wages in manufacturing or trade being missing; 1920 and 1930 farm values, owner occupied housing values and rental rates; a quadratic in 1920 and 1930 white share; the share of the population age 5+ that are illiterate in 1920 and 1930; the 1920 and 1930 share of whites who are foreign born; the 1930 share of households with a radio; the 1930 unemployment rate, maximum elevation, and elevation range (to capture mountainous terrain).

${ }^{9}$ In principle, this spillover could be positive or negative. On the one hand, border counties may benefit from higher demand for labor because of demand leakages from infrastructure construction inside TVA. On the other hand, border counties may experience a decline in labor demand if the program induces firms that would have located there
} 
The Oaxaca-Blinder regression has the advantage over standard regression methods of identifying the average treatment effect on treated counties in the presence of treatment effect heterogeneity. ${ }^{10}$ Another appealing characteristic is its dual interpretation as a propensity score reweighting estimator (Kline, 2011). Each control county is implicitly assigned a weight in providing an estimate of the counterfactual TVA mean: counties that look more similar to TVA counties in the years before TVA receive more weight. This weight is proportional to an estimate of the odds of treatment. The weights generated by a Oaxaca regression in the set of all non-TVA counties satisfying our selection criteria are depicted in Figure III. The map indicates that in generating a counterfactual, our estimates place more weight on Southern counties, which tend to be substantially more comparable to TVA counties in terms of their pre-intervention characteristics.

When comparing TVA to the rest of the country and the South, we further increase comparability of TVA and control counties by dropping from our models control counties which, based on their pre-program characteristics, appear to be substantially different from TVA counties (see Angrist and Pischke, 2008 for a similar exercise). In practice, we estimate a logit model of the probability of being included in the TVA service area based on the aforementioned vector of regressors. We drop from the analysis all non-TVA counties with a predicted probability of treatment in the bottom 25 percent. This criterion leads us to drop 584 non-TVA counties (25\% of the total-by construction), 16 of which are located in the South (2\% of the Southern total). Appendix Figure A1 provides a map of counties in our trimmed estimation sample. Columns 5 and 6 in Table I show the unconditional averages in the trimmed estimation sample. While the exclusion of counties with low probability of treatment reduces some of the differences with TVA counties, other important differences remain, both in levels and trends. When comparing TVA to the failed authorities, we do not drop counties with low propensity scores because we want this identification strategy to be based only on the historical accident of the failed authorities.

An important concern in estimating equation 1 is that the residual is likely to spatially correlated. We deal with this possibility by presenting two sets of standard errors. First, we compute standard errors clustered by state. These variance estimates allow for unrestricted spatial correlation across counties within each state, but assume no correlation across states. Second, we use a spatial Heteroscedasticity and Autocorrelation Consistent (HAC) variance estimator based upon the method of Conley (1999), which allows for correlation between counties that are geographically close but belong to different states.

Of course, the TVA was not the only spatially biased intervention occurring over our sample period. Since the 1930's, the federal government has adopted a wealth of policies that affect the geography of economic activity. This is obviously true of explicitly location based policies like Empowerment Zones (Busso, Gregory, and Kline, 2013) but also of other federal interventions that affect local labor demand, like the construction of the federal highway system (Michaels, 2008) or

to locate in the TVA region instead.

${ }^{10}$ In practice, standard regression models yield similar results. 
military expenditures (Blanchard and Katz, 1992). More generally a variety of government policies may have had uneven geographic impacts including federal taxation (Albouy, 2009), environmental regulation (Chay and Greenstone, 2003, 2005) or labor regulation (the Taft-Hartley Act, for example, effectively allowed Southern states to become right-to-work states). Thus, our estimates are to be interpreted as the impact of the TVA on the TVA region, allowing for the potentially endogenous response of other federal and local policies that might have occurred over the time period in question.

\section{III.B. Placebo Test}

In order to evaluate the effectiveness of our controls in matching the pre-treatment growth patterns of the TVA region, Table II shows the results of a placebo analysis, where we estimate the "effect" of the TVA on 1900-1940 changes in population, employment, housing units, manufacturing wages, industry structure and agricultural land values. This false experiment tests whether, conditional on controls, our outcome variables are trending differently in TVA counties and non-TVA counties in the decades leading up to the policy intervention. Because the period 1900-1940 is temporally prior to the TVA treatment, the finding of significant differences between TVA counties and controls would be evidence of selection bias. ${ }^{11}$

Column 1 shows the unconditional difference between TVA counties and non-TVA counties, while column 3 shows the difference conditioning on our vector of controls. Columns 2 and 4 report standard errors clustered by state. Column 5 reports standard errors obtained from a spatial Heteroscedasticity and Autocorrelation Consistent (HAC) variance estimator (Conley, 1999), where we use a bandwidth of 200 miles. Throughout the paper, we report decadalized growth rates to aid comparability across tables. In Table II, for example, the 1900-1940 changes are divided by four. Thus, entries are to be interpreted as average differences in 10-year growth rates experienced by TVA counties relative to non-TVA counties in the four decades between 1900 and 1940.

A comparison of Columns 1 and 3 in panel A highlights the importance of our controls in the sample of all U.S. counties. Column 1 indicates that while trends in population, employment, housing units and manufacturing wages are similar in TVA and non-TVA counties, statistically different trends are present in manufacturing and agricultural share and the value of agricultural land. Though they are statistically significant, the differential trends in manufacturing and agricultural share are relatively small. The trend in agricultural land values however is quite large. These differences may be evidence that, in the absence of treatment, TVA counties would have caught up with the rest of the country, at least along some dimensions. However, column 3 shows that, after conditioning on 1920 and 1930 covariates, all of these differences become statistically indistinguishable from zero. Notably, this is due to the point estimates shrinking substantially rather than an increase in the standard errors.

\footnotetext{
${ }^{11}$ All our controls are measured in 1920 and 1930. We focus on the 1900-1940 change in order to avoid the possibility of a spurious mechanical correlation between the regressors and outcomes due to measurement error. As we argued before, the vast majority of the federal investment took place after 1940.
} 
Panel B reports analogous figures for the sample of Southern counties. In this panel, we focus on spatial HAC standard errors because state clustered standard errors are unlikely to be valid when considering just one region of the country. In this case, both the unconditional differences and the conditional differences are statistically indistinguishable from zero. Thus, even before controlling for any covariates, the economic and demographic trends in TVA counties are not different from the rest of the South. This suggests that Southern counties may represent a good counterfactual for the TVA region.

Panel C presents the result of a placebo experiment based on the proposed authorities. Only the change in agricultural land values appears to be statistically different before conditioning (column 1). Like for panel $\mathrm{A}$, the difference in land value trends is economically very large. However, the difference becomes considerably smaller and statistically insignificant after conditioning on our controls (column 3).

Overall, we interpret the evidence in Table II as broadly supportive of the notion that our controls capture the bulk of the selectivity biases associated with a comparison of TVA to non-TVA counties. In the case of the South, TVA counties seems comparable even before conditioning on our controls.

Of course, the tests in Tables II are based on features of local economies that we can observe. They cannot tell us whether there are unobserved features of the TVA region that differ from our comparison groups. Thus we can not completely rule out the possibility that TVA counties experienced unique unobserved shocks between 1940 and 2000. However, we think it unlikely that the three sets of comparison groups (the U.S., the South, and the proposed authorities) would suffer from identical selection biases. Hence, we focus on conclusions that appear robust across the three sets of controls.

\section{III.C. Estimates of the Local Effects of the TVA}

Long Run Estimates. Panel A in Table III provides estimates of the effect of TVA on long run growth rates, using all U.S. counties as a comparison group. Column 1 reports the unconditional difference between TVA counties and non-TVA counties in the 1940-2000 decadalized change in the relevant outcome. Column 3, our preferred specification, shows the corresponding conditional difference. As was the case in Table II, the substantial differences between our unconditional and conditional estimates illustrate the importance of controlling for pre-treatment characteristics in the entire U.S. sample. The TVA region appears to have been poised for greater growth, along several dimensions, even in the absence of the program. Many of these effects, however, are eliminated by our covariate adjustments.

After conditioning, the most pronounced effects of the TVA appear to be on the sectoral mix of employment. TVA is associated with a sharp shift away from agriculture toward manufactur-

ing. Specifically, column 3 in Panel A indicates that the 1940-2000 growth rate of agricultural 
employment was significantly smaller and the growth rate of manufacturing employment was significantly larger in TVA counties than non-TVA counties. These estimated impacts on growth rates are economically large, amounting to $-5.6 \%$ and $5.9 \%$ per decade, respectively.

Perhaps surprisingly, manufacturing wages do not respond significantly to the TVA intervention. These small wage effects suggest that, in the long run, workers are quite mobile across sectors and space, allowing the employment mix to change without large corresponding changes in the price of labor. Similarly, the lack of an effect on housing prices may reflect the lack of supply constraints. The estimated effect on median family income (available only since 1950) is statistically insignificant, but quantitatively sizable.

Panel B provides estimates of the effect of TVA on long run growth rates, using only Southern counties as a comparison group. Consistent with the findings in panel B in Table II, we find evidence that selection is less of a concern in this sample, as our conditional and unconditional estimates are more similar. Reassuringly, many of the estimated impacts in column 3 are similar to those in the corresponding column of Panel A in Table III. The estimated impact on agricultural employment and manufacturing employment are -0.51 and .063, respectively. Unlike Panel A in Table III, however, the effect on family income is statistically significant at conventional levels, while the effect on agricultural employment falls to marginal significance and that on manufacturing wages to statistical (and economic) insignificance.

Panel C provides estimates of the effect of TVA on long run growth rates using proposed authorities as a comparison group. ${ }^{12}$ The conditional estimates in column 3 appear to be similar to the ones in Panel A and, especially, the ones in Panel B. The estimated impact on agricultural employment is -0.071 , while the estimated impact on manufacturing employment is 0.053. Like in Panel $\mathrm{B}$, median family income in the TVA region appears to increase faster than in the counterfactual areas.

In general, results based on a comparison of TVA with the rest of the U.S., the rest of the South, and the proposed authorities all yield a consistent picture. The strongest effect of the program was on jobs in agriculture and manufacturing. There is little evidence that local prices, particularly manufacturing wages and housing prices, changed significantly. But median family income seems to have improved, driven presumably by the replacement of agricultural jobs with better paying manufacturing jobs.

Data limitations prevent us from separately identifying the impact of each feature of the TVA program. Kitchens (2011) provides some preliminary evidence on this question. Using archival data on contracted electricity rates, he finds that residents of counties with a TVA electricity contract faced electricity prices comparable to those elsewhere, although large manufacturing firms faced lower rates. He also finds a limited effect of TVA electricity contracts on manufacturing value added. These findings suggest that changes in the local electricity market may not solely account

\footnotetext{
${ }^{12}$ Like for the models that include only Southern counties, we rely on a HAC variance estimator for inference due to the limited number of states in this sample.
} 
for the program's impacts that we uncover. ${ }^{13}$

It is interesting to know what happened to the counties outside, but near, the TVA region. On one hand, it is possible that the TVA led to some displacement of economic activity from geographically proximate regions. On the other hand, it is possible that economic growth within TVA spilled over into neighboring counties. In unreported results, we tried estimating the effects of TVA on adjacent counties using the same models as in Table III. This exercise failed to detect any significant spillover effects (see Table A1 in the Appendix).

Estimates by Period. In Table IV, we present separate estimates for the period 1940-1960 and 1960-2000. Specifically, we estimate Oaxaca-Blinder models analogous to those in column 3 of Table III. We report estimates based on the comparison of TVA counties with all other U.S. counties in columns 1 and 2; with Southern counties in columns 3 and 4; and with counties in proposed authorities in columns 5 and 6 .

Recall that 1940-1960 is the period of maximum generosity of the federal subsidies to TVA. In this period, the TVA region experienced a major increase in transportation infrastructure and electricity supply relative to the rest of the country, paid for by federal funds. By contrast, the four decades after Congress makes TVA financially self-sustaining in 1959 are characterized by limited federal transfers to TVA.

Empirically, the differences between the two periods are striking. In the earlier period the 10-year growth rate of employment in both agriculture and manufacturing is 10.6 - 11.9 percentage points larger in the TVA region than in the rest of the U.S. and the rest of the South. When estimated relative to the proposed authorities, these figures are 11.9 and 9.7 percentage points respectively. These are remarkably large employment effects, probably explained by an increase in labor demand due to the rapid electrification of the region and the addition of new transportation infrastructure. The impacts on growth rates of population and farm land values also appear substantial, however the estimates are very imprecise and preclude definitive conclusions. The value of farm production increases significantly.

In the later period the estimated impacts on manufacturing and agricultural employment are quite different. Consistent with the end of federal investment, and the lack of important agglomeration economies, employment growth in agriculture falls behind, reversing the gains of the previous period. Estimates range between -13 and -16 percentage points, depending on the comparison group.

By contrast, even after the cessation of federal outlays, manufacturing employment keeps growing

\footnotetext{
${ }^{13}$ Our paper and Kitchens' paper seek to answer different questions. Kitchens' models include state by year dummies and use an instrumental variable based on distance to TVA dams to identify program effects. Identification comes from the comparison of counties near TVA dams with other counties within the same state and year that are further away from the dam. Therefore, Kitchens' approach aims to estimate the heterogeneity in the TVA treatment effect resulting from the supply of electricity. By contrast, our approach compares the entire TVA region with other areas and seeks to estimate the overall effect of the TVA program on the regional economy, abstracting from the heterogeneity of the effect within the region and irrespective of the specific channel.
} 
significantly faster in TVA counties (although less fast than in the early period). Estimates that use as a comparison group the entire U.S., the South or the proposed authorities, are 3.3, 3.5 and 3.2 percentage points, respectively. We see little evidence of an impact on population or agricultural land values during this period.

\section{III.D. Discussion}

Comparisons of TVA counties against our three control groups yield a picture that is qualitatively and quantitatively very similar. In 1930, the counties of the TVA service area were largely agricultural and their share of manufacturing was significantly lower than the corresponding share in non-TVA counties. The reduced-form evidence indicates that the Authority deeply affected the local economy of treated counties by dramatically accelerating the pace of industrialization, shifting employment out of agriculture and into manufacturing over and above the trends experienced by similar counties outside TVA.

This was accomplished with limited long run impact on local wage rates. Lack of significant wage effects points to a large supply of potential workers capable of moving to the local manufacturing sector from outside the TVA region, the local agricultural sector or the local home sector. The effect on housing values and agricultural land prices also appears to be rather modest. This is consistent with an elastic supply of housing and land - certainly plausible in a region traditionally characterized by limited legal and political constraints to development and very permissive land use regulations.

Importantly, our analysis uncovered a striking degree of temporal heterogeneity in this employment response. Over the period 1940-1960 - when TVA enjoyed large federal transfers - we find a sharp increase both in manufacturing and agricultural employment. While over the period 1960-2000 - when the TVA subsidies were scaled back - we find a retrenchment in agriculture. Manufacturing employment, by contrast, continued to grow even after the end of federal investment.

Of course, the TVA dams and public infrastructure did not disappear when transfers to the region stopped. Rather, the value of these investments gradually depreciated. Our finding that agricultural employment growth collapses after 1960 is consistent with the notion that, without maintenance, the infrastructure put in place between 1930 and 1959 would have fully depreciated by $2000 .{ }^{14}$ In practice, of course, the TVA infrastructure was not allowed to fully depreciate. But from 1959 onwards maintenance of the TVA capital stock was paid for by local taxpayers and local users of electricity.

The resilience of manufacturing employment in the face of this depreciation of the initial capital infusion indicates that firms in the region enjoyed a competitive advantage even after the subsidies lapsed. This is suggestive of agglomeration effects in manufacturing of the type documented by

\footnotetext{
${ }^{14}$ We find this degree of depreciation reasonable. In fact, it is not inconsistent with the rate of depreciation for roads, dams and other public capital estimated by engineers and actually used by planners and governmental agencies in the South, which is often around 5\%. See for example, Mississippi State Auditor (2002).
} 
Greenstone, Hornbeck and Moretti (2010). By contrast, the retrenchment of the agricultural sector after 1960 suggests agglomeration effects in agriculture are limited, a view consistent with recent evidence by Hornbeck and Naidu (2012) who conclude that "agricultural production does not appear to generate local economic spillovers." Because the manufacturing sector paid higher wages than agriculture, these sectoral shifts raised aggregate income in the TVA region for an extended period of time.

\section{A Framework to Evaluate the Effect of TVA on the National Economy}

While the evidence provided in the previous section indicates that the TVA program generated benefits for its service region, its aggregate impact is unclear. A key concern with place based policies is that they may simply reallocate economic activity across space without raising national income. Lack of knowledge of their aggregate impact precludes any assessment of whether these policies are effcient from the point of view of the nation.

We now turn to estimates of the effect of the TVA program on the entire U.S. national economy. Doing so requires adopting a different methodology than the previous section, as we cannot find a suitable control group to serve as an estimate of the counterfactual for the entire U.S. economy in the absence of the TVA. Like other researchers seeking to identify general equilibrium impacts (Donaldson, 2012; Donaldson and Hornbeck, 2012; Ahlfeldt et al., 2012), we need to impose some structure on the data. In the following two sections, we lay the groundwork for a structured costbenefit analysis of the TVA's national labor market impacts. Our framework sufficiently general that it can easily be adapted to other place based policies.

In this Section, we develop a simple spatial equilibrium model that can rationalize the reduced form impacts of the TVA uncovered thus far. Our model allows the TVA to affect labor productivity in two ways. First, the TVA may directly raise labor productivity via public infrastructure investments. Second, it may indirectly raise labor productivity due to agglomeration economies. The magnitude of this second effect hinges on the exact form of the agglomeration economies (Glaeser and Gottlieb, 2008). Using the model, we derive the conditions under which endogenous reallocation of manufacturing activity can raise aggregate output through agglomeration effects. In the next

Section, we take the model to the data, estimate its key structural parameters and use them to compute the economic rate of return on the TVA federal investment.

\section{IV.A. Model}

We model U.S. counties as small open economies with price taking behavior on capital, labor, and output markets. Heterogeneity in county level outcomes results from three fundamental sources: amenity differences, unobserved locational productivity advantages, and endogenous agglomeration 
externalities. Capital and labor are assumed to be perfectly mobile across counties at decadal frequencies. This assumption is in keeping with evidence from Blanchard and Katz (1992) who find that labor and capital adjustment to local shocks completes within a decade. Likewise, workers are assumed to possess homogenous tastes as in the classic model of Roback (1982). ${ }^{15}$ The mobility and homogeneity assumptions imply that utility, which we model as a Cobb-Douglas function of wages $w_{i t}$ and amenity levels $M_{i t}$, is equalized across counties in each year. Hence we have that:

$$
\ln w_{i t}+M_{i t}=\bar{u}_{t}
$$

where the reservation utility level $\bar{u}_{t}$ varies only across years. As detailed in section V.E., $\bar{u}_{t}$ is an equilibrium object, determined by aggregate supply and demand in the national labor market.

Manufacturing output $\left(Y_{i t}\right)$ is produced in each county using capital, labor, and a fixed factor via a Cobb-Douglas production technology,

$$
Y_{i t}=A_{i t} K_{i t}^{\alpha} F_{i}^{\beta} L_{i t}^{1-\alpha-\beta}
$$

where $A_{i t}$ is a local productivity level, $L_{i t}$ is the number of manufacturing workers, $K_{i t}$ is the local capital stock, and $F_{i}$ is a fixed factor leading the derived demand for labor to slope down each period.

Normalizing the price of manufacturing output (which is assumed to be sold on global markets) to 1 , price taking behavior on the part of firms implies the usual first order conditions and the following inverse labor demand curve:

$$
\ln w_{i t}=C-\frac{\beta}{1-\alpha} \ln L_{i t}+\frac{\beta}{1-\alpha} \ln F_{i}-\frac{\alpha}{1-\alpha} \ln r_{t}+\frac{1}{1-\alpha} \ln A_{i t}
$$

where $r_{t}$ is the (natiomnwide) price of capital and $C \equiv \ln (1-\alpha-\beta)+\frac{\alpha}{1-\alpha} \ln \alpha$.

Consistent with much of the growth and urban economics literature on agglomeration economies, we assume that the productivity of firms in a county depends upon both fixed locational fundamentals and endogenous agglomeration effects. Specifically, we assume that the log productivity level $\left(\ln A_{i t}\right.$ ) may be decomposed into a locational advantage component, a component due to agglomeration effects, an effect of TVA, and an idiosyncratic component as follows:

$$
\ln A_{i t}=g\left(\frac{L_{i t-1}}{R_{i}}\right)+\delta_{t} D_{i}+\eta_{i}+\gamma_{t}+\varepsilon_{i t}
$$

where $D_{i}$ is a dummy for whether a county is exposed to TVA and $\delta_{t}$ is a measure of the direct effect

\footnotetext{
${ }^{15}$ The homogeneity assumption is a strong one and, in many cases, would not be appropriate for modeling place based policies as argued by Kline (2010) and Moretti (2011). We employ it here because our focus is on long run changes - so that the process of regional adjustment may in fact span generations - and, especially, because we found little empirical evidence of wage impacts in our evaluation despite large effects on manufacturing employment. As in Roback, we additionally assume that the amount of labor supplied by each worker is fixed.
} 
of TVA investments on local productivity in year $t$. This specification offers a deliberately simplified representation of how TVA investment in local infrastructure -new roads, canals and electricity increase productive in manufacturing. (An alternative would be a model where transportation infrastructure and electricity explicitly enter the production function and TVA investment increases their supply. This model would be notationally more complicated but yield identical results.) The fixed effect $\eta_{i}$ captures the time invariant suitability of the county for manufacturing due to, for example, proximity to a body of water. Heterogeneity in this factor leads manufacturing steady states to differ across counties based upon locational fundamentals. The decade effect $\gamma_{t}$ captures national changes in productivity common to all counties. The error $\varepsilon_{i t}$ represents the idiosyncratic component of county productivity. Following Blanchard and Katz (1992), who study the persistence of local employment changes, we assume $\varepsilon_{i t}$ contains a unit root, so that:

$$
\varepsilon_{i t}=\varepsilon_{i t-1}+\xi_{i t}
$$

where $\xi_{i t}$, which may itself be serially or spatially correlated, represents unobserved shocks to productivity. Such shocks could include unobserved changes in local infrastructure, shifts in the preferences of consumers, changes in the regulatory environment, or technological innovations.

The term $g\left(\frac{L_{i t-1}}{R_{i}}\right)$ captures the local agglomeration effects of manufacturing activity. The variable $R_{i}$ is the square mileage of the county. Hence, we assume agglomeration effects vary as a function of the density of manufacturing employment per square mile and operate with a decade lag. As discussed in a similar context by Adsera and Ray (1998), allowing the agglomeration effect to operate with a lag, no matter how short, ensures that the model yields deterministic predictions each period. This determinism is desirable as it rules out implausible situations where a county could take on, in any given period, wildly different levels of manufacturing activity by chance (see Krugman, 1991; Matsuyama, 1991 for further discussion).

In our model, agglomeration forces drive the persistent local impacts of the TVA on productivity and manufacturing employment. This is in contrast to much of the big push literature which has traditionally focused on models with demand externalities, whereby income growth in an area causes increases in the demand for local goods and services and stimulates entry of firms with better technologies, ultimately resulting in higher aggregate productivity (Rosenstein-Rodan, 1943; Murphy, Shleifer, and Vishny, 1989). Such models are better suited to explaining productivity growth in the local non-traded sector than the manufacturing sector whose demand is arguably national in scope. Explanations for agglomeration economies that are relevant to our context are technological externalities that may arise through social interactions and learning (Glaeser et al., 1992) or through thick market effects either in the labor market or the intermediate input market (Moretti, 2011). ${ }^{16}$ Our choice to allow agglomeration to operate through the density of manufacturing employment

\footnotetext{
${ }^{16}$ In principle, input-output linkages may further increase the effect of technological externalities, but in the absence of agglomeration economies of some type they would not generate persistent effects.
} 
per square mile is consistent with both types of technological externalities. Distinguishing between these two type of externalities is behind the scope of this paper.

\section{IV.B. The Effect of TVA on Aggregate Output}

Our model allows for both direct and indirect effects of TVA on national output. The direct effects operate through the impact of TVA's public infrastructure on local productivity as captured by the $\delta_{t}$ coefficients. The indirect effects of TVA operate through the agglomeration channel, as increases in employment may feed back into further increases in productivity.

To study these effects in more detail it is useful to consider the properties of the model's deterministic steady state. We write steady state productivity as:

$$
\ln A_{i}=g\left(\frac{L_{i}}{R_{i}}\right)+\eta_{i}+\delta D_{i}
$$

Likewise, steady state output can be written:

$$
\ln Y_{i}=\frac{\alpha}{1-\alpha} \ln \alpha+\frac{1-\alpha-\beta}{1-\alpha} \ln L_{i}+\frac{\beta}{1-\alpha} \ln F_{i}-\frac{\alpha}{1-\alpha} \ln r+\frac{1}{1-\alpha} \ln A_{i} .
$$

The impact of a marginal increase in the productivity of TVA's investments on the output of county $i$ is:

$$
\frac{d Y_{i}}{d \delta}=\frac{1}{1-\alpha} Y_{i}\left(D_{i}+\frac{1-\alpha-\beta+\sigma_{i}}{L_{i}} \frac{d L_{i}}{d \delta}\right)
$$

where $\sigma_{i} \equiv \frac{d \ln A_{i}}{d \ln \left(\frac{L_{i}}{R_{i}}\right)}=g^{\prime}\left(\frac{L_{i}}{R_{i}}\right) \frac{L_{i}}{R_{i}}$ is the local agglomeration elasticity (i.e. the elasticity of county productivity with respect to manufacturing density). Note that $\sigma_{i}$, may vary across counties depending on the shape of the agglomeration function $g\left(\frac{L_{i}}{R_{i}}\right)$ and the density of local manufacturing employment.

Thus, a scaling up of TVA has two effects. First, a direct effect, which is to raise output in affected areas by $\frac{1}{1-\alpha}$ percent. ${ }^{17}$ Second, an indirect effect that operates through endogenous labor adjustment. This indirect effect has two components. Adding manufacturing workers mechanically raises output by an amount proportional to labor's share and average labor productivity in the county $\left(\frac{Y_{i}}{L_{i}}\right)$. It also raises output through agglomeration, as represented by the agglomeration elasticity $\sigma_{i}$.

This result is useful because it allows us to better understand the aggregate impact of place based policies, and TVA in particular. Summing across all counties, we obtain the nationwide impact of TVA on U.S. output. It is straightforward to see that the direct effect of TVA on nation-wide

\footnotetext{
${ }^{17}$ The productivity-output elasticity is greater than one because capital adjustment augments a productivity change. When capital's share is zero, the elasticity becomes 1.
} 
manufacturing output is unambiguously positive. Intuitively, an exogenous increase in productive infrastructure paid for by the federal government can only raise total output in the sector. ${ }^{18}$ By contrast, the indirect effect due to labor reallocation is ambiguous and depends on whether the agglomeration benefits in the counties that gains workers outweigh the costs in counties that lose workers. More precisely, endogenous reallocation of a worker from county $i$ to county $j$ raises aggregate output if and only if:

$$
\frac{Y_{i}}{L_{i}}\left(1-\alpha-\beta+\sigma_{i}\right)<\frac{Y_{j}}{L_{j}}\left(1-\alpha-\beta+\sigma_{j}\right)
$$

which depends upon the average labor productivity and agglomeration elasticity in each county.

Consider first the special case when amenities are equal across the two communities, in which case wages must also be equal. In our setting, equal wages imply equal average labor productivity. Hence, reallocation from county $i$ to $j$ raises output only when the agglomeration elasticity is greater in community $j$. When the agglomeration elasticities are everywhere equal $\left(\sigma_{i}=\sigma\right)$, spatially reallocating labor has no aggregate effects. Intuitively, a constant elasticity implies that the benefits in the counties that gain workers are identical to the costs in the counties that lose workers.

When the agglomeration elasticity is constant but amenity levels differ across communities, aggregate output can be raised by moving workers to lower amenity areas where wages (and hence average labor productivity) are higher. However, this comes at a utility cost to workers who must make do with worse amenities. One can show that this utility cost perfectly offsets the value of any increases in aggregate output. ${ }^{19}$ Thus, although agglomeration economies generate market failures at the local level, these inefficiencies may "cancel out" in the aggregate if agglomeration elasticities are constant. A similar point was made by Glaeser and Gottleib (2008) in a static model of spatial equilibrium with agglomeration.

To preview our results, our empirical analysis in section $\mathrm{V}$. will point to a constant agglomeration elasticity. Because we care about national welfare rather than output per se, this finding casts doubt on the efficiency rationale for government policies aimed at shifting the spatial distribution of economic activity.

\section{IV.C. Dynamic Behavior}

Figure IV contrasts a hypothetical county's dynamic behavior when the agglomeration elasticity is constant with its behavior when the elasticity is not constant. Specifically, Figure IVa depicts the case where $g($.$) is log-linear - so that \sigma_{i}$ is the same in all counties - while Figure IVb depicts the case where $g($.$) is substantially nonlinear in \operatorname{logs}$ - so that $\sigma_{i}$ varies significantly across counties

\footnotetext{
${ }^{18}$ Of course, we have ignored the issue of how the federal funds were raised, a concern to which we will return below.

${ }^{19}$ More precisely, it is possible to show that when $\sigma_{i}=\sigma$, the decentralized allocation of workers across communities maximizes aggregate utility, defined as $\sum_{i} L_{i}\left(\ln w_{i}+M_{i}\right)$. We provide a local version of this result in section V.E..
} 
depending upon the local manufacturing density.

Consider first Figure IVa. Our assumption of perfect labor mobility yields a horizontal county labor supply locus at the going wage $w$. The SR curve depicts the standard short run inverse demand curve given in (3), when $A_{i t}$ is taken as given. This curve has slope $-\frac{\beta}{1-\alpha}$ equal to the inverse of the short run elasticity of labor demand. The slope is negative because of the fixed factor $F_{i}$. The long run inverse demand curve LR incorporates the agglomeration effects of changes in local manufacturing activity given in (4). The LR curve is flatter than the SR curve because the agglomeration economies dampen the effects of the fixed factor on labor productivity.

The first panel depicts the initial equilibrium: the intersection of the LR curve with the horizontal labor supply curve determines the steady state level of manufacturing employment which, in this setting, is unique. ${ }^{20}$ The second panel shows what happens with the introduction of TVA. Because the new infrastructure makes firms in TVA more productive, the new LR curve is to the right of the initial LR curve. Specifically, the Authority shifts both the SR and LR curves up by an amount $\delta_{t}$, which motivates a series of employment increases as manufacturing employment converges towards its new steady state. The one period lag in agglomeration yields geometric adjustment to the steady state, depicted in the final panel of Figure IVa. Hence, the model exhibits conditional convergence of the sort found in traditional growth models (Barro and Sala-i-Martin, 2004), albeit due to agglomeration forces rather than capital adjustment. ${ }^{21}$

In this setting, a constant agglomeration elasticity has two implications. First, there can be no aggregate effect of TVA on manufacturing productivity other than through the direct effects of the TVA infrastructure. As argued above, the productivity gains to this region associated with the additional workers must equal the losses in the counties from which those workers came.

Second, given positive depreciation, the TVA can have only temporary effects on employment. Once the direct productivity effects of TVA lapse, the LR curve slowly reverts back to its original position as the initial infrastructure investment depreciates (the $\delta_{t}$ coefficients go negative) and the employment gains are gradually reversed.

Contrast this setting with Figure IVb. Here $g($.) exhibits strong threshold effects so that productivity increases rapidly once the sector reaches some critical level of density but begins to decrease afterward due to the presence of the fixed factor.

Two key differences emerge here relative to the log-linear case. First, and most importantly for our purposes, the influx of workers to the TVA region can have a positive effect on aggregate productivity. Due to the nonlinearity, the productivity gains to the TVA region may be much larger than the losses in the rest of the country. In fact, if workers come from developed regions on the downward sloping portion of the LR curve, productivity in those areas may actually rise as they

\footnotetext{
${ }^{20}$ Note however that this "steady state" is in fact conditional on the idiosyncratic component of productivity $\varepsilon_{i t}$. Because $\varepsilon_{i t}$ contains a unit root, the intercept of the LR curve is itself non-stationary.

${ }^{21}$ Convergence is conditional because each county may possess a different intercept for its LR demand curve based upon locational fundamentals $\left(\eta_{i}\right.$ in our setting) and the current state of the idiosyncratic component $\varepsilon_{i t}$.
} 
lose workers because outmigration alleviates crowding of the fixed factor.

An important goal of our empirical analysis in the next section is to determine whether Figure IVa or Figure IVb provides a better approximation to the dynamics of county growth. Uncovering the shape of the function $g($.$) is critical to understanding whether place based policies like TVA$ can be welfare improving for the U.S. as a whole.

The second difference with the log-linear case is that now the program has long lasting effects, even after the end of the federal investment. In Figure IVb, multiple steady state equilibria are present, two of which are stable and one of which is an unstable tipping point. Consider the prospects of a county stuck in the low employment "poverty trap." If the direct productivity effects of the TVA are sufficiently large for the tipping point depicted in the final panel of Figure IVb to be crossed, manufacturing employment will fall within the basin of attraction of the developed equilibrium.

Recall that our estimates in Table IV in the previous section pointed to a long lasting effect of TVA on manufacturing employment growth. We note that either form of agglomeration may

yield long lasting effects qualitatively consistent with the evidence uncovered in Table IV, since even the log-linear model exhibits momentum due to the convergence process. Structural estimates are necessary to determine whether truly permanent effects underlie the qualitative patterns of the previous section or whether simple slow adjustment is at work.

\section{Structural Estimates and Cost Benefit Analysis}

We now use the model outlined in Section IV to estimate the effects of TVA on the U.S. economy and compare them to the program's costs. Specifically, we develop an instrumental variables approach to estimating the magnitude of the direct productivity effects of the TVA program and the parameters governing the shape of the local agglomeration forces, which are important for quantifying the indirect benefits of the program. These estimates are then used to conduct a quantitative cost-benefit analysis of the TVA program.

\section{V.A. Estimating Equation}

A key object of interest in our model is the agglomeration function $g($.$) . The shape of this$ function is unknown with, to our knowledge, no compelling prior evidence on functional form. As such, we approximate it with a three piece linear spline in manufacturing density:

$$
g\left(\frac{L_{i t}}{R_{i}} ; \theta\right)=\sum_{k=1}^{3} \theta_{k} g_{k}\left(\frac{L_{i t}}{R_{i}}\right)
$$

where the $g_{k}($.$) are the spline basis functions. We consider two choices for these functions: In the$ "levels" specification, $g($.$) is piecewise linear in the level of manufacturing density and the \theta_{k}$ give 
the proportional effect on manufacturing productivity of increasing manufacturing density by one worker per square mile. In the "logs" specification, $g($.$) is piecewise log linear and the \theta_{k}$ give the elasticity of manufacturing productivity with respect to manufacturing density - that is, they give the local agglomeration elasticity. ${ }^{22}$ Note that a constant agglomeration elasticity requires that $g($. be concave in density levels and linear in logs.

We introduce covariates into the model by assuming the productivity shocks $\xi_{i t}$ in (5) may be written:

$$
\xi_{i t}=X_{i}^{\prime} \lambda+\nu_{i t}
$$

where $X_{i}$ contains the vector of covariates used in our earlier reduced form analysis of TVA.

With these additions, we can rewrite (3) in terms of the direct demand relationship to obatin our key estimating equation:

$$
\begin{aligned}
\ln \left(L_{i t}\right)-\ln \left(L_{i t-1}\right)= & -\frac{1-\alpha}{\beta}\left(\ln w_{i t}-\ln w_{i t-1}\right)+\frac{\delta_{t}-\delta_{t-1}}{\beta} D_{i} \\
& +\sum_{k=1}^{3} \frac{\theta_{k}}{\beta}\left[g_{k}\left(\frac{L_{i t-1}}{R_{i}}\right)-g_{k}\left(\frac{L_{i t-2}}{R_{i}}\right)\right] \\
& +X_{i}^{\prime} \widetilde{\lambda}+\widetilde{\gamma}_{t}-\widetilde{\gamma}_{t-1}+\widetilde{\nu}_{i t} .
\end{aligned}
$$

where we have removed county fixed effects by differencing over time and we use tilde's over variables to indicate they have been renormalized by $\frac{1}{\beta}$. The primary objects of interest are:

- The coefficients $\frac{\delta_{t}-\delta_{t-1}}{\beta}$ which give the change in the direct effects of TVA between decades;

- The spline coefficients $\frac{\theta_{k}}{\beta}$ which determine the indirect effects of the program since they give the labor demand effects of increasing manufacturing density within the relevant density range. We refer to $\frac{\theta_{1}}{\beta}$ as the agglomeration effect at "low" density, $\frac{\theta_{2}}{\beta}$ the effect at "medium" density, and $\frac{\theta_{3}}{\beta}$ the effect at "high" density.

\footnotetext{
${ }^{22}$ More formally:

$$
\begin{gathered}
g_{k}^{\text {levels }}(x) \equiv \begin{cases}\min \left\{x, q_{1}\right\} & \text { if } k=1 \\
\min \left\{x-q_{k-1}, q_{k}-q_{k-1}\right\} 1\left[x>q_{k-1}\right] & \text { if } k>1\end{cases} \\
g_{k}^{\text {logs }}(x) \equiv \begin{cases}\min \left\{\ln x, \ln q_{1}\right\} & \text { if } k=1 \\
\min \left\{\ln x-\ln q_{k-1}, \ln q_{k}-\ln q_{k-1}\right\} 1\left[x>q_{k-1}\right] & \text { if } k>1\end{cases}
\end{gathered}
$$

where the $q_{k}$ 's are the spline knots We choose $q_{1}=5.26, q_{2}=15.28, q_{3}=\infty$. The points $q_{1}$ and $q_{2}$ are knots corresponding to the 60th and 85th percentiles of the 1980 distribution of county manufacturing density measured in workers per square mile. These percentiles were chosen in order to yield approximately equal variation in the first difference of each spline component over our sample period. For reference, the median county in our estimation sample has a 1980 manufacturing density of approximately 3.8 (the corresponding figure for TVA counties is 7.1).
} 


\section{V.B. Identification}

Estimation of (8) is challenging for several reasons. To see why, consider the response of a typical U.S. county to a permanent increase in local manufacturing productivity brought on, say, by an improvement in the local transportation infrastructure. With higher productivity, more manufacturing jobs will be created, thereby attracting more manufacturing workers. But if agglomeration forces are important, this inflow will feed back into further increases in local productivity, thereby generating more jobs and attracting even more workers. To isolate the strength of the agglomeration channel then, one must be able to separate a county's initial employment response to a shock from the feedback effects of that response - the stronger the feedback, the stronger the agglomeration. In addition, detecting nonlinearities in the agglomeration forces requires inferring whether these feedback effects are stronger in underdeveloped counties than in counties with more established manufacturing bases.

Ideally, one would like to be able to investigate this question by randomly assigning manufacturing plants to counties and measuring how many additional workers are subsequently attracted to areas awarded plants. Recent research by Greenstone, Hornbeck and Moretti (2010) attempts to approximate such an experiment by examining the consequences of the siting decisions of million dollar manufacturing plants. Though the authors find evidence of substantial agglomeration effects, they lack the statistical power necessary to detect subtle nonlinearities of the sort necessary for setting policy. Moreover, their study restricts attention to a small subset of U.S. counties that bid for manufacturing plants.

To address these shortcomings, we will analyze four decades worth of observational changes in manufacturing employment in the baseline sample of U.S. counties considered in our earlier analysis. The fundamental difficulty confronting such an exercise is that the shocks leading county manufacturing to change in the first place may be persistent across decades, in which case we may mistake the persistence of the shocks for the feedback effects of increases in manufacturing density. Thus, we face the traditional econometric challenge of separating state dependence from serial correlation in unobservables.

More precisely, OLS estimation of (8) is problematic because $\nu_{i t}$ may be serially correlated, which would lead to bias in OLS estimates of the $\theta$ coefficients (Nickell, 1981; Arellano and Bond, 1991). This bias emerges because a regression will attribute all of the serial correlation in employment changes to state dependence (agglomeration) when some of it is actually the result of additional shocks. If the $\nu_{i t}$ are positively correlated any agglomeration effects will be overstated. If, on the other hand, the shocks are negatively correlated, agglomeration effects will be understated. While some interpretations of the distribution of city sizes (e.g., Gabaix, 1999; Eeckhout, 2004) suggest that local growth may be the result of a series of uncorrelated permanent shocks, we think it prudent to consider seriously the possibility that shocks are correlated. To address this problem, we employ

an instrumental variables strategy relying on lagged manufacturing changes. Our instruments are 
of the form:

$$
Z_{i t}^{(k)} \equiv g_{k}\left(\frac{L_{i t-2}}{R_{i}}\right)-g_{k}\left(\frac{L_{i t-3}}{R_{i}}\right)
$$

for $k \in\{1,2,3\}$. That is, the instruments are changes in the spline components of manufacturing density lagged by two decades. This functional form mirrors that of the endogenous variables in $(8) .{ }^{23}$

In the context of our model, these instruments induce exogenous variation in employment changes through the process of agglomeration. That is, regardless of why the manufacturing base changes in a period, that change should affect manufacturing growth in subsequent periods through its effects on local productivity. For the instruments to be valid we need that: ${ }^{24}$

$$
E\left[\nu_{i t} Z_{i t}^{(k)}\right] \forall k
$$

A sufficient condition for this restriction to hold is that the shocks to productivity $\nu_{i t}$ be independent over a horizon of 20 years. Note that this prohibits counties from possessing long lasting heterogeneous trends in productivity growth.

One important reason why trends might be present is if counties exhibit conditional convergence in manufacturing activity for reasons having little to do with agglomeration (e.g., as in the capital mobility arguments of Barro and Sala-i-Martin (1991, 1992a, 1992b)). Several points are worth highlighting in this respect. First, as mentioned, we condition on the vector $X_{i}$ of 38 baseline controls, which include 1920 and 1930 population and quadratics in 1920 and 1930 agricultural and manufacturing shares. These variables ought to absorb a significant fraction of the heterogeneity in initial conditions that could give rise to convergence. Second, in some specifications, we also condition on 1940 manufacturing density. If conditional convergence were still present after controlling for the vector $X_{i}$ of covariates, counties with lower 1940 manufacturing density would have faster growth in the following decades. In this case, controlling for 1940 manufacturing density would absorb additional heterogeneity in initial conditions, which should significantly change our estimates. We find instead that our results are insensitive to this control. Third, we also examine the robustness of our results to the inclusion of fixed regional trends, and find that our estimates are not very sensitive. Finally, we have also estimated models where the instruments are changes in the spline components of manufacturing density lagged by three decades instead of two. The first stage in these models was not statistically significant, lending further credibility to the assumption

\footnotetext{
${ }^{23}$ To avoid any mechanical correlation with the elements of $g\left(\frac{L_{i t-1}}{R_{i}} ; \theta\right)-g\left(\frac{L_{i t-2}}{R_{i}} ; \theta\right)$ that might result from measurement errors in $L_{i t-2}$, we construct these instruments using manufacturing employment data from the Economic Census while the endogenous variables are measured using employment data from the Decennial Census.

${ }^{24}$ Identification also requires that the instruments have sufficient predictive power. Our tables report first stage partial F-statistics which indicate a strong relationship between the instruments and each of the spline components. We note however that, if treated as a truly nonparametric problem, identification of $g($.$) is inherently untestable$ without further assumptions (Canay, Santos, and Shaikh, 2013). Testability would follow however if we were to assume the innovations in our model are normally distributed, see Newey (2013) for discussion.
} 
that our instrument is not picking up long run trends.

While these robustness exercises do not guarantee that all trend heterogeneity has been removed, we believe they suggest our results are not spurious. Moreover, we note that many of our conclusions

rest on the relative magnitude of the three $\frac{\theta_{k}}{\beta}$ parameters. Even if assumption 10 were violated, we see little reason for omitted trends to induce (or suppress) any nonlinearities in the agglomeration process. As we shall see in section V.E., our cost-benefit analysis hinges more on the shape of the agglomeration function than the estimated strength of any agglomeration effects.

A separate impediment to the estimation of (8) is the potential endogeneity of $\ln w_{i t}-\ln w_{i t-1}$ which might be correlated with $\nu_{i t}$ if amenity shocks are contemporaneously correlated with productivity shocks. This regressor also faces a potential division bias (Borjas, 1980) due to measurement errors in manufacturing employment which are used as the denominator in our manufacturing wage measure. To deal with this potential correlation, in our baseline model we calibrate $-\frac{1-\alpha}{\beta}$, which represents the (short-run) elasticity of labor demand. Based on Hamermesh (1993)'s influential review, we use 1.5 as the most plausible estimate of the relevant labor demand elasticity. ${ }^{25}$ We use this as our starting point, and then assess the sensitivity of our estimates to different values of the elasticity.

\section{V.C. Structural Estimates}

Table V provides estimates of (8) based on four decades of changes in log manufacturing density. ${ }^{26}$ This table assumes that $g($.$) is piecewise linear in density. The first three columns provides$ baseline OLS estimates which exhibit evidence of modest agglomeration effects and a concave relationship with density. Columns 4 through 6 instrument for density changes using twice lagged density changes. Instrumenting raises the magnitude of the estimated agglomeration effects and induces a strikingly concave pattern of marginal effects. For example, column 4 indicates that raising manufacturing density by one worker per square mile in a low density county is associated with an $8.7 \%$ increase in labor demand while a corresponding increase in a medium density county is associated with a 3.0\% increase in demand. Raising density in a high density county has essentially no effect. These coefficients are estimated quite precisely - we easily reject the null that the agglomeration effects are equal across density levels, with a p-value of 0.0004 (see bottom of the table). The results are also robust to changes in specification, with only very minor effects on the point estimates of controlling for 1940 population density and/or regional trends (columns 5 and 6). In Appendix Tables A2 through A4, we show that our results are also robust to different assumptions on the short run elasticity of labor demand and the spline knots.

Overall, these findings point to significant non-linearities in the agglomeration function. The

\footnotetext{
${ }^{25}$ Hamermesh (1993) documents a variety of estimates of national labor demand elasticities, centered in the range 1 to 1.5. Since we are interested in regional demand, we pick a parameter on the high end of the spectrum for our baseline specification.

${ }^{26}$ Specifically, the data consist of changes over the intervals 1960-1970, 1970-1980, 1980-1990, and 1990-2000.
} 
pattern that emerges is one of marked concavity in $g($.$) , whereby increases in manufacturing density$ are estimated to have significantly stronger effects in counties with a weak manufacturing presence than in counties with a more established presence. One might be tempted to infer that place based policies should reallocate manufacturing employment from high density areas to low density areas. However, as discussed in section IV.B., this intuition is incorrect. Reallocating workers to low density areas only raise aggregate worker welfare if lower density counties have a greater agglomeration elasticity.

Thus, we turn now to direct estimates of agglomeration elasticities. Table VI repeats our analysis using a three piece spline in the log of manufacturing density. This specification provides estimates of elasticities for counties with low, medium, and high levels of density respectively and it enables us to directly test for constant elasticities. We find similar estimates across the three density groups, with a $10 \%$ increase in density estimated to yield a 3\%-3.5\% increase in labor demand. As with the levels specification, the estimates are robust to controlling for baseline density and regional trends. Notably, we cannot reject a constant elasticity relationship in any of the IV specifications. The p-values reported at the bottom of the table for the null hypothesis of equal elasticity are all above 0.89 , and the point estimates are tightly clustered in the range $0.30-0.32$. We conclude that manufacturing productivity exhibits a nearly constant elasticity relationship with manufacturing density.

We turn now to the direct productivity effects of the TVA, which result from the program's federally financed public investments. Because the model is in differences, the coefficient on the TVA dummy in equation (8) reflects the change over time in the direct effects. In the specifications reported in Tables V and VI, the estimated coefficient on the TVA dummy is statistically indistinguishable from zero, suggesting the direct productivity effects of TVA were roughly constant over the sample interval (1960-2000).

Table VII examines this finding more closely by recomputing the direct effects over three distinct horizons. ${ }^{27}$ We consider both the specification where $g($.$) is piecewise linear and where it is piecewise$ $\log$ linear. Reassuringly, the two specifications yield very similar results. Consistent with our reduced form findings in Section III, the TVA is estimated to have substantially boosted productivity over the period 1940-1960. If we assume capital's share in manufacturing $\alpha$ is in this period approximately 0.3 (Griliches, 1967), and that the elasticity of demand $\frac{1-\alpha}{\beta}$ is 1.5 , then we expect $\beta \approx 0.47$. Taking $\beta=0.47$, we have that TVA raised local productivity by approximately $8.4 \%$ over the 1940 1960 period. This was followed by insignificant negative direct effects in later periods, which is in keeping with the earlier evidence that TVA transfers scaled down over this horizon and that local infrastructure began to depreciate.

\footnotetext{
${ }^{27}$ The estimates in the Table were computed via a regression of residuals of the form $Q_{i t} \equiv \ln L_{i t}-\ln L_{i t-2}-$ $\widehat{\widehat{\theta_{1}}}\left[g_{1}\left(\frac{L_{i t-1}}{R_{i}}\right)-g_{1}\left(\frac{L_{i t-3}}{R_{i}}\right)\right]-\frac{\widehat{\theta_{2}}}{\beta}\left[g_{2}\left(\frac{L_{i t-1}}{R_{i}}\right)-g_{2}\left(\frac{L_{i t-3}}{R_{i}}\right)\right]-\frac{\widehat{\theta_{3}}}{\beta}\left[g_{3}\left(\frac{L_{i t-1}}{R_{i}}\right)-g_{3}\left(\frac{L_{i t-3}}{R_{i}}\right)\right]-1.5\left(\ln w_{i t}-\ln w_{i t-2}\right)$ on baseline covariates and a TVA dummy. Hats denote estimated coefficient values, which come from column (4) of Table V in the "Spline in levels" specification and column (4) of Table VI in the "Spline in logs" specification.
} 


\section{V.D. Discussion}

Four points are worth noting regarding our structural estimates. First, the estimates can be used to predict the dynamic effects of the TVA on manufacturing activity. In the appendix, we show that these predictions are closely in line with the reduced form estimates of Table IV. Specifically, we show that the estimated sequence of direct effects and the agglomeration function yield predicted changes in manufacturing employment over the 1940-1960 and 1960-2000 intervals close to the reduced form impacts reported in Table IV. This finding is important: using a substantially different source of variation, it corroborates our modeling strategy and the exclusion restrictions necessary for our instruments to be valid. We also fit a capital accumulation model to the sequence of estimated direct effects and show that they are consistent with an infrastructure depreciation rate of roughly $1 \%$.

Second, the magnitude of the implied agglomeration economies is in line with existing estimates in the literature. With $\beta=0.47$, the agglomeration elasticities $\theta_{k}$ implied by Table VI are in the neighborhood of 0.14. A recent meta-analysis of 34 different studies of agglomeration economies (Melo et al., 2009) indicates that our estimates are squarely in the middle of the distribution of existing estimates, and well within the range of elasticities reported in several of the most prominent recent studies. ${ }^{28}$

Third, our estimates strongly suggest that agglomeration economies are concave in manufacturing density and that this concavity is well-approximated by a logarithmic function. This finding has important policy implications. As discussed in section (IV.B.), a near constant elasticity severely proscribes the ability of governments to raise welfare via pure reallocations of manufacturing activity. Though agglomeration economies have external effects not captured by the price system, our finding of constant elasticity indicates that these effects cancel out in the aggregate. Thus, our estimates suggest manufacturing agglomeration is an interesting case where the existence of a market failure does not generate efficiency losses in the aggregate.

Fourth, according to our estimates, the effects of TVA will eventually die out. Figure V depicts our calibrated short run inverse labor demand function along with the estimated long run inverse labor demand function and its $95 \%$ confidence interval. This Figure is the empirical equivalent of Figure IV. ${ }^{29}$ Based on the discussion in Section IV.C it is clear that the estimated shape of the curve implies the system admits a unique steady state equilibrium so that the TVA region will ultimately revert back to its pre-program equilibrium.

\footnotetext{
${ }^{28}$ For example, Henderson (2003) obtains an elasticity of productivity with respect to density of same industry plants of 0.01-0.08. Estimates for France in Combes et al. (2010) and Combes et al. (2012) imply elasticities of 0.029 and 0.032, respectively. At the other extreme, Greenstone, Hornbeck and Moretti (2010)'s estimates imply an elasticity in the range 1.25-3.1. Of course, part of the variation in these estimates is due to the fact that models, data, time periods and industries used in the studies are vastly different.

${ }^{29}$ As expected, the estimated long run curve is less steep than the short run curve because the presence of agglomeration economies reduces the limiting effect of the fixed factor on worker productivity.
} 


\section{V.E. Cost Benefit Analysis}

We now use our structural parameter estimates to conduct a quantitative cost-benefit analysis of the TVA's long run effects. Our goal is to assess whether the program was welfare enhancing from the point of view of the United States as a whole. Computing the program's costs is straightforward: we use the 1940 present value of the year by year stream of federal appropriations to the TVA listed in Figure I. Computing program benefits is more challenging and relies upon the structure of our model. To quantify the nationwide benefits of the productivity gains associated with the TVA, we compute the steady state elasticity of worker utility with respect to the TVA's productivity effects. This elasticity is combined with our estimates of the direct productivity effects of the TVA to compute an impact on worker welfare which is then converted to dollars terms. In the Appendix we show that the aggregate elasticity of worker utility with respect to TVA's local investments can be written:

$$
\frac{d \bar{u}}{d \delta}=\frac{1}{1-\alpha} \frac{\sum_{i} \frac{D_{i} L_{i}}{\beta-\sigma_{i}}}{\sum_{i} \frac{L_{i}}{\beta-\sigma_{i}}}
$$

Our finding of a roughly constant agglomeration elasticity $\left(\sigma_{i}=\sigma\right)$ implies this expression simplifies to:

$$
\frac{d \bar{u}}{d \delta}=\frac{1}{1-\alpha} \frac{\sum_{i} D_{i} L_{i}}{\sum_{i} L_{i}}
$$

Note that this formula doesn't depend upon the strength of agglomeration forces $\sigma$. This is because, with a constant elasticity, the agglomeration effects of worker reallocation cancel out. Hence, worker utility simply increases in proportion to the TVA region's share of the manufacturing workforce. In essence, this expression tells us that TVA should be thought of as only nominally place based in nature. Rather, it is a national investment that raises welfare through its direct effects on the productivity of a fraction of the manufacturing workforce.

Using this formula, we find that the net present value of this stream of benefits using a real annual discount rate of $3 \%$ is $\$ 22-\$ 32.3 \mathrm{~B}$, depending on what assumptions are made on the elasticity of labor supply (see the Appendix for a detailed explanation of the methodology and the results). This is to be compared with the present value of federal transfers which amount to $\$ 17.3 \mathrm{~B}$. Hence, we find a positive rate of return to the TVA's public investments.

\section{Conclusions}

This paper makes two primary contributions. Our substantive contribution is to estimate the local and aggregate effects of one of the largest place based policies in U.S. history. To our knowledge, 
we are the first to empirically quantify the long run social costs and benefits of such a place based policy. A second contribution is methodological: we have developed a tractable empirical framework for evaluating the aggregate welfare effects of placed based policies, with the potential to be applied to many other settings.

Our empirical findings are policy relevant. The evaluation design of Section III. provides strong evidence that the TVA sped the industrialization of the Tennessee Valley and provided lasting benefits to the region in the form of high paying manufacturing jobs. Notably, the impact on manufacturing employment persisted well beyond the lapsing of the regional subsidies, suggesting the presence of powerful agglomeration economies. By contrast, the agricultural sector, which is unlikely to exhibit substantial agglomeration forces, retracted dramatically once subsidies terminated.

Our analysis in Section V.E. suggests the TVA raised the productivity of the U.S. manufacturing sector by roughly $0.3 \%$ between 1940 and 1960 . We estimate that the stream of benefits associated with this increase exceeded the program's costs, though this conclusion rests on several unverifiable assumptions regarding the functioning of labor markets.

Most of the national impact of the TVA on worker welfare is accounted for by the direct effects of the program's vast investments in public infrastructure. Our finding of a roughly constant agglomeration elasticity suggests the program's indirect effects were minimal. A noteworthy implication is that although agglomeration economies represents an important market failure at the local level, this failure does not provide a rationale for federal intervention in the spatial distribution of manufacturing activity.

We caution, however, that our findings do not necessarily apply to all contexts, as the strength and shape of agglomeration economies may well vary across industries, periods and levels of aggregation. Our results are specific to the manufacturing sector and a period of U.S. history when manufacturing employment was expanding and earnings were relatively high. An important task for future work is to assess whether similar qualitative results hold for modern development efforts, such as those centered on building high tech clusters. 


\section{Bibliography}

1. Adsera, Alicia and Debra Ray. 1998. "History and Coordination Failure", Journal of Economic Growth 3: 267-276, September.

2. Ahlfeldt, Gabriel M., Stephen J. Redding, Daniel M. Sturm, and Nikolaus Wolf. 2012. "The Economics of Density: Evidence from the Berlin Wall." working paper.

3. Albouy, David. 2009. "The Unequal Geographic Burden of Federal Taxation." Journal of Political Economy 117(4): 635-667.

4. Albouy, David. 2012. "Evaluating the Efficiency and Equity of Federal Fiscal Equalization" Journal of Public Economics 96(9-10): 824-839.

5. Angrist, J.D. and Pischke, J. 2008. Mostly Harmless Econometrics, Princeton University Press.

6. Arellano, Manuel and Bond, Stephen, 1991. "Some Tests of Specification for Panel Data: Monte Carlo Evidence and an Application to Employment Equations," Review of Economic Studies, Wiley Blackwell, vol. 58(2), pages 277-97, April

7. Azariadis, Costas and Allan Drazen. 1990. "Threshold Externalities in Economic Development," The Quarterly Journal of Economics, MIT Press, vol. 105(2),

8. Azariadis, Costas and John Stachurski. 2005. "Poverty Traps," Ch. 5 in Handbook of Economic Growth, eds. by P. Aghion and S. Durlauf, Elsevier Publishers, 2005.

9. Barbour, George B. 1937. The Tennessee Valley Project. The Royal Geographical Society.

10. Barro, Robert J and Sala-i-Martin, Xavier, 1991. "Convergence Across States and Regions," Brookings Papers on Economic Activity, 22(1):107-182.

11. Barro, Robert J and Sala-i-Martin, Xavier, 1992a. "Convergence," Journal of Political Economy, University of Chicago Press, vol. 100(2), pages 223-51, April.

12. Barro, Robert J and Sala-i-Martin, Xavier, 1992b. "Regional growth and migration: A JapanUnited States comparison," Journal of the Japanese and International Economies, Elsevier, vol. 6(4), pages 312-346, December

13. Barro, Robert J and Sala-i-Martin, Xavier, 2004. Economic Growth, 2nd Edition. MIT Press.

14. Bartik, Timothy J, 1991. Who Benefits from State and Local Economic Development Policies? W.E. Upjohn Institute, Kalamazoo, MI.

15. Bateman, Fred; Jaime Ros, and Jason E. Taylor. 2009. "Did New Deal and World War II Public Capital Investments Facilitate a Big Push in the American South?" in Journal of Institutional and Theoretical Economics JITE, Volume 165, Number 2, pp. 307-341(35)

16. Baum-Snow, Nathaniel. 2007. "Did Highways Cause Suburbanization?" Quarterly Journal of Economics 122(2): 775-805. 
17. Baum-Snow, Nathaniel. "Changes in Transportation Infrastructure and Commuting Patterns in U.S. Metropolitan Areas, 1960-2000, American Economic Review Papers and Proceedings), 2010, 100(2): 378-382.

18. Blanchard, Olivier, Katz, Larry, 1992. "Regional evolutions." Brookings Papers on Economic Activity

19. Borjas, George. 1980. "The Relationship Between Wages and Weekly Hours of Work: The Role of Division Bias." Journal of Human Resources 15(3):409-423.

20. Boyce, Ronald R. 2004. "Geographers and the Tennessee Valley Authority." Geographical Review, Vol. 94, No. 1. American Geographical Society.

21. Busso, Matias, Jesse Gregory and Patrick Kline. 2013. "Assessing the Incidence and Efficiency of a Prominent Place Based Policy" American Economic Review, 103(2): 897-947.

22. Carrington, William. 2013. "The Unemployment Insurance System." accessed online on 5/13/2013 at: http://www.cbo.gov/publication/44041.

23. Canay, Ivan, Andres Santos, and Azeem Shaikh. 2013. "On the Testability of Identification in Some Nonparametric Models with Endogeneity" Econometrica, forthcoming.

24. Chay, Kenneth Y. and Michael Greenstone. 2003. "The Impact Of Air Pollution On Infant Mortality: Evidence From Geographic Variation In Pollution Shocks Induced By A Recession," The Quarterly Journal of Economics, MIT Press, vol. 118(3), pages 1121-1167, August.

25. Chay Kenneth Y. and Michael Greenstone, 2005. "Does Air Quality Matter? Evidence from the Housing Market," Journal of Political Economy, University of Chicago Press, vol. 113(2), pages 376-424, April.

26. Clark, Wesley C. 1946. "Proposed 'Valley Authority' Legislation." American Political Science Review, 40(1): 62-70.

27. Combes, P.-P., G. Duranton, L. Gobillon, and S. Roux. 2010. "Estimating Agglomeration Effects With History, Geology, and Worker Fixed-Effects," in Agglomeration Economics, Vo 1. 1, ed. by E. L. Glaeser. Chicago, IL: Chicago University Press, 15-65.

28. Combes, Pierre-Philippe, Gilles Duranton, Laurent Gobillon, Diego Puga, and Sebastien Roux. 2012. "The productivity advantages of large cities: Distinguishing agglomeration from firm selection" Econometrica, forthcoming.

29. Conley, T. G., 1999. "GMM estimation with cross sectional dependence," Journal of Econometrics, Elsevier, vol. 92(1), pages 1-45, September

30. Criscuolo, Chiara, Ralf Martin, Henry G. Overman, and John Van Reenen. 2012. "The Causal Effects of an Industrial Policy." SERC Discussion Paper \#0098.

31. Davis, Donald R. and David E. Weinstein. 2002. "Bones, Bombs, and Breakpoints: The Geography of Economic Activity," American Economic Review, 92(5): 1269-1289. 
32. Davis Donald and David E. Weinstein, 2008. "A Search for Multiple Equilibria in Urban Industrial Structure" Journal of Regional Science.

33. Donaldson, David. 2012. "Railroads of the Raj: Estimating the Impact of Transportation Infrastructure" Working paper.

34. Donaldson, Dave and Richard Hornbeck. 2012. "Railroads and American Economic Growth: New Data and Theory." Working paper

35. Duranton, Gilles and Overman, Henry G., 2002. "Testing for Localization Using MicroGeographic Data," CEPR Discussion Papers 3379, C.E.P.R. Discussion Papers.

36. Duranton, Gilles and Diego Puga. 2004. "Micro-foundations of urban agglomeration economies." in Handbook of Regional and Urban Economics, J. V. Henderson \& J. F. Thisse (ed.), Vol 4., pp. 2063-2117, Elsevier.

37. Duranton, Gilles. 2007. "Urban Evolutions: The Fast, the Slow, and the Still." American Economic Review 97(1): 197-221.

38. Duranton, Gilles, Laurent Gobillon, and Sebastien Roux. 2008. "Estimating Agglomeration Economies with History, Geology, and Worker Effects," CEPR Discussion Papers 6728, C.E.P.R.

39. Duranton, Gilles. 2011. "California Dreamin': The Feeble Case for Cluster Policies," Review of Economic Analysis, vol. 3(1), pages 3-45, July.

40. Duranton, Gilles and Laurent Gobillon. 2011. "The identification of agglomeration economies," Journal of Economic Geography, Oxford University Press, vol. 11(2), pages 253-266, March

41. Eeckhout, Jan. 2004. "Gibrat's Law for All Cities." American Economic Review 94(5): $1429-1451$.

42. Ellison, Glenn, Glaeser, Edward L., 1997. "Geographic concentration in US manufacturing industries: a dartboard approach." Journal of Political Economy 105 (5), 889-927.

43. Ellison, Glenn, Glaeser, Edward L., 1999. "The geographic concentration of industry: does natural advantage explain agglomeration?" American Economic Review Papers and Proceedings $89(2), 311-316$.

44. Ellison, Glenn, Glaeser, Edward L., Kerr, William, 2010. "What causes industry agglomeration? Evidence from coagglomeration patterns." American Economic Review 100(3): 11951213.

45. Fishback, Price and Michael Haines, and Shawn Kantor. 2011. "Births, Deaths, and New Deal Relief During the Great Depression." forthcoming in the Review of Economics and Statistics.

46. Gabaix, Xavier. 1999. "Zipf's Law for Cities: An Explanation.” Quarterly Journal of Economics 114(3): 739-767.

47. Glaeser, Edward and Joshua Gottlieb. 2008. "The Economics of Place-Making Policies." Brookings Papers on Economic Activity 2: 155-239. 
48. Glaeser, E.L, H.D. Kallal, J.A. Scheinkman and A. Shleifer. 1992. "Growth in Cities." Journal of Political Economy, 100:1126-1152.

49. Government Accountability Office. 2012. "Federal Economic Development Grants to Communities with High Rates of Poverty and Unemployment." GAO-12-938R.

50. Graham, Bryan and Jonathan Temple. 2006. "Rich Nations, Poor Nations: How Much Can Multiple Equilibria Explain?" Journal of Economic Growth. 11(1):5-41.

51. Greenstone, Hornbeck and Moretti. 2010. "Identifying Agglomeration Spillovers: Evidence from Winners and Losers of Large Plant Openings" Journal of Political Economy, 118(3).

52. Zvi Griliches, 1967. "Production Functions in Manufacturing: Some Preliminary Results," NBER Chapters, in: The Theory and Empirical Analysis of Production, pages 275-340 National Bureau of Economic Research, Inc.

53. Ham, John, Swenson, Charles, Ayse Imrohoroglu, and Heonjae Song. 2011. "Government Programs Can Improve Local Labor Markets: Evidence from State Enterprise Zones, Federal Empowerment Zones and Federal Enterprise Communities." Journal of Public Economics 95:779-797.

54. Hamermesh, Daniel. 1993. Labor Demand Princeton University Press.

55. Henderson, Vernon. 1994. "Where Does an Industry Locate," Journal of Urban Economics, $35,83-104$.

56. Henderson, Vernon. 1995. "Industrial Development in Cities," Journal of Political Economy, 103, 1067-1090.

57. Henderson, Vernon. 1997. "Externalities and Industrial Development," Journal of Urban Economics, 1997, 42, 449-470.

58. Henderson, Vernon. 2003. "Marshall's Scale Economies" Journal of Urban Economics, 53, $1-28$

59. Henderson, Vernon. 2005. "Urbanization and Growth," Handbook of Economic Growth, P. Aghion and S. Durlauf (eds.), North Holland.

60. Hodge, Clarence Lewis (PhD). The Tennessee Valley Authority: A National Experiment in Regionalism. The American University Press. 1938. Washington, D. C.

61. Hornbeck, Richard. 2010. "Barbed Wire: Property Rights and Agricultural Development," Quarterly Journal of Economics, Vol. 125, No. 2, pp. 767-810 (2010)

62. Hornbeck, Richard. 2012a. "The Enduring Impact of the American Dust Bowl: Short and Long-run Adjustments to Environmental Catastrophe," American Economic Review, 102(4):1477-1507.

63. Hornbeck, Richard. 2012b. "Nature versus Nurture: The Environment's Persistent Influence through the Modernization of American Agriculture," American Economic Review, 102(3):245249 . 
64. Hornbeck, Richard and Suresh Naidu. 2012. "When the Levee Breaks: Labor Mobility and Economic Development in the American South," NBER Working Paper \#18296.

65. House of Representatives, Bill No. 1824. "The Conservation Authorities Act." Introduced by Representative John E. Rankin, Jan. 29, 1945.

66. Jacobs, Jane. 1984. "Why TVA Failed." New York Review of Books

67. Kimble, Ellis. 1933. "The Tennessee Valley Project." The Journal of Land and Public Utility Economics Vol. 9 No. 4. University of Wisconsin Press.

68. Kiminori Matsuyama. 1991. "Increasing Returns, Industrialization, and Indeterminacy of Equilibrium." The Quarterly Journal of Economics, 106(2): 617-650.

69. Kitchens, Carl. 2011. "The Role of Publicly Provided Electricity in Economic Development: The Experience of the Tennessee Valley Authority 1929 - 1955." Working paper.

70. Kline, Patrick. 2011. "Oaxaca-Blinder as a Reweighting Estimator" American Economic Review: Papers and Proceedings 101 (May), pp. 532-537.

71. Kline, Patrick. 2010. "Place Based Policies, Heterogeneity, and Agglomeration." American Economic Review: Papers and Proceedings 100 (May), pp. 383-387

72. Paul Krugman, 1991. "History Versus Expectations." The Quarterly Journal of Economics 106(2):651-667.

73. Leuchtenburg, William E. 1952. "Roosevelt, Norris and the Seven Little TVAs." The Journal of Politics, 14(3): 418-441.

74. Leuchtenburg, William E. 1997. The FDR Years: On Roosevelt and His Legacy. Columbia University Press.

75. Mccarty, Charles (Former General Counsel of the TVA). 1950. "TVA and the Tennessee Valley." The Town Planning Review Vol. 21, No.2. July, Liverpool University Press.

76. Melo, P. C., D. J. Graham, and R. B. Noland. 2009. "A Meta-Analysis of Estimates of Urban Agglomeration Economies," Regional Science and Urban Economics, 39 (3): 332-342.

77. Menhinick, Howard K. and Durisch Lawrence L. Tennessee. 1953. Valley Authority: Planning in Operation. Liverpool University Press.

78. Michaels, Guy. 2008. "The Effect of Trade on the Demand for Skill - Evidence from the Interstate Highway System" Review of Economics and Statistics, November 90(4): 683-701

79. Michaels Guy, Ferdinand Rauch and Stephen Redding. 2012. "Urbanization and Structural Transformation." Quarterly Journal of Economics 127(2): 535-586.

80. Miguel, Edward and Gerard Roland. 2011. "The Long Run Impact of Bombing Vietnam." Journal of Development Economics 96:1-15.

81. Mississippi State Auditor. 2002. "Capitalization and Depreciation of Infrastructure." Office of the State Auditor, Division of Technical Assistance, October 22. 
82. Morgan, Arthur E. 1934. "Purposes and Methods of the Tennessee Valley Authority." American Academy of Political and Social Science.

83. Moretti, Enrico. 2011. "Local Labor Markets." Chapter 14 in Handbook of Labor Economics, Volume 4b, eds. David Card and Orley Ashenfelter, New York: Elsevier, pp. 1237-1313.

84. Morris, Stephen and Shin, Hyun Song, 1998. "Unique Equilibrium in a Model of Self-Fulfilling Currency Attacks," American Economic Review, American Economic Association, vol. 88(3), pages $587-97$,

85. Murphy, Kevin M., Andrei Shleifer, and Robert Vishny. 1989. "Industrialization and the Big Push" Journal of Political Economy 97(5): 1003-1026.

86. Nickell, Steven J. 1981. "Biases in Dynamic Models With Fixed Effects." Econometrica 49(6):1417-1426.

87. Neumark, David and Jed Kolko. 2010. "Do Enterprise Zones Create Jobs? Evidence from California's Enterprise Zone Program." Journal of Urban Economics 67(1):103-115.

88. Newey, Whitney. 2013. "Nonparametric instrumental variables estimation." working paper.

89. Redding Stephen, Daniel M. Sturm and Nikolaus Wolf. 2011. "History and Industry Location: Evidence from German Airports," Review of Economics and Statistics, 93(3):814-831.

90. Roback, Jennifer, 1982. "Wages, rents and the quality of life." Journal of Political Economy 90 (December), 1257-1278

91. Rosenthal, Stuart S. and William Strange. 2004. "Evidence on the Nature and Sources of Agglomeration Economies." in Handbook of Urban and Regional Economics, Volume 4, pp. 2119-2172, Elsevier, eds. Vernon Henderson and Jacques Thisse.

92. Story, Louise 2013 "As Companies Seek Tax Deals, Governments Pay High Price", New York Times, Dec 1, 2013.

93. Satterfield, M. H. Intergovernmental Cooperation in the Tennessee Valley. The Journal of Politics, Vol. 9, No. 1. Cambridge University Press. 1947.

94. Tennessee Valley Authority, Department of Regional Planning Studies, Social and Economic Research Division. 1938. "Local Social and Economic Effects of the Norris Dam Project." Knoxville, Tennessee, August 8.

95. Wang, Jin. 2010 "The Economic Impact of Special Economic Zones: Evidence from Chinese Municipalities." working paper.

96. Wren, Colin and Jim Taylor. 1999. "Industrial Restructuring and Regional Policy." Oxford Economic Papers 51:487-516.

97. Ziliak, James P. 2011. Appalachian Legacy: Economic Opportunity after the War on Poverty, Washington, DC: Brookings Institution Press. 


\section{Appendix A: Data}

\section{Data on TVA Appropriations}

Data on federal appropriations for the TVA plotted in Figure II of the paper was collected using financial statements from the TVA's Annual Reports. From 1934 to 1976, these are Reports to Congress. From 1977 onwards, they are the usual reports released by corporations in the U.S. The actual names of those reports changed over time as follows:

- 1934/1939: Annual Report of the Tennessee Valley Authority for the Fiscal Year Ended June 30 , of the relevant year.

- 1945: Audit of Tennessee Valley Authority for Fiscal Year Ended June 30, 1945. It contains information from 1938 until 1945.

- 1946-47: Report on the Audit of Tennessee Valley Authority for the Fiscal Year Ended June 30, 1946 and 1947.

- 1948-1950: Report on the Audit of Tennessee Valley Authority for the Fiscal Year Ended on June 30 pof the relevant year.

- 1951-1957: Audit Report of Tennessee Valley Authority for the Fiscal Year Ended June 30 of the relevant year.

- 1958: Audit Report of Tennessee Valley Authority Fiscal Year 1958.

- 1959-1962: Report on Audit of the Tennessee Valley Authority.

- 1963: Report on Audit of Financial Statements of Tennessee Valley Authority Fiscal Year 1963.

- 1964: Report on Audit of the Financial Statements of the Tennessee Valley Authority, Fiscal Year Ended June 30, 1964.

- 1965: Report on the Examination of Financial Statements, Tennessee Valley Authority, Fiscal Year 1965.

- 1966: An Audit of the Tennessee Valley Authority, Fiscal Year 1966.

- 1967: An Examination of Financial Statements of the Tennessee Valley Authority, Fiscal Year 1967.

- 1968-1969: An Examination of Financial Statements Tennessee Valley Authority.

- 1970-1976: Examination of Financial Statements of the Tennessee Valley Authority.

- 1977-1986: Annual Report of the Tennessee Valley Authority, Volume II Appendix, For the Fiscal Year Ending September 30 of the relevant year.

- 1987-1989: Tennessee Valley Authority, Financial Statements for the Fiscal Year Ended September 30 of the relevant year. 
- 1991-1993: Annual Report TVA.

- 1994: Tennessee Valley Authority 1994 Annual Report.

- 1995: We did not find report for this year, but we recovered the information for it using the reports of 1994 and 1996. That was possible because each of those reports presents information comparing the financial situation in the current and in the previous year.

- 1996: 1996 Annual Report, Tennessee Valley Authority.

- 1997: Tennessee Valley Authority Financial Statements 1997.

- 1998-1999: We did not find report for these years, but we got the information for them in the Amended 2002 Information Statement Tennessee Valley Authority. This amendment provides annual information for the period 1998-2002.

- 2000: TVA Annual Report 2000.

\section{Data Used in the Empirical Analysis and Their Limitations}

We work with county level data for the years 1900 to 2000. The data for the years 1900 to 1930 was obtained from Historical, Demographic, Economic, and Social Data: The United States, 1790-2000, ICPSR 2896 (Parts 20, 22, 24, 2629 and 85 which correspond to the 1900 Census, 1910 Census, 1920 Census, 1930 Census Part I, 1930 Census Part IV Families and the 1910 Census of Agriculture) with the exception of the variables manuf, agr, and other, which were built from individual level data from IPUMS from a 1\% extract from the 1900, 1910, 1920 and 1930 Census respectively.

For 1940 to 1970 each variable was built from two alternative data sources: the County and City Data Book [United States] Consolidated File: County Data, 1947-1977, from ICPSR 7736; and from Historical, Demographic, Economic, and Social Data: The United States, 1790-2000, ICPSR 2896 (Parts 70, 72, 74 and 76, which correspond to the 1947 County Data Book, the 1952 County Data Book, the 1962 County Data Book and the 1972 County Data Book). In most cases the variable definitions are the same using these two alternative data sources. When the definitions are different, we use the one from ICPSR 2896.

The data for year 1980 to 2000 was obtained from census extracts from the National Historical Geographic Information System (NHGIS), with the exception of variables mwage and vfprod, which were obtained from ICPR 2896 (Parts 79, 80 and 81, which correspond to the 1988 County Data Book, the 1994 County Data Book and the 2000 County Data Book).

Additionally, we use data on county topography and demographics from the paper "Data Set for Births, Deaths, and New Deal Relief During the Great Depression" by Price Fishback, Michael Haines, and Shawn Kantor generously made available on Price Fishback's website.

To avoid issues with county splits and merges we drop areas with more than a three percent change in square mileage between 1930 and 2000 and we drop the state of Virginia where splits and merges are common. We also drop counties in Hawaii or Alaska and underpopulated counties with population less than 1,000 in any decade in the 20th century.

The quality of some of the key variables is not ideal. Substantial measurement error is likely to be present at the beginning of our sample period. Moreover, in early years, direct data on workers wages are unavailable at the county level. As an expedient, we proxy for the average wage in 
manufacturing by dividing the total annual wage bill in manufacturing by the estimated number of workers in the industry. This is unlikely to provide a perfect measure of the marginal product of labor as it fails to account for differences in the number of hours worked and quality of workers. Moreover, in some counties, the wage bill is missing. For agriculture, the county wage bill is not available, so there is no good way to compute an average agricultural wage.

More specifically, the key variables are the following:

- Pop: Total population of each county.

- Popurb: Urban population in each county. For 1900 to 1920 it was calculated as population residing in places of 2,500 or more persons. For 1930, 1940, 1950 and 2000, calculated directly as total urban population. For 1960 and 1970, defined as percentage urban times the total population. For 1980 and 1990 it was calculated as urban population inside urbanized areas plus urban population outside urbanized area.

- White: Share of Population of White Race. For 1900-1940 and 1970-2000 defined as total white population over total population. For 1950 and 1960, it was defined as 1 minus the share of black and races other than white.

- Emp: Total Employment. Missing for 1900-1920. For 1930, defined as the number of "gainful workers" in a county, for 1940 and 1950 defined as the total employed workers, for 1960 and 1980 defined as the total civilian labor force employed and for 1970 defined as the total civilian force aged 16 or more employed. For 1990, defined as the male civilian labor force employed plus the female labor force employed. For 2000, defined as the population 16 and over who worked in 1999.

- Manuf: Share of employment in manufacturing. For 1900 to 1920 defined from individual level data as the number of individuals who reported working on manufacturing over the total number of individuals with reported industry. For 1930, defined as the average number of wage earners in manufacturing in 1929 over total employment. For 1940 defined as workers in manufacturing over total employment. For 1950-1970, defined both directly as share of employment in manufacturing and also as workers in manufacturing over total employment for 1950, as labor force employed in manufacturing of durable goods plus labor force employed in manufacturing of nondurable goods over total employment for 1960, and as civilian labor force aged 16+ employed in manufacturing for 1970. For 1980-1990, defined as workers in manufacturing of durable goods plus workers in manufacturing of nondurable goods, over total employment. For 2000, defined as female workers in manufacturing plus male workers in manufacturing, over total employment.

- Manuftot: Manufacturing total employment. For 1900-1940 it was defined as the average number of manufacturing wage earners and for 1947-1997 as manufacturing production workers.

- Agr: Share of employment in agriculture. For 1900 to 1930 defined from individual level data as the number of individuals who reported working on agriculture over the total number of individuals with reported industry. For 1940-1960, defined as workers in agriculture over total employment. Missing for 1970. For 1980 and 1990 it was defined as the number of workers employed in agriculture, forestry and fisheries over total employment. For 2000, defined as the 
sum of males and females employed in agriculture, forestry, fisheries and hunting and mining over total employment.

- Medfaminc: Median family income. Missing for 1900 to 1940. For 1980 defined as Median family income in 1979. For 1990 defined as Median family income in 1989. For 2000 defined as Median income in 1999.

- Mwage: Total county level manufacturing wages in thousands of dollars. For 1900, 1920, 1930, given in dollars, so divided by 1,000. For 1940 defined as 1939 wages. For 1950 defined as 1954 wages. For 1960 defined as 1963 wages. For 1970 defined as 1972 wages, given in millions of dollars, so multiplied by 1,000. For 1980 defined 1982 wages, given in millions of dollars, so multiplied by 1,000. For 1990 defined as 1987 wages, given in millions of dollars, so multiplied by 1,000 . For 2000 , defined as 1997 wages.

- Pcmwage: per capita county level manufacturing wage. Defined as mwage over manuftot.

- House: Total number of housing units. For 1900-1930 defined as total dwellings. For 1940-2000 defined as total housing units.

- Vfprod: Value of farm products in thousands of dollars. Total value of farm products for each county in thousands of dollars. For 1900, defined as the value of miscellaneous crops with acreage reported in 1899 plus the value of miscellaneous crops without acreage reported in 1899. For 1910-1930, defined as value of all crops divided by 1,000. For 1940, defined as value of all farm products sold, traded or used. For 1950-1960, defined as value of all farm products sold, in thousands of dollars. For 1970, we use the value of farm products sold in farms with sales of $\$ 2,500$ or more in 1969. For 1980, defined as value of farm products sold in 1982 in millions of dollars, so multiplied by 1000. For 1990, defined as value of farm products sold in 1987 in thousands of dollars. For 2000, defined as value of farm products sold in 1997 in thousands of dollars.

- Vfland: Value of land. For 1900-1910 defined directly as average value of land per acre. For 1920 and 1930 defined as value of land in farms divided the number of acres in farms. For 1940-1970, value of farmland in 1945, 1954, 1959 and 1969.

\section{Geographic Definition of TVA}

The service area expanded over time, though by 1940 TVA already served most of its final area. In our analysis below we use the most recent and therefore most comprehensive definition of the TVA service area. A handful of counties were only partially covered by the TVA service area. For the purpose of our analysis, we include these counties in the list of TVA counties.

\section{Geographic Definition of Proposed Authorities}

Here we describe the process used to identify the most likely geographical scope of the proposed authorities. We rely on the historical account of the deliberations in Leuchtenburg $(1952,1997)$ and on bill HR 1824, titled "The Conservation Authorities Act," introduced on Jan. 29, 1945, by

Representative John E. Rankin of Mississippi. Among the 10 bills in front of Congress in 1945, HR 1824 appears to be the most detailed. We assume that within each region, the exact boundaries of 
each authority would have have been identified using the same criteria used by TVA geographers and listed in Section 2.2.

In practice, we started with the definition of the broad regional authorities enumerated in bill HR 1824:

1. Atlantic Seaboard: Drainage basins of rivers flowing into the Atlantic Ocean and the Gulf of Mexico from the east

2. Great Lakes-Ohio Valley: Drainage basins of rivers flowing into or from the Great Lakes, the Niagara River, the St. Lawrence River and the Ohio River (except drainage basins of Tennessee and Cumberland Rivers) and of the rivers flowing into the Mississippi River above Cairo, Illinois, from the east

3. Missouri Valley: Drainage basins of the Missouri River and Red River of the North and rivers flowing into the Mississippi River above Cairo, Illinois, from the west

4. Arkansas Valley: Drainage basins of the Arkansas River, Red River, White River, Rio Grande River and rivers flowing into the Mississippi River below Cairo, Illinois, from the west and rivers flowing into the Gulf of Mexico west of the Mississippi River

5. Columbia Valley: Drainage basins of the Columbia River and rivers flowing into the Pacific Ocean north of the California-Oregon line

6. Great Basin: Drainage basins of rivers flowing into the Great Basin (have no outlet to the sea)

7. California: Drainage basins of rivers flowing into the Pacific Ocean below the CaliforniaOregon line

8. Colorado: Drainage basin of the Colorado River

While HR 1824 splits the Western authority into three separate authorities: Great Basin Authority, California Authority, and Colorado Authority, Leuchtenburg presents as more likely the scenario where these three authorities are merged into one. Following Leuchtenburg, we merge the last three into one authority, called Western authority. For each authority, we merged the relevant hydrology polygons (HUC-2, hydrologic unit code 2) on ArcGIS and obtained the relevant area. We then merged the data with the Administrative Counties Boundaries with the area. HUC-2 polygons were obtained from the U.S. Geological Survey. The polygons are aggregations of Basins and Sub-Basins in this USGS map http://viewer.nationalmap.gov/viewer/nhd.html? $\mathrm{p}=$ nhd.

As explained in the main text, the proposed legislation broadly identified the regions that each authority was supposed to belong to, but did not identify precisely which set of counties within each region would have belonged to each authority. This is consistent with the process that was adopted for TVA. Recall that when Congress passed legislation to create TVA, it defined its regional scope only broadly. The precise list of counties that ended up belonging to the TVA service area was identified by geographers at the Division of Land Planning and Housing only later. The geographers defined the borders of service area based a number of criteria provided by Congress. In Section 2 of the paper we list the main criteria. The map of TVA drafted by geographers was ultimately approved by the TVA Board of Directors. 
In order to come up with a concrete definition of the geographic scope of each proposed authority, we had to select subregions within each authority area, just like the TVA geographers did. To make our selection the least arbitrary as possible, we sought to replicate the criteria originally used by the geographers at the Division of Land Planning and Housing to define the TVA borders. For each of the six regions, we defined each authority as encompassing the subregion with land mass equal to a third of the region that matches most closely the TVA geographers' criteria.

Specifically, we used the following algorithm:

1. For each of the 6 proposed authorities, we used a Python script to generate all possible sets of spatially adjacent counties within the region. ${ }^{30}$

2. For the Western authority, we removed all sets that included counties within the Bonneville Power Administration (BPA) service area. The BPA is a federal nonprofit agency created by Congress in 1937. Its area includes parts of Oregon and Washington states. Similarly to TVA, BPA was charged by Congress to built dams and roads, with most of the federal investment taking place between the 1940's and the 1960's. The BPA region is clearly not a good counterfactual, since it did receive treatment similar to that of TVA. Additionally, we removed all sets that contained counties that touch the boundary of a region. This was done in order to prevent the authority subregions from touching each other. For authorities 1 to 4, we also removed all the counties touching counties belonging to TVA, and all the counties touching counties that touch counties belonging to TVA. This was done in order to assure that there are at least two "rings" of counties between the authority subregions and TVA.

3. We kept all subregions that had an area equal to a third of the total area in the region. ${ }^{31}$ The resulting number of counties is 227 for region 1; 233 for region 2; 179 for region 3; 250 for region 4; and 43 for region 5 and 6 . (Counties in the West are much larger than counties in the rest of the country.)

4. We used the following vector of (standardized) variables measured in 1920 and 1930 to proxy for the criteria used by the TVA geographers:

- urban share and share of agriculture over total employment (To identify areas that are particularly rural);

- percent illiterate (to identify areas that lack schools and libraries);

- manufacturing wage, manufacturing share, population, employment, average farm value, median housing value and median rent (to identify areas that are economically underdeveloped);

An important limitation is that we have no way of measuring other criteria used by TVA geographer, such as willingness to receive technical and advisory assistance from the Authority;

\footnotetext{
${ }^{30}$ More specifically, starting from the list of all counties, the Python script generated all combinations of "seed clusters" within that list. The seed clusters consisted of 4 adjacent counties. The information on adjacent counties is obtained from the Contiguous County File, 1991 [United States], available from the ICPSR archive at http://dx.doi.org/10.3886/ICPSR09835.v1

${ }^{31}$ We expanded the seed clusters by attaching the set of all contiguous counties until the final cluster size is such that the resulting authority subregion has an area that is equal to a third of the total area in the region. More specifically, in order to determine the final cluster size, we started from the county that contains the centroid of a region. We attached the set of counties contiguous to that county, then the set of counties contiguous to those counties and so on up to the point when the total area of the sub-region reaches a third of the are of the region. To achieve the exact final cluster size, the Python script grows the cluster until it exceeds that size, then randomly chooses counties to remove from the last layer added.
} 
existence of planning agencies and enabling legislation; willingness to experiment with new fertilizers.

5. Of all subregions within each region, we selected the subregion that minimized the Euclidean distance between each subregion's vector and TVA's vector.

The resulting six authorities are shown in Appendix Figure A2. 


\section{Appendix B: Comparison of structural predictions with reduced form estimates}

We can use our estimated parameters from Tables VI and VII of the paper to compute impulse responses to the TVA intervention. These predictions can be compared to the reduced form impacts of Table IV as a check on the model's assumptions. We will conduct this exercise in two ways: first without restricting the direct effects and then assuming that the direct effects obey a capital accumulation equation.

\section{VI.A. Unrestricted Direct Effects}

From Table VII, the direct effect of TVA on local labor demand over the 1940-1960 period is roughly $9 \%$ per decade on average. Table VI reports autoregressive coefficients ranging over the interval 0.31-0.35 with a standard error of roughly 0.10. Given an autoregressive coefficient of 0.35 , one expects a composite change between 1940 and 1960 in direct demand of $.09 \times 1.35+.09=.212$ which is very close to the reduced form $22.8 \%$ impact in column 1 of Table IV. ${ }^{32}$ Table VII reports no significant difference in direct effects between 1960 and 1980 or between 1980 and 2000. The implied impact on growth over the subsequent 1960-2000 period, assuming no further changes in the direct impacts of TVA, is $\left(0.35+(0.35)^{2}+(0.35)^{3}+(0.35)^{4}\right) \times .212=.112$ which is a bit below the $13.2 \%$ growth impact implied by column 2 of Table IV but well within sampling error. This finding is reassuring and lends additional credibility to our structural estimates. Despite using completely different sources of variation for identification, our structural estimates are in line with the reduced form impacts of section III.

\section{VI.B. Capital Accumulation}

The above calculations assume the direct effects of TVA don't depreciate after 1960. An alternative approach is to assume the direct effects $\delta_{t}$ obey the recursion:

$$
\delta_{t}=(1-d) \delta_{t-1}+I_{t},
$$

where $d \in(0,1)$ is a decadal rate of depreciation and $I_{t}$ a flow rate of infrastructure accumulation between decade $t-1$ and $t$. Supposing that the direct investment effects of TVA cease after 1960, we have three unknown parameters $\left(I_{50}, I_{60}, d\right)$. These parameters can be fit to our three estimated moments $\left(\delta_{60}-\delta_{40}, \delta_{80}-\delta_{60}, \delta_{2000}-\delta_{80}\right)$ reported in Table VII. Assuming, as usual, that $\delta_{40}=0$, we have that:

$$
\begin{gathered}
\delta_{60}-\delta_{40}=I_{60}+(1-d) I_{50} \\
\delta_{80}-\delta_{60}=[-d-d(1-d)]\left(\delta_{60}-\delta_{40}\right) \\
\delta_{2000}-\delta_{80}=[-d-d(1-d)]\left(\delta_{80}-\delta_{60}\right) .
\end{gathered}
$$

\footnotetext{
${ }^{32}$ The estimates in Table IV are decadalized. Throughout this section we multiply by the appropriate number of decades to infer the total change over the specified period.
} 
From Table VII, $\left(\delta_{60}-\delta_{40}, \delta_{80}-\delta_{60}, \delta_{2000}-\delta_{80}\right)=(0.179,-0.029,-0.002)$ with corresponding standard errors $(0.091,0.023,0.039)$. A variance weighted nonlinear least squares fit to these moments yields $\left(\hat{I}_{50}, \hat{I}_{60}, \hat{d}\right)=(0.051,0.131,0.069) .{ }^{33}$ Note that this estimate implies an annual depreciation rate of $1-(1-0.069)^{1 / 10}=0.007$, which is small but not implausible.

Using these parameter estimates (and continuing with our autoregressive point estimate of 0.35) we predict an increase in log manufacturing employment over the 1940-1960 period of $I_{60}+$ $(1+.35-d) I_{50}=0.197$ which is slightly below the reduced form estimate of 0.228 from column 1 of Table IV and almost identical to the estimate of 0.194 derived from column 5 of Table IV which relies on proposed authorities for controls. Over the 1960-2000 period, we predict an increase in manufacturing employment of $0.197\left(\sum_{k=1}^{4}(.35-d)^{k}\right)=0.077$. This is a more substantial underestimate as the corresponding reduced form figure from column 2 of Table IV is 0.132 . However, it is still within sampling error. A modest increase of the autoregressive parameter to 0.45 raises the predicted change over the 1960-2000 interval to 0.122 which is very close. This exercise suggests TVA's direct effects are consistent with infrastructure investments obeying a small but positive depreciation rate.

\footnotetext{
${ }^{33}$ Although there are three moments and three parameters, the estimated moments do not exactly obey the parametric restrictions. This necessitates the nonlinear least squares approach which searches for the best fitting set of parameters.
} 


\section{Appendix C: Cost Benefit Analysis}

To quantify the nationwide benefits of the productivity gains associated with the TVA, we compute the steady state elasticity of worker utility with respect to the TVA's productivity effects. This elasticity is combined with our estimates of the direct productivity effects of the TVA to compute an impact on worker welfare which is then converted to dollars terms.

We begin by deriving the formula for the elasticity of worker utility with respect to TVA's local investments under the assumption of fixed sectoral labor supply. In the next subsection we compare costs and benefits of the program under this assumption. We then generalize our analysis to the more plausible case of elastic supply. In the last subsection we highlight some key limitations.

\section{TVA and Worker Utility}

We begin by developing the additional general equilibrium assumptions necessary to conduct our analysis. In particular, we add to our model the following sectoral market clearing condition:

$$
L_{t}^{S}\left(\bar{u}_{t}\right)=L_{t}^{D}\left(\bar{u}_{t}\right)
$$

where $L_{t}^{S}$ denotes the aggregate supply of manufacturing workers in period $t$ which is increasing in the utility level $\bar{u}_{t} . L_{t}^{D} \equiv \sum_{i} L_{i t}$ denotes aggregate labor demand which is decreasing in manufacturing wages and hence, also in $\bar{u}_{t}$.

A useful baseline assumption for our analysis is to assume that the supply of manufacturing workers is fixed at each moment in time $\left(L_{t}^{S}\left(\bar{u}_{t}\right)=\bar{L}_{t}\right)$. We will relax this assumption below. With fixed supply, gains in the TVA region must be offset by losses elsewhere and increases in aggregate demand must be offset by changes in wages.

Though our model is dynamic, our structural estimates indicate the rate of adjustment to the steady state is relatively rapid, which suggests that a steady state analysis should provide a good approximation to a full dynamic solution. ${ }^{34}$ The steady state of our model is given by equation (6) in the paper and the following equations:

$$
\begin{gathered}
\sum_{i} L_{i}=\bar{L} \\
\ln w_{i}+M_{i}=\bar{u} \\
\ln w_{i}=C-\frac{\beta}{1-\alpha} \ln L_{i}+\frac{\beta}{1-\alpha} \ln F_{i}-\frac{\alpha}{1-\alpha} \ln r+\frac{1}{1-\alpha} \ln A_{i}
\end{gathered}
$$

We are interested in the elasticity of worker utility with respect to TVA's local investments, which can be written:

$$
\frac{d \bar{u}}{d \delta}=\frac{d \ln w_{i}}{d \delta}=-\frac{1}{1-\alpha} \frac{1}{L_{i}}\left(\beta-\sigma_{i}\right) \frac{d L_{i}}{d \delta}+\frac{1}{1-\alpha} D_{i}
$$

\footnotetext{
${ }^{34}$ In addition to its simplicity, a steady state analysis has the advantage of formalizing our intuition from section IV of the paper that a constant agglomeration elasticity renders the magnitude of agglomeration economies irrelevant for welfare purposes.
} 
Solving for $\frac{d L_{i}}{d \delta}$ yields:

$$
\frac{d L_{i}}{d \delta}=\frac{D_{i}-(1-\alpha) \frac{d \bar{u}}{d \delta}}{\frac{1}{L_{i}}\left(\beta-\sigma_{i}\right)}
$$

But (13) implies:

$$
\sum_{i} \frac{d L_{i}}{d \delta}=\sum_{i} \frac{D_{i}-(1-\alpha) \frac{d \bar{u}}{d \delta}}{\frac{1}{L_{i}}\left(\beta-\sigma_{i}\right)}=0
$$

Hence, the elasticity of interest can be written:

$$
\frac{d \bar{u}}{d \delta}=\frac{1}{1-\alpha} \frac{\sum_{i} \frac{D_{i} L_{i}}{\beta-\sigma_{i}}}{\sum_{i} \frac{L_{i}}{\beta-\sigma_{i}}}
$$

With a constant agglomeration elasticity $\left(\sigma_{i}=\sigma\right)$, this expression simplifies to:

$$
\frac{d \bar{u}}{d \delta}=\frac{1}{1-\alpha} \frac{\sum_{i} D_{i} L_{i}}{\sum_{i} L_{i}}
$$

Note that this formula doesn't depend upon the strength of agglomeration forces $\sigma$. This is because, with a constant elasticity, the agglomeration effects of worker reallocation cancel out. Hence, worker utility simply increases in proportion to the TVA region's share of the manufacturing workforce. In essence, this expression tells us that TVA should be thought of as only nominally place based in nature. Rather, it is a national investment that raises welfare through its direct effects on the productivity of a fraction of the manufacturing workforce.

While it is certainly possible that agglomeration elasticities do vary across communities, our point estimates of $g($.$) are so close to log-linear that we expect the effects of small nonlinearities to$ be trivial. Hence, we turn now to using the simple expression in (14) to assess TVA's benefits.

\section{Comparing Aggregate Costs and Benefits}

We now have all the pieces that are needed to compare the TVA's costs to its benefits. TVA's share of national manufacturing employment in 1940 was approximately $3.3 \%$ which we use as our estimate of $\frac{\sum_{i} D_{i} L_{i}}{\sum_{i} L_{i}}$. This number, along with our estimates from Table VII, allow us to quantify TVA's impact on national productivity. Specifically, we find that the program raised national productivity by $.084 \times .033 \times 100=.3 \%$ between 1940 and 1960 . This is a plausible magnitude that will be shown to imply important effects on worker utility.

Given that $\frac{1}{1-\alpha} \approx 1.43$, our estimate of the utility elasticity of TVA productivity is $\frac{d \bar{u}}{d \delta} \approx$ $1.43 \times .033=.047$. From Table VII, we know that $\delta$ increased by roughly .084 between 1940 and 1960 and may have declined slowly in subsequent years. Interpolating linearly, we assume $\delta$ grew by .0042 per year between 1940 and 1960 and then fell by .0002 per year afterward due to depreciation. Appendix Table A5 details this calculation. Multiplying $\frac{d \bar{u}}{d \delta}$ by each year's level of $\delta$ yields the proportional utility gain in the manufacturing sector in that year. We then multiply this figure by the manufacturing wage bill in that year in order to value the utility gain measured in 2000 dollars. 
This yields the flow of program benefits in column 4 of Appendix Table A5. The net present value of this stream of benefits using a real annual discount rate of $3 \%$ is roughly $\$ 32.3 \mathrm{~B} .{ }^{35}$ This is to be compared with the present value of federal transfers which amount to $\$ 17.3 \mathrm{~B}$. Hence, we find a substantial rate of return to the TVA's public investments, with benefits nearly double program costs.

\section{Relaxing Fixed Supply}

The fixed supply assumption upon which the above estimates are predicated is a strong one. If sectoral labor supply is not fixed, manufacturing gains in the TVA region need not crowd out the manufacturing bases of other geographic areas. Rather, workers will be diverted, in part, from other sectors (e.g. agriculture or home production). Suppose we replace (13) with the assumption that

$$
\sum_{i} L_{i}=\bar{L}(\bar{u})
$$

This implies that

$$
\sum_{i} \frac{d L_{i}}{d \delta}=\sum_{i} \frac{D_{i}-(1-\alpha) \frac{d \bar{u}}{d \delta}}{\frac{1}{L_{i}}(\beta-\sigma)}=\bar{L}^{\prime}(\bar{u}) \frac{d \bar{u}}{d \delta}
$$

Some algebra yields a new expression for the utility elasticity of the TVA's productivity effects:

$$
\frac{d \bar{u}}{d \delta}=\frac{1}{1-\alpha+(\beta-\sigma) \psi} \frac{\sum_{i} D_{i} L_{i}}{\sum_{i} L_{i}},
$$

where $\psi \equiv \bar{L}^{\prime}(\bar{u}) / \bar{L}$ is the elasticity of labor supply to the manufacturing sector. Note that now the level of the agglomeration elasticity is relevant for our calculation. This is because increases in market size lead to additional agglomeration everywhere and hence additional productivity. This force is offset by the fixed factor which yields declining marginal products as market size increases. Given the basic regularity condition that $\beta>\sigma$, this expression has the intuitive property that the utility consequences of TVA on manufacturing workers dissipate as the elasticity of labor supply to the sector increases. ${ }^{36}$ Moreover, if the elasticity is zero, we return to the expression for the fixed supply case.

To assess the impact of a reasonable degree of elasticity to the manufacturing sector we set $\psi=1$. And following our earlier calibrations, we take $\beta-\sigma=.33$. This gives us $\frac{1}{1-\alpha+(\beta-\sigma) \psi} \approx 1$ and hence $\frac{d \bar{u}}{d \delta} \approx .033$. The stream of benefits associated with this choice of parameters is reported in columns (5) and (6) of Table VIII. Under this calibration, the net present value of benefits in the manufacturing sector falls to approximately $\$ 22.7 \mathrm{~B}$ - still above program costs but significantly lower than before.

\footnotetext{
${ }^{35}$ This figure assumes the benefits end discretely in the year 2000, when our data end. If one assumes a permanent effect after 2000 , our estimate rises slightly to $\$ 34.7 \mathrm{~B}$

${ }^{36}$ If $\beta<\sigma$ the model would become unstable as the steady state demand curve for labor would slope up globally. This would lead to an equilibrium where all labor locates at a single point.
} 


\section{Caveats}

Several caveats are worth keeping in mind when interpreting our results. First, with variable supply, the outflow of workers from other sectors may yield wage increases in those sectors which are not captured in our accounting of benefits. However, if the sectors from which workers are diverted exhibit roughly constant returns to scale, then wages may remain stable in the face of outflows, provided workers are not too heterogeneous in their tastes for sectors.

Second, for a variety of reasons, labor market impacts probably capture only a fraction of the true general equilibrium impact of TVA. For example, with transport costs or trading frictions, it is possible that the productivity enhancements associated with TVA would depress the national price of manufactured goods. This would result in increased consumer surplus ignored in our calculation.

In the other direction, we have ignored the social costs associated with raising the federal funds transferred to TVA via taxation. Feldstein (1999), for example, estimates the marginal cost of funds at thirty cents on the federal dollar. We are not aware of econometric estimates of the marginal cost of funds for the 1940-1960 period during which TVA received the bulk of its transfers but can imagine that the costs were substantial. This dead weight loss is likely to increase substantially the ultimate social costs of the program.

Finally, our analysis relies on steady state approximations to the time path of welfare impacts on manufacturing workers. These approximations simplify our analysis dramatically, but a more sophisticated analysis taking into account out of steady state dynamics would be interesting, if tedious. In particular, such an analysis would have the advantage of capturing interactions (which we ignore) between national shocks to manufacturing and TVA's dynamic productivity effects. 
Table I: Summary Statistics

\begin{tabular}{|c|c|c|c|c|c|c|}
\hline & \multicolumn{4}{|c|}{ Overall } & \multicolumn{2}{|c|}{ Trimmed Sample } \\
\hline & TVA & Non-TVA & $\begin{array}{l}\text { Non-TVA } \\
\text { South } \\
\text { (3) }\end{array}$ & $\begin{array}{c}\text { Non-TVA } \\
\text { Proposed } \\
\text { Authorities } \\
(4)\end{array}$ & Non-TVA & $\begin{array}{c}\text { Non-TVA } \\
\text { South } \\
(6)\end{array}$ \\
\hline \multicolumn{7}{|l|}{1930 Characteristics } \\
\hline Log Population & 9.991 & 9.977 & 9.989 & 9.940 & 9.905 & 9.979 \\
\hline Log Employment & 8.942 & 8.967 & 8.959 & 8.908 & 8.881 & 8.947 \\
\hline Log \# of Houses & 8.445 & 8.508 & 8.455 & 8.466 & 8.442 & 8.445 \\
\hline Log Average Manufacturing Wage & 1.406 & 1.802 & 1.545 & 1.685 & 1.728 & 1.538 \\
\hline Manufacturing Employment Share & 0.075 & 0.090 & 0.080 & 0.077 & 0.080 & 0.078 \\
\hline Agricultural Employment Share & 0.617 & 0.455 & 0.541 & 0.510 & 0.487 & 0.547 \\
\hline$\%$ White & 0.813 & 0.885 & 0.722 & 0.830 & 0.863 & 0.724 \\
\hline$\%$ Urbanized & 0.153 & 0.280 & 0.233 & 0.216 & 0.242 & 0.215 \\
\hline \% Illiterate & 0.088 & 0.045 & 0.092 & 0.060 & 0.051 & 0.092 \\
\hline$\%$ of Whites Foreign Born & 0.002 & 0.059 & 0.013 & 0.020 & 0.030 & 0.011 \\
\hline Log Average Farm Value & 5.252 & 5.646 & 5.386 & 5.552 & 5.579 & 5.370 \\
\hline Log Median Housing Value & 9.271 & 9.581 & 9.360 & 9.452 & 9.516 & 9.358 \\
\hline Log Median Contract Rent & 8.574 & 9.030 & 8.679 & 8.834 & 8.934 & 8.672 \\
\hline \% Own Radio & 0.079 & 0.296 & 0.114 & 0.210 & 0.256 & 0.112 \\
\hline Max Elevation (meters) & 1576.190 & 2364.531 & 1068.943 & 1758.893 & 2044.656 & 1070.334 \\
\hline Elevation Range (Max-Min) & 1127.761 & 1521.322 & 712.336 & 1083.293 & 1251.074 & 715.253 \\
\hline$\%$ Counties in South & 1.000 & 0.342 & 1.000 & 0.554 & 0.447 & 1.000 \\
\hline \multicolumn{7}{|l|}{ Changes 1920-1930 } \\
\hline Log Population & 0.051 & 0.049 & 0.067 & 0.004 & 0.037 & 0.060 \\
\hline Log Employment & 0.082 & 0.096 & 0.111 & 0.045 & 0.083 & 0.103 \\
\hline Log \# of Houses & 0.078 & 0.092 & 0.108 & 0.046 & 0.078 & 0.100 \\
\hline Log Average Manufacturing Wage & 0.117 & 0.217 & 0.108 & 0.172 & 0.197 & 0.103 \\
\hline Manufacturing Employment Share & -0.010 & -0.035 & -0.018 & -0.018 & -0.026 & -0.018 \\
\hline Agricultural Employment Share & -0.047 & -0.036 & -0.047 & -0.046 & -0.042 & -0.047 \\
\hline$\%$ White & 0.012 & -0.011 & -0.010 & 0.000 & -0.006 & -0.004 \\
\hline$\%$ Urbanized & 0.047 & 0.064 & 0.080 & 0.042 & 0.054 & 0.069 \\
\hline$\%$ Illiterate & -0.030 & -0.014 & -0.029 & -0.019 & -0.015 & -0.028 \\
\hline$\%$ of Whites Foreign Born & -0.001 & -0.023 & -0.016 & -0.012 & -0.015 & -0.012 \\
\hline Log Average Farm Value & -0.013 & -0.076 & 0.025 & -0.182 & -0.102 & 0.013 \\
\hline \# of Observations & 163 & 2326 & 795 & 828 & 1744 & 779 \\
\hline \# of States & 6 & 46 & 14 & 25 & 43 & 14 \\
\hline
\end{tabular}

Notes: The unit of observation is a county. The trimmed sample is obtained by dropping control counties which, based on their preprogram characteristics, have a predicted probability of treatment in the bottom 25 percent. All monetary values are in constant 2000 dollars. Data are from the 1920 and 1930 Census of Population and Housing, with the exception of farm value data, which are from the 1920 and 1930 Agricultural Census, and elevation data, which were collected by Fishback, Haines, and Kantor (2011). Manufacturing wage is obtained by dividing the total annual wage bill in manufacturing by the estimated number of workers in the industry. Details on data construction and limitations are provided in the Appendix. 
Table II: Decadalized Growth Rates in TVA Region vs. Conterfactual Regions 1900-1940

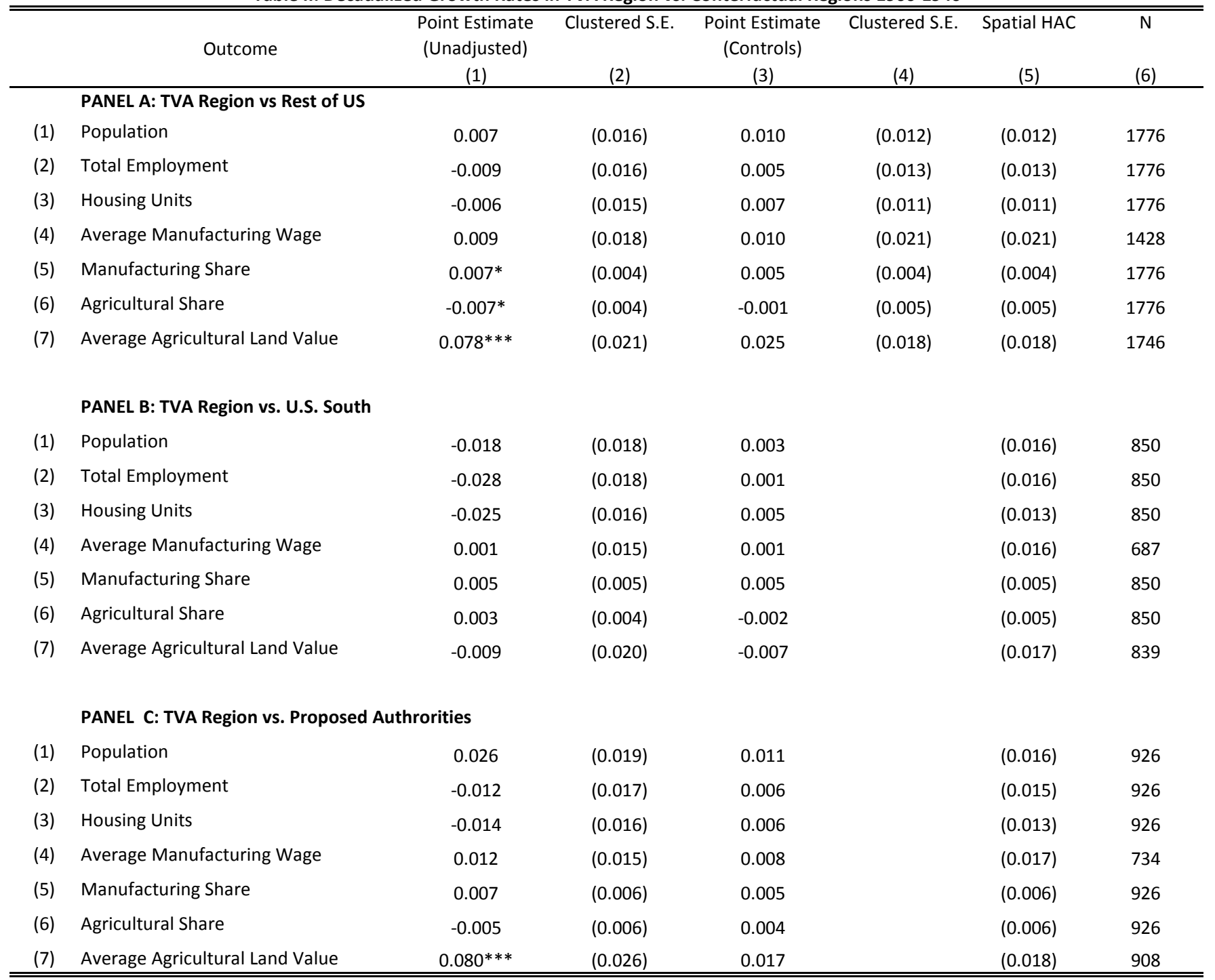

Notes: Column (1) gives the unconditional difference between TVA and non-TVA counties in the 1900-1940 change in the log of the relevant outcome divided by four (shares not converted to logs). Column (3) adjusts for pre-program differences between TVA counties and controls via a Oaxaca-Blinder regression as in Kline (2011). Covariates include time invariant geographic characteristics and levels and trends in pre-program industrial mix, population, and demographic characteristics (see Section III.A for full list of covariates). Clustered S.E. columns provide standard errors estimates clustered by state. Spatial HAC column provides standard error estimates based upon technique of Conley (1999) using bandwidth of 200 miles. Stars based upon clustered standard errors. Legend: * significant at $10 \%$ level, ${ }^{* *}$ significant at $5 \%$ level, ${ }^{* * *}$ significant at $1 \%$ level. 


\begin{tabular}{|c|c|c|c|c|c|c|c|}
\hline & \multirow[t]{2}{*}{ Outcome } & \multirow{2}{*}{$\begin{array}{c}\text { Point Estimate } \\
\text { (Unadjusted) } \\
\text { (1) } \\
\end{array}$} & \multirow{2}{*}{$\begin{array}{c}\text { Clustered S.E. } \\
\text { (2) }\end{array}$} & \multirow{2}{*}{$\begin{array}{c}\text { Point Estimate } \\
\text { (Controls) } \\
\text { (3) }\end{array}$} & \multirow{2}{*}{$\begin{array}{c}\text { Clustered S.E. } \\
\begin{array}{c}(4) \\
\end{array}\end{array}$} & \multirow{2}{*}{$\begin{array}{c}\text { Spatial HAC } \\
\text { (5) }\end{array}$} & \multirow{2}{*}{$\begin{array}{l}\mathrm{N} \\
(6) \\
\end{array}$} \\
\hline & & & & & & & \\
\hline & PANEL A: TVA Region vs Rest of US & & & & & & \\
\hline (1) & Population & 0.004 & $(0.021)$ & 0.007 & $(0.020)$ & $(0.018)$ & 1907 \\
\hline (2) & Average Manufacturing Wage & $0.027^{* * *}$ & $(0.006)$ & 0.005 & $(0.004)$ & $(0.005)$ & 1172 \\
\hline (3) & Agricultural Employment & $-0.130 * * *$ & $(0.026)$ & $-0.056 * *$ & $(0.024)$ & $(0.027)$ & 1907 \\
\hline (4) & Manufacturing Employment & $0.076^{* * *}$ & $(0.013)$ & $0.059 * * *$ & $(0.015)$ & $(0.023)$ & 1907 \\
\hline (5) & Value of Farm Production & -0.028 & $(0.028)$ & 0.002 & $(0.032)$ & (0.026) & 1903 \\
\hline (6) & Median Family Income (1950-2000 only) & $0.072^{* * *}$ & $(0.014)$ & 0.021 & $(0.013)$ & $(0.011)$ & 1905 \\
\hline (7) & Average Agricultural Land Value & $0.066^{* * *}$ & $(0.013)$ & -0.002 & $(0.012)$ & (0.016) & 1906 \\
\hline \multirow[t]{2}{*}{ (8) } & Median Housing Value & $0.040^{* *}$ & $(0.017)$ & 0.005 & $(0.015)$ & $(0.015)$ & 1906 \\
\hline & PANEL B: TVA Region vs. U.S. South & & & & & & \\
\hline (1) & Population & -0.007 & $(0.018)$ & 0.014 & & (0.019) & 942 \\
\hline (2) & Average Manufacturing Wage & 0.003 & $(0.006)$ & 0.001 & & $(0.005)$ & 610 \\
\hline (3) & Agricultural Employment & $-0.097^{* * *}$ & $(0.030)$ & $-0.051^{*}$ & & $(0.027)$ & 942 \\
\hline (4) & Manufacturing Employment & $0.079 * * *$ & $(0.023)$ & $0.063^{* * *}$ & & $(0.024)$ & 942 \\
\hline (5) & Value of Farm Production & -0.005 & $(0.025)$ & -0.006 & & (0.026) & 939 \\
\hline (6) & Median Family Income (1950-2000 only) & $0.041^{* * *}$ & $(0.012)$ & $0.024 * *$ & & $(0.011)$ & 942 \\
\hline (7) & Average Agricultural Land Value & $0.031^{*}$ & $(0.018)$ & -0.003 & & $(0.017)$ & 942 \\
\hline \multirow[t]{2}{*}{ (8) } & Median Housing Value & 0.019 & $(0.017)$ & 0.007 & & $(0.016)$ & 942 \\
\hline & PANEL C: TVA Region vs. Proposed Authro & & & & & & \\
\hline (1) & Population & 0.011 & $(0.018)$ & 0.001 & & $(0.017)$ & 991 \\
\hline (2) & Average Manufacturing Wage & $0.018^{* * *}$ & $(0.007)$ & 0.005 & & $(0.006)$ & 618 \\
\hline (3) & Agricultural Employment & $-0.101^{* * *}$ & $(0.029)$ & $-0.071^{* * *}$ & & $(0.027)$ & 991 \\
\hline (4) & Manufacturing Employment & $0.066^{* * *}$ & $(0.024)$ & $0.053^{* *}$ & & $(0.024)$ & 991 \\
\hline (5) & Value of Farm Production & 0.002 & $(0.026)$ & 0.011 & & $(0.035)$ & 989 \\
\hline (6) & Median Family Income (1950-2000 only) & $0.060^{* * *}$ & $(0.012)$ & $0.025 * *$ & & $(0.011)$ & 991 \\
\hline (7) & Average Agricultural Land Value & $0.060^{* * *}$ & $(0.019)$ & -0.003 & & $(0.016)$ & 991 \\
\hline (8) & Median Housing Value & $0.033 * *$ & $(0.016)$ & 0.009 & & $(0.016)$ & 991 \\
\hline
\end{tabular}

Notes: Point estimates obtained from regression of 1940-2000 change in outcomes divided by six on TVA dummy. All outcomes besides share Notes: Point estimates obtained from regression of 1940-2000 change in outcomes divided by six on TVA dummy. All outcomes besides shar
variables are transformed to logarithms before taking difference. In specification titled controls, counterfactual change in TVA sample computed via Oaxaca-Blinder regression as in Kline (2011). Covariates include time invariant geographic characteristics and levels and trends in pre-program industrial mix, population, and demographic characteristics (see Section III.A for full list of covariates). Clustered S.E. column provides standard errors estimates clustered by state. Spatial HAC column provides standard error estimates based upon technique of Conley (1999) using bandwidth of 200 miles. Stars based upon clustered standard errors. Legend: * significant at 10\% level, ** significant at $5 \%$ level, $* * *$ significant at $1 \%$ level. 
Table IV: Decadalized Impact of TVA on Growth Rate of Outcomes Over Two Sub-Periods

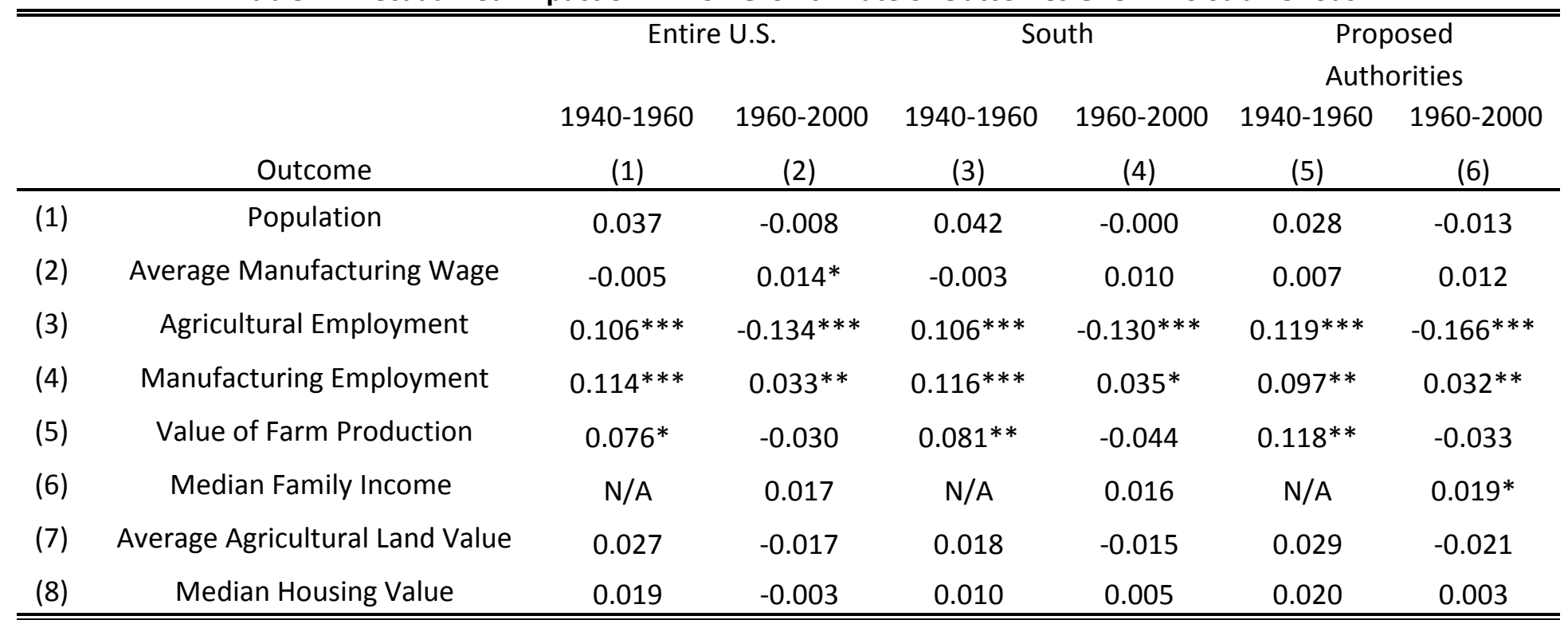

Notes: Full set of controls included in all specifications. Point estimates obtained from Oaxaca-Blinder regression of 19401960 or 1960-2000 change in log outcomes divided by two or four respectively on TVA dummy and interacted controls as in Kline (2011). Covariates include time invariant geographic characteristics and levels and trends in pre-program industrial mix, population, and demographic characteristics (see Section III.A for full list of covariates). Stars based on standard errors clustered by state (entire U.S.) or spatial HAC estimates (South and Proposed Authorities) using technique of Conley (1999) with bandwidth of 200 miles. Legend: * significant at $10 \%$ level, ${ }^{* *}$ significant at $5 \%$ level, ${ }^{* * *}$ significant at $1 \%$ level. 
Table V: Structural Estimates of Agglomeration Function (linear basis)

\begin{tabular}{|c|c|c|c|c|c|c|}
\hline & $(1)$ & $(2)$ & (3) & $(4)$ & $(5)$ & (6) \\
\hline & OLS & OLS & OLS & 2SLS & 2SLS & 2SLS \\
\hline \multicolumn{7}{|c|}{ Change in Manufacturing Density Spline Components: } \\
\hline & 0.030 & 0.025 & 0.024 & 0.087 & 0.078 & 0.078 \\
\hline \multirow{2}{*}{ Low } & $(0.010)$ & $(0.010)$ & $(0.010)$ & $(0.030)$ & $(0.031)$ & $(0.030)$ \\
\hline & & & & {$[124.66]$} & [115.79] & [114.53] \\
\hline \multirow{3}{*}{ Medium } & 0.006 & 0.007 & 0.006 & 0.030 & 0.030 & 0.029 \\
\hline & $(0.004)$ & $(0.005)$ & $(0.005)$ & $(0.010)$ & $(0.010)$ & $(0.010)$ \\
\hline & & & & [100.33] & [99.71] & [100.36] \\
\hline \multirow{3}{*}{ High } & -0.000 & 0.000 & 0.000 & 0.001 & 0.001 & 0.001 \\
\hline & $(0.001)$ & $(0.001)$ & $(0.001)$ & $(0.001)$ & $(0.001)$ & $(0.001)$ \\
\hline & & & & [31.91] & [31.37] & [25.98] \\
\hline Log Manufacturing Wages & -1.5 & -1.5 & -1.5 & -1.5 & -1.5 & -1.5 \\
\hline \multirow{2}{*}{ TVA } & 0.022 & 0.025 & 0.026 & 0.006 & 0.010 & 0.010 \\
\hline & $(0.013)$ & $(0.013)$ & $(0.014)$ & $(0.012)$ & $(0.012)$ & $(0.013)$ \\
\hline Regional Trends & no & no & yes & no & no & yes \\
\hline 1940 Manufacturing Density & no & yes & yes & no & yes & yes \\
\hline Decade Effects & yes & yes & yes & yes & yes & yes \\
\hline Controls for 1920 and 1930 characteristics & yes & yes & yes & yes & yes & yes \\
\hline P-value equal slopes & 0.013 & 0.048 & 0.058 & 0.000 & 0.001 & 0.002 \\
\hline P-value slopes equal zero & 0.027 & 0.082 & 0.099 & 0.001 & 0.003 & 0.005 \\
\hline $\mathrm{N}$ & 5462 & 5462 & 5462 & 5328 & 5328 & 5328 \\
\hline \multicolumn{7}{|c|}{$\begin{array}{l}\text { Notes: Dependent variable is change in log county manufacturing employment. Manufacturing density is } \\
\text { manufacturing employment per square mile. Standard errors clustered by state in parentheses. Angrist-Pischke } \\
\text { cluster robust first stage F-stat in brackets. All estimates weighted by } 1950 \text { county population. "Low" refers to } \\
\text { spline component corresponding to density below } 60 \text { th percentile of } 1980 \text { distribution, "Medium" to density } \\
\text { between 60th and } 85 \text { th percentile of } 1980 \text { distribution, and "High" to density above } 85 \text { th percentile of } 1980 \\
\text { distribution. Spline coefficients give the proportional effect on labor demand of an increase in lagged } \\
\text { manufacturing density of one worker per square mile over the relevant range. The instruments are changes in } \\
\text { the spline components of manufacturing density lagged by two decades. }\end{array}$} \\
\hline
\end{tabular}


Table VI: Structural Estimates of Agglomeration Function (log basis)

\begin{tabular}{|c|c|c|c|c|c|c|}
\hline & $\overline{(1)}$ & (2) & (3) & $7(4)$ & (5) & (6) \\
\hline & OLS & OLS & OLS & 2SLS & 2SLS & 2SLS \\
\hline \multicolumn{7}{|c|}{ Change in Log Manufacturing Density Spline Components: } \\
\hline & 0.078 & 0.053 & 0.052 & 0.349 & 0.323 & 0.325 \\
\hline \multirow[t]{3}{*}{ Low } & $(0.030)$ & $(0.031)$ & $(0.030)$ & (0.109) & $(0.122)$ & $(0.123)$ \\
\hline & & & & [182.83] & [149.61] & [148.34] \\
\hline & 0.072 & 0.075 & 0.069 & 0.339 & 0.327 & 0.319 \\
\hline \multirow{3}{*}{ Medium } & $(0.049)$ & $(0.050)$ & $(0.050)$ & $(0.097)$ & $(0.101)$ & $(0.103)$ \\
\hline & & & & [92.69] & [96.61] & [97.01] \\
\hline & 0.084 & 0.090 & 0.086 & 0.306 & 0.304 & 0.307 \\
\hline \multirow[t]{2}{*}{ High } & $(0.059)$ & $(0.059)$ & (0.059) & $(0.134)$ & $(0.135)$ & $(0.136)$ \\
\hline & & & & [206.26] & [204.81] & [202.69] \\
\hline Log Manufacturing Wages & -1.5 & -1.5 & -1.5 & -1.5 & -1.5 & -1.5 \\
\hline TVA & $\begin{array}{c}0.024 \\
(0.013)\end{array}$ & $\begin{array}{c}0.027 \\
(0.013)\end{array}$ & $\begin{array}{c}0.029 \\
(0.014)\end{array}$ & $\begin{array}{c}0.008 \\
(0.011)\end{array}$ & $\begin{array}{c}0.011 \\
(0.011)\end{array}$ & $\begin{array}{c}0.012 \\
(0.012)\end{array}$ \\
\hline Regional Trends & no & no & yes & no & no & yes \\
\hline 1940 Manufacturing Density & no & yes & yes & no & yes & yes \\
\hline Decade Effects & yes & yes & yes & yes & yes & yes \\
\hline Controls for 1920 and 1930 characteristics & yes & yes & yes & yes & yes & yes \\
\hline P-value equal slopes & 0.981 & 0.799 & 0.837 & 0.891 & 0.980 & 0.982 \\
\hline P-value slopes equal zero & 0.039 & 0.141 & 0.173 & 0.002 & 0.007 & 0.012 \\
\hline $\mathrm{N}$ & 5462 & 5462 & 5462 & 5318 & 5318 & 5318 \\
\hline
\end{tabular}

Notes: Dependent variable is change in log county manufacturing employment. Manufacturing density is manufacturing employment per square mile. Standard errors clustered by state in parentheses. Angrist-Pischke cluster robust first stage F-stat in brackets. All estimates weighted by 1950 county population. "Low" refers to spline component corresponding to log density below 60th percentile of 1980 distribution, "Medium" to log density between 60th and 85th percentile of 1980 distribution, and "High" to log density above 85th percentile of 1980 distribution. Spline coefficients give the elasticity of labor demand with respect to lagged manufacturing density over the relevant range. The instruments are changes in the spline components of log manufacturing density lagged by two decades. 
Table VII: Direct Effects of TVA on Labor Demand, by Period

\begin{tabular}{cccc}
\hline \hline & $(1)$ & $(2)$ & $(3)$ \\
& $1940-1960$ & $1960-1980$ & $1980-2000$ \\
\hline Spline in Levels & $0.179 * *$ & 0.002 & -0.016 \\
& $(0.069)$ & $(0.029)$ & $(0.042)$ \\
\hline \multirow{2}{*}{ Spline in Logs } & $0.179^{* *}$ & -0.029 & -0.002 \\
& $(0.091)$ & $(0.023)$ & $(0.039)$ \\
\hline Controls for 1920 and 1930 & yes & yes & \multirow{2}{*}{ yes } \\
characteristics & & & \\
\hline $\mathrm{N}$ & 1364 & 1357 & 1168 \\
\hline \hline
\end{tabular}

Notes: Dependent variable is residualized change in log county employment over specified horizon (see text for details). Coefficients obtained from regression of residual on TVA dummy and baseline controls. 'Spline in levels' specification forms residual assuming agglomeration function is three piece spline in levels with coefficients from column (4) of Table V. 'Spline in Logs' specification assumes agglomeration function is three piece spline in log of manufacturing density with coefficients from coulmn (4) of Table VI. Standard errors clustered by state. 
Figure I: The TVA Service Area

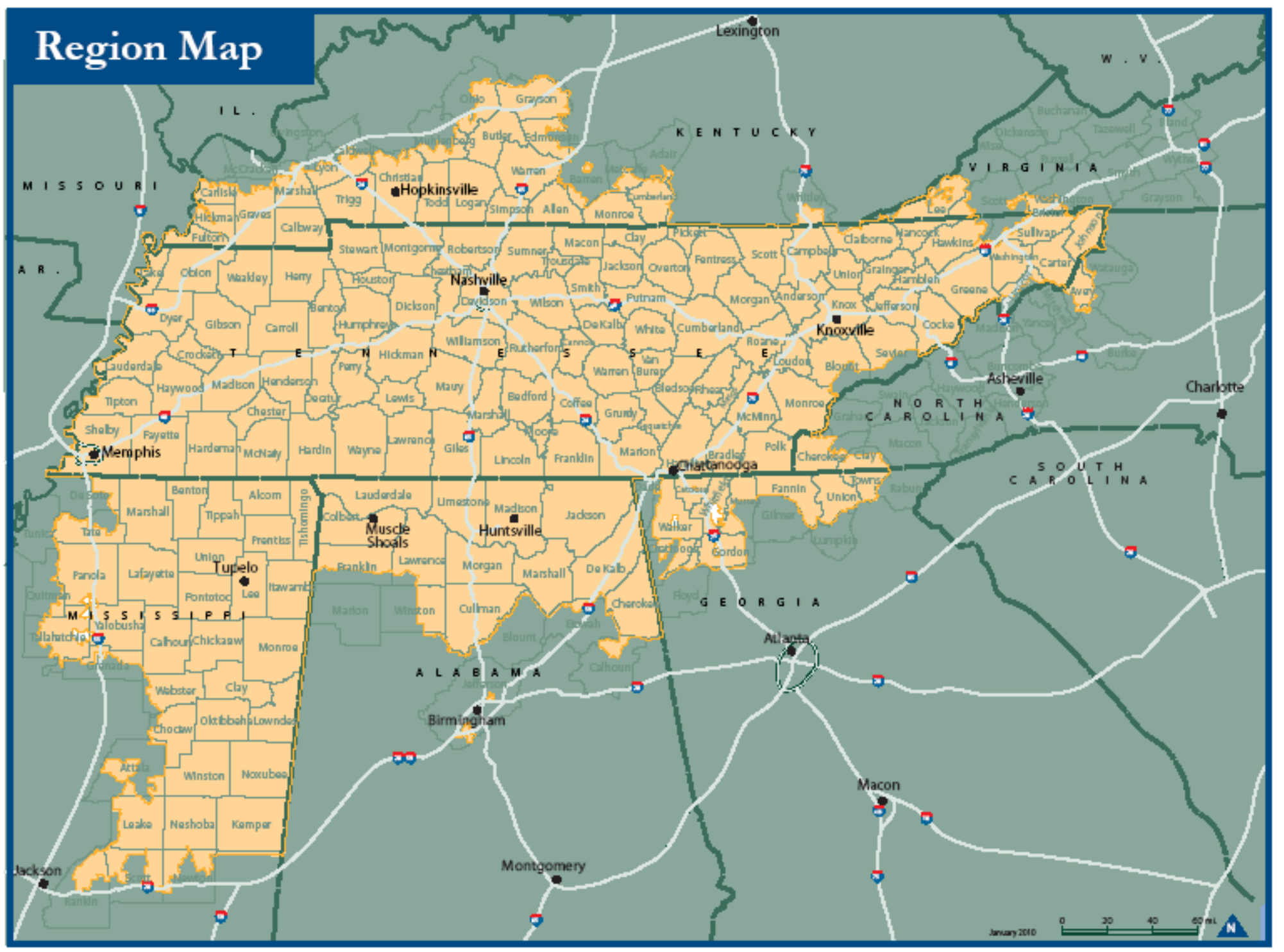

Notes: Figure depicts TVA service area as of 2010. 


\section{Figure II: Federal Transfers to TVA by Year (2000 Dollars)}

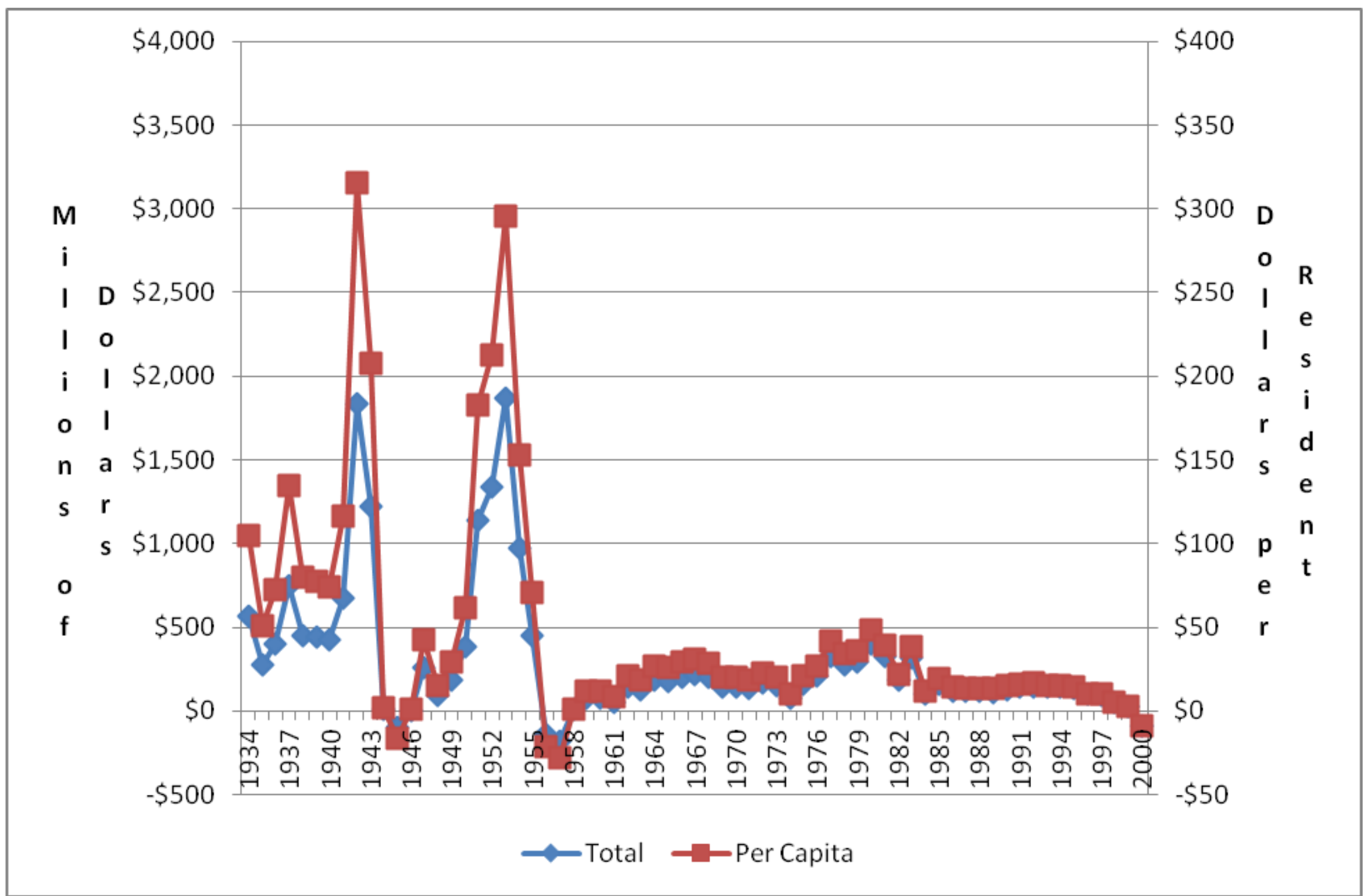

Notes: Federal transfers defined as net federal outlays plus property transfers minus repayments (see Data Appendix for sources). 


\section{Figure III: Weight on Untreated Counties}

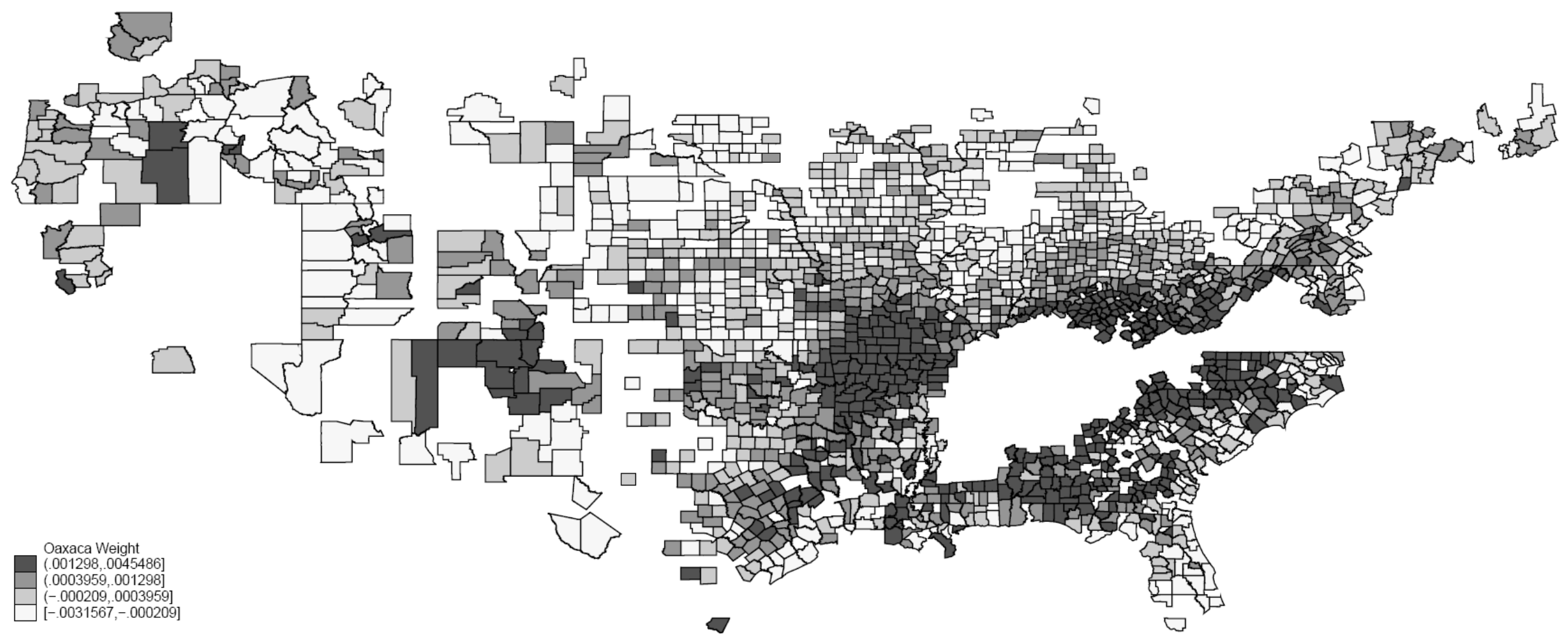

Notes: In a Oaxaca-Blinder regression, each control county is implicitly assigned a weight: counties that look more similar to TVA counties in the years before TVA receive more weight. The weight, which may be negative, is proportional to an estimate of the odds of treatment. See Kline (2011) for discussion. 


\section{Figure IVa: Dynamics under Linear Agglomeration}
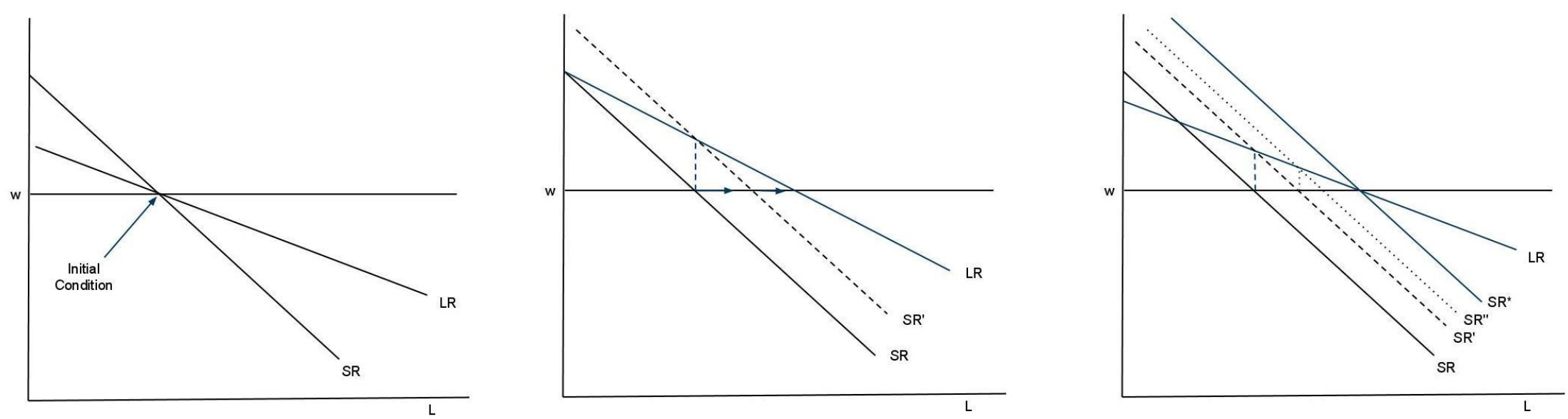

\section{Figure IVb: Dynamics under Nonlinear Agglomeration}
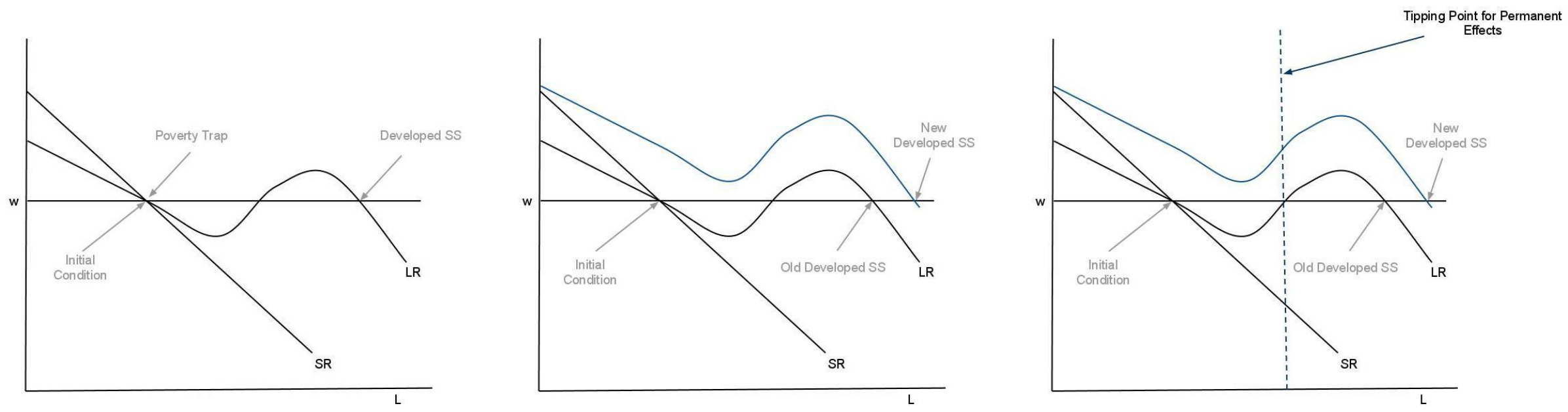

Notes: In each figure, the horizontal axis is log manufacturing density and the vertical axis is the log manufacturing wage. SR and LR refer to short run and long run inverse demand curves respectively (see section IV.C of text). Figure IVa depicts convergence from initial condition to the new unique steady state under linear agglomeration after a permanent productivity shift. Figure IVb depicts effects of transitory productivity shift on steady state in the presence of nonlinear agglomeration effects. 
Figure V: Short and Long Run Inverse Labor Demand Functions

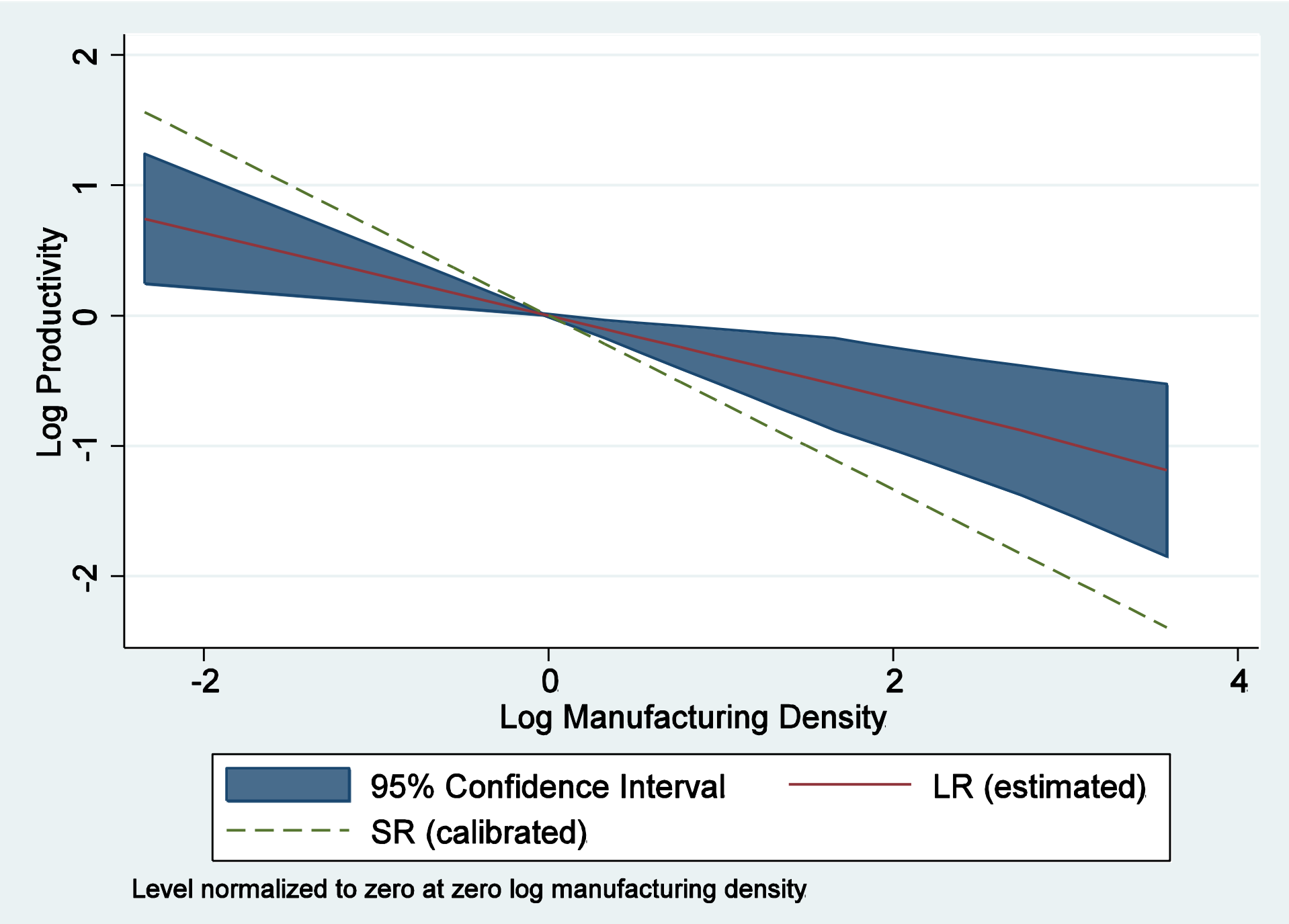

Notes: This figure depicts the short and long run inverse labor demand functions implied by our estimates from column (4) of Table VI, together with a 95\% confidence interval for the long run inverse demand function. The short run inverse demand function is calibrated with slope of -1.5 based on Hamermesh (1993). 
Table A1: Decadalized Impact of TVA on Growth Rate of Outcomes of Counties Around TVA (1940-2000)

\begin{tabular}{|c|c|c|c|c|c|c|c|}
\hline & & $\begin{array}{c}\text { Point Estimate } \\
\text { (Unadjusted) }\end{array}$ & Clustered S.E. & $\begin{array}{c}\text { Point Estimate } \\
\text { (Controls) }\end{array}$ & Clustered S.E. & Spatial HAC & $\mathrm{N}$ \\
\hline & Outcome & (1) & $(2)$ & (3) & (4) & (5) & (6) \\
\hline (1) & Population & -0.022 & $(0.022)$ & 0.020 & $(0.024)$ & $(0.025)$ & 1881 \\
\hline$(2)$ & Employment & 0.009 & $(0.024)$ & 0.011 & $(0.023)$ & $(0.021)$ & 1906 \\
\hline (2) & Average Manufacturing Wage & $0.024 * * *$ & $(0.006)$ & 0.005 & $(0.004)$ & $(0.004)$ & 1101 \\
\hline (3) & Agricultural Employment & $-0.115^{* * *}$ & $(0.027)$ & -0.030 & $(0.024)$ & $(0.021)$ & 1881 \\
\hline (4) & Manufacturing Employment & -0.006 & $(0.025)$ & 0.015 & $(0.029)$ & $(0.025)$ & 1881 \\
\hline (5) & Value of Farm Production & -0.027 & $(0.025)$ & 0.017 & $(0.030)$ & $(0.026)$ & 1877 \\
\hline (6) & Median Family Income (1950-2000 only) & $0.062 * * *$ & $(0.013)$ & 0.011 & $(0.013)$ & $(0.018)$ & 1877 \\
\hline (7) & Average Agricultural Land Value & $0.070 * * *$ & $(0.026)$ & -0.006 & $(0.027)$ & $(0.029)$ & 1880 \\
\hline
\end{tabular}

Note: Counties arriound TVA are defined as counties neighboring TVA and counties neighboring counties neighboring TVA. Column (1) gives the unconditional difference between counties around TVA and non-TVA counties in the 1940-2000 change in the log of the relevant outcome divided by six. Column (3) adjusts for pre-program differences between counties around TVA and controls via a Oaxaca-Blinder regression as in Kline (2011). Covariates include time invariant geographic characteristics and levels and trends in pre-program industrial mix, population, and demographic characteristics (see Section III.A for full list of covariates). Clustered S.E. columns provide standard errors estimates clustered by state. Spatial HAC column provides standard

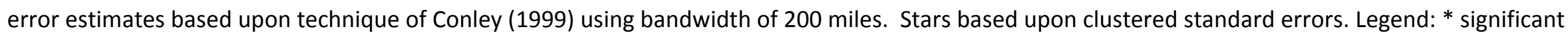
at $10 \%$ level, ${ }^{* *}$ significant at $5 \%$ level, ${ }^{* * *}$ significant at $1 \%$ level. 
Table A2: Alternative Structural Estimates of Agglomeration Function (Wage Coefficient is estimated Instead of Imputed)

\begin{tabular}{|c|c|c|c|c|c|c|}
\hline & (1) & $(2)$ & (3) & (4) & (5) & (6) \\
\hline & OLS & OLS & OLS & 2SLS & 2SLS & 2SLS \\
\hline \multicolumn{7}{|c|}{ Change in Manufacturing Density Spline Components: } \\
\hline & 0.028 & 0.022 & 0.022 & 0.065 & 0.054 & 0.053 \\
\hline \multirow[t]{3}{*}{ Low } & $(0.009)$ & $(0.009)$ & $(0.009)$ & $(0.022)$ & $(0.022)$ & $(0.022)$ \\
\hline & & & & {$[124.71]$} & {$[115.85]$} & [114.58] \\
\hline & 0.010 & 0.010 & 0.010 & 0.023 & 0.023 & 0.022 \\
\hline \multirow[t]{3}{*}{ Medium } & $(0.004)$ & $(0.004)$ & $(0.004)$ & $(0.006)$ & $(0.006)$ & $(0.007)$ \\
\hline & & & & [102.18] & [101.58] & [102.31] \\
\hline & -0.000 & -0.000 & -0.000 & 0.000 & 0.000 & 0.000 \\
\hline \multirow[t]{2}{*}{ High } & $(0.001)$ & $(0.001)$ & $(0.001)$ & $(0.001)$ & $(0.001)$ & $(0.001)$ \\
\hline & & & & [31.83] & [31.30] & [25.89] \\
\hline \multirow[t]{2}{*}{ Log Manufacturing Wages } & 0.072 & 0.070 & 0.070 & 0.074 & 0.072 & 0.072 \\
\hline & $(0.037)$ & $(0.037)$ & $(0.037)$ & $(0.039)$ & $(0.039)$ & $(0.038)$ \\
\hline \multirow[t]{2}{*}{ TVA } & 0.012 & 0.016 & 0.014 & 0.003 & 0.007 & 0.006 \\
\hline & $(0.013)$ & $(0.013)$ & $(0.014)$ & $(0.012)$ & $(0.012)$ & $(0.013)$ \\
\hline Regional Trends & no & no & yes & no & no & yes \\
\hline 1940 Manufacturing Density & no & yes & yes & no & yes & yes \\
\hline Decade Effects & yes & yes & yes & yes & yes & yes \\
\hline Controls for 1920 and 1930 characteristics & yes & yes & yes & yes & yes & yes \\
\hline P-value equal slopes & 0.000 & 0.002 & 0.002 & 0.000 & 0.001 & 0.002 \\
\hline P-value slopes equal zero & 0.001 & 0.005 & 0.006 & 0.000 & 0.002 & 0.005 \\
\hline $\mathrm{N}$ & 5462 & 5462 & 5462 & 5328 & 5328 & 5328 \\
\hline
\end{tabular}

Notes: This table reports estimates of models similar to the ones in Table $\mathrm{V}$, but here the coefficient on wages is estimated, not calibrated. Dependent variable is change in log county manufacturing employment.

Manufacturing density is manufacturing employment per square mile. Standard errors clustered by state in parentheses. Angrist-Pischke cluster robust first stage F-stat in brackets. All estimates weighted by 1950 county population. "Low" refers to spline component corresponding to density below 60th percentile of 1980 distribution, "Medium" to density between 60th and 85th percentile of 1980 distribution, and "High" to density above 85th percentile of 1980 distribution. Spline coefficients give the proportional effect on labor demand of an increase in lagged manufacturing density of one worker per square mile over the relevant range. 
Table A3: Alternative Structural Estimates of Agglomeration Function (Alternate Values for Short Run Elasticity of Demand)

\begin{tabular}{|c|c|c|c|c|c|c|}
\hline & (1) & $(2)$ & (3) & (4) & (5) & (6) \\
\hline & 2SLS & 2SLS & 2SLS & 2SLS & $2 S L S$ & $2 S L S$ \\
\hline \multicolumn{7}{|c|}{ Change in Manufacturing Density Spline Components: } \\
\hline & 0.079 & 0.070 & 0.069 & 0.095 & 0.087 & 0.087 \\
\hline \multirow[t]{3}{*}{ Low } & $(0.026)$ & $(0.026)$ & $(0.026)$ & $(0.035)$ & $(0.036)$ & $(0.036)$ \\
\hline & {$[124.66]$} & {$[115.79]$} & [114.53] & [124.66] & {$[115.79]$} & [114.53] \\
\hline & 0.028 & 0.028 & 0.027 & 0.033 & 0.033 & 0.032 \\
\hline \multirow[t]{3}{*}{ Medium } & $(0.008)$ & $(0.008)$ & $(0.008)$ & $(0.012)$ & $(0.012)$ & $(0.012)$ \\
\hline & [100.33] & [99.71] & {$[100.36]$} & [100.33] & [99.71] & [100.36] \\
\hline & 0.001 & 0.001 & 0.001 & 0.001 & 0.001 & 0.001 \\
\hline \multirow[t]{2}{*}{ High } & $(0.001)$ & $(0.001)$ & $(0.001)$ & $(0.001)$ & $(0.001)$ & $(0.001)$ \\
\hline & [31.91] & [31.37] & [25.98] & [31.91] & [31.37] & [25.98] \\
\hline Log Manufacturing Wages & -1 & -1 & -1 & -2 & -2 & -2 \\
\hline TVA & $\begin{array}{c}0.005 \\
(0.012)\end{array}$ & $\begin{array}{c}0.009 \\
(0.012)\end{array}$ & $\begin{array}{c}0.008 \\
(0.013)\end{array}$ & $\begin{array}{c}0.007 \\
(0.013)\end{array}$ & $\begin{array}{c}0.011 \\
(0.013)\end{array}$ & $\begin{array}{c}0.011 \\
(0.014)\end{array}$ \\
\hline Regional Trends & no & no & yes & no & no & yes \\
\hline 1940 Manufacturing Density & no & yes & yes & no & yes & yes \\
\hline Decade Effects & yes & yes & yes & yes & yes & yes \\
\hline Controls for 1920 and 1930 characteristics & yes & yes & yes & yes & yes & yes \\
\hline P-value equal slopes & 0.000 & 0.000 & 0.001 & 0.001 & 0.002 & 0.004 \\
\hline P-value slopes equal zero & 0.000 & 0.001 & 0.003 & 0.003 & 0.006 & 0.010 \\
\hline $\mathrm{N}$ & 5462 & 5462 & 5462 & 5328 & 5328 & 5328 \\
\hline
\end{tabular}

Notes: This table reports estimates of models similar to the ones in Table V, using alternative values for th short run elasticity of demand. Dependent variable is change in log county manufacturing employment.

Manufacturing density is manufacturing employment per square mile. Standard errors clustered by state in parentheses. Angrist-Pischke cluster robust first stage F-stat in brackets. All estimates weighted by 1950 county population. "Low" refers to spline component corresponding to density below 60th percentile of 1980 distribution, "Medium" to density between 60th and 85th percentile of 1980 distribution, and "High" to density above 85th percentile of 1980 distribution. Spline coefficients give the proportional effect on labor demand of an increase in lagged manufacturing density of one worker per square mile over the relevant range. 
Table A4: Alternative Structural Estimates of Agglomeration Function (Tercile Knots Different from Baseline)

\begin{tabular}{|c|c|c|c|c|c|c|}
\hline & (1) & $(2)$ & (3) & (4) & (5) & (6) \\
\hline & OLS & OLS & OLS & 2SLS & $2 S L S$ & 2SLS \\
\hline \multicolumn{7}{|c|}{ Change in Manufacturing Density Spline Components: } \\
\hline & 0.058 & 0.029 & 0.029 & 0.170 & 0.133 & 0.138 \\
\hline \multirow[t]{3}{*}{ Bottom Tercile } & $(0.034)$ & $(0.036)$ & $(0.036)$ & $(0.097)$ & $(0.110)$ & $(0.110)$ \\
\hline & & & & {$[120.81]$} & [91.87] & {$[90.72]$} \\
\hline & 0.020 & 0.018 & 0.017 & 0.092 & 0.086 & 0.085 \\
\hline \multirow[t]{3}{*}{ Middle Tercile } & $(0.008)$ & $(0.008)$ & $(0.008)$ & $(0.025)$ & $(0.025)$ & $(0.026)$ \\
\hline & & & & [78.89] & [77.36] & [76.20] \\
\hline & 0.000 & 0.000 & 0.000 & 0.001 & 0.001 & 0.001 \\
\hline \multirow[t]{2}{*}{ Top Tercile } & $(0.001)$ & $(0.001)$ & $(0.001)$ & $(0.001)$ & $(0.001)$ & $(0.001)$ \\
\hline & & & & [32.64] & [32.32] & [26.75] \\
\hline Log Manufacturing Wages & -1.5 & -1.5 & -1.5 & -1.5 & -1.5 & -1.5 \\
\hline \multirow[t]{2}{*}{ TVA } & 0.023 & 0.026 & 0.028 & 0.007 & 0.010 & 0.011 \\
\hline & $(0.014)$ & $(0.014)$ & $(0.015)$ & $(0.013)$ & $(0.013)$ & $(0.014)$ \\
\hline Regional Trends & no & no & yes & no & no & yes \\
\hline 1940 Manufacturing Density & no & yes & yes & no & yes & yes \\
\hline Decade Effects & yes & yes & yes & yes & yes & yes \\
\hline Controls for 1920 and 1930 characteristics & yes & yes & yes & yes & yes & yes \\
\hline P-value equal slopes & 0.046 & 0.090 & 0.118 & 0.001 & 0.003 & 0.004 \\
\hline P-value slopes equal zero & 0.101 & 0.181 & 0.228 & 0.002 & 0.008 & 0.011 \\
\hline $\mathrm{N}$ & 5462 & 5462 & 5462 & 5328 & 5328 & 5328 \\
\hline
\end{tabular}

Notes: This table reports estimates of models similar to the ones in Table $\mathrm{V}$, using different values for the spline knots. Dependent variable is change in log county manufacturing employment. Manufacturing density is manufacturing employment per square mile. Standard errors clustered by state in parentheses. Angrist-Pischke cluster robust first stage F-stat in brackets. All estimates weighted by 1950 county population. "Bottom Tercile" refers to spline component corresponding to density below 33rd percentile of 1980 distribution, "Middle Tercile" to density between 33rd and 66th percentile of 1980 distribution, and "Top Tercile" to density above 66th percentile of 1980 distribution. Spline coefficients give the proportional effect on labor demand of an increase in lagged manufacturing density of one worker per square mile over the relevant range. 
Table A5: Estimated Benefits of TVA

\begin{tabular}{|c|c|c|c|c|c|c|}
\hline (1) & (2) & (3) & (4) & (5) & (6) & (7) \\
\hline Year & $\begin{array}{c}\text { Log } \\
\text { Manufacturing } \\
\text { Wage Bill (2000 } \\
\text { \$) }\end{array}$ & $\begin{array}{l}\text { Direct } \\
\text { Productivity } \\
\text { Effect }\end{array}$ & $\begin{array}{l}\text { Utility Gain in } \\
\text { Manufacturing } \\
\text { Sector } \\
\text { (Fixed Supply) }\end{array}$ & $\begin{array}{l}\text { Dollar Value } \\
\text { (Fixed Supply) }\end{array}$ & $\begin{array}{c}\text { Utility Gain in } \\
\text { Manufacturing } \\
\text { Sector } \\
\text { (Variable Supply) }\end{array}$ & $\begin{array}{c}\text { Dollar Value } \\
\text { (Variable Supply) }\end{array}$ \\
\hline 1940 & 25.558 & 0.000 & $0.00 \%$ & $\$ 0$ & $0.00 \%$ & $\$ 0$ \\
\hline 1941 & 25.614 & 0.004 & $0.02 \%$ & $\$ 26,258,336$ & $0.01 \%$ & $\$ 18,436,704$ \\
\hline 1942 & 25.670 & 0.008 & $0.04 \%$ & $\$ 55,540,180$ & $0.03 \%$ & $\$ 38,996,297$ \\
\hline 1943 & 25.726 & 0.013 & $0.06 \%$ & $\$ 88,106,638$ & $0.04 \%$ & $\$ 61,862,108$ \\
\hline 1944 & 25.782 & 0.017 & $0.08 \%$ & $\$ 124,238,859$ & $0.06 \%$ & $\$ 87,231,540$ \\
\hline 1945 & 25.838 & 0.021 & $0.10 \%$ & $\$ 164,239,478$ & $0.07 \%$ & $\$ 115,317,080$ \\
\hline 1946 & 25.894 & 0.025 & $0.12 \%$ & $\$ 208,434,157$ & $0.08 \%$ & $\$ 146,347,387$ \\
\hline 1947 & 25.950 & 0.029 & $0.14 \%$ & $\$ 257,173,235$ & $0.10 \%$ & $\$ 180,568,441$ \\
\hline 1948 & 26.006 & 0.034 & $0.16 \%$ & $\$ 310,833,488$ & $0.11 \%$ & $\$ 218,244,790$ \\
\hline 1949 & 26.062 & 0.038 & $0.18 \%$ & $\$ 369,820,015$ & $0.12 \%$ & $\$ 259,660,862$ \\
\hline 1950 & 26.118 & 0.042 & $0.20 \%$ & $\$ 434,568,247$ & $0.14 \%$ & $\$ 305,122,386$ \\
\hline 1951 & 26.174 & 0.046 & $0.22 \%$ & $\$ 505,546,099$ & $0.15 \%$ & $\$ 354,957,899$ \\
\hline 1952 & 26.230 & 0.050 & $0.24 \%$ & $\$ 583,256,264$ & $0.17 \%$ & $\$ 409,520,356$ \\
\hline 1953 & 26.285 & 0.055 & $0.26 \%$ & $\$ 668,238,673$ & $0.18 \%$ & $\$ 469,188,855$ \\
\hline 1954 & 26.341 & 0.059 & $0.28 \%$ & $\$ 761,073,108$ & $0.19 \%$ & $\$ 534,370,480$ \\
\hline 1955 & 26.397 & 0.063 & $0.30 \%$ & $\$ 862,382,009$ & $0.21 \%$ & $\$ 605,502,262$ \\
\hline 1956 & 26.453 & 0.067 & $0.32 \%$ & $\$ 972,833,459$ & $0.22 \%$ & $\$ 683,053,280$ \\
\hline 1957 & 26.509 & 0.071 & $0.34 \%$ & $\$ 1,093,144,378$ & $0.24 \%$ & $\$ 767,526,903$ \\
\hline 1958 & 26.565 & 0.076 & $0.36 \%$ & $\$ 1,224,083,931$ & $0.25 \%$ & $\$ 859,463,186$ \\
\hline 1959 & 26.621 & 0.080 & $0.38 \%$ & $\$ 1,366,477,170$ & $0.26 \%$ & $\$ 959,441,417$ \\
\hline 1960 & 26.677 & 0.084 & $0.39 \%$ & $\$ 1,521,208,918$ & $0.28 \%$ & $\$ 1,068,082,857$ \\
\hline 1961 & 26.706 & 0.084 & $0.39 \%$ & $\$ 1,561,158,208$ & $0.28 \%$ & $\$ 1,096,132,359$ \\
\hline 1962 & 26.734 & 0.084 & $0.39 \%$ & $\$ 1,602,147,503$ & $0.28 \%$ & $\$ 1,124,912,076$ \\
\hline 1963 & 26.762 & 0.083 & $0.39 \%$ & $\$ 1,644,203,589$ & $0.28 \%$ & $\$ 1,154,440,818$ \\
\hline 1964 & 26.791 & 0.083 & $0.39 \%$ & $\$ 1,687,353,937$ & $0.27 \%$ & $\$ 1,184,737,871$ \\
\hline 1965 & 26.819 & 0.083 & $0.39 \%$ & $\$ 1,731,626,713$ & $0.27 \%$ & $\$ 1,215,823,011$ \\
\hline 1966 & 26.847 & 0.083 & $0.39 \%$ & $\$ 1,777,050,799$ & $0.27 \%$ & $\$ 1,247,716,518$ \\
\hline 1967 & 26.875 & 0.083 & $0.39 \%$ & $\$ 1,823,655,811$ & $0.27 \%$ & $\$ 1,280,439,187$ \\
\hline 1968 & 26.904 & 0.082 & $0.39 \%$ & $\$ 1,871,472,116$ & $0.27 \%$ & $\$ 1,314,012,337$ \\
\hline 1969 & 26.932 & 0.082 & $0.39 \%$ & $\$ 1,920,530,852$ & $0.27 \%$ & $\$ 1,348,457,832$ \\
\hline 1970 & 26.960 & 0.082 & $0.39 \%$ & $\$ 1,970,863,945$ & $0.27 \%$ & $\$ 1,383,798,089$ \\
\hline 1971 & 26.989 & 0.082 & $0.38 \%$ & $\$ 2,022,504,132$ & $0.27 \%$ & $\$ 1,420,056,092$ \\
\hline 1972 & 27.017 & 0.082 & $0.38 \%$ & $\$ 2,075,484,977$ & $0.27 \%$ & $\$ 1,457,255,409$ \\
\hline 1973 & 27.045 & 0.081 & $0.38 \%$ & $\$ 2,129,840,896$ & $0.27 \%$ & $\$ 1,495,420,203$ \\
\hline 1974 & 27.074 & 0.081 & $0.38 \%$ & $\$ 2,185,607,175$ & $0.27 \%$ & $\$ 1,534,575,251$ \\
\hline 1975 & 27.102 & 0.081 & $0.38 \%$ & $\$ 2,242,819,993$ & $0.27 \%$ & $\$ 1,574,745,953$ \\
\hline 1976 & 27.130 & 0.081 & $0.38 \%$ & $\$ 2,301,516,445$ & $0.27 \%$ & $\$ 1,615,958,355$ \\
\hline 1977 & 27.159 & 0.081 & $0.38 \%$ & $\$ 2,361,734,561$ & $0.27 \%$ & $\$ 1,658,239,160$ \\
\hline 1978 & 27.187 & 0.080 & $0.38 \%$ & $\$ 2,423,513,334$ & $0.27 \%$ & $\$ 1,701,615,745$ \\
\hline 1979 & 27.215 & 0.080 & $0.38 \%$ & $\$ 2,486,892,741$ & $0.26 \%$ & $\$ 1,746,116,180$ \\
\hline 1980 & 27.243 & 0.080 & $0.38 \%$ & $\$ 2,551,913,767$ & $0.26 \%$ & $\$ 1,791,769,241$ \\
\hline 1981 & 27.224 & 0.080 & $0.38 \%$ & $\$ 2,495,368,890$ & $0.26 \%$ & $\$ 1,752,067,518$ \\
\hline 1982 & 27.204 & 0.080 & $0.37 \%$ & $\$ 2,440,061,597$ & $0.26 \%$ & $\$ 1,713,234,738$ \\
\hline 1983 & 27.184 & 0.079 & $0.37 \%$ & $\$ 2,385,965,071$ & $0.26 \%$ & $\$ 1,675,252,071$ \\
\hline 1984 & 27.164 & 0.079 & $0.37 \%$ & $\$ 2,333,053,070$ & $0.26 \%$ & $\$ 1,638,101,092$ \\
\hline 1985 & 27.144 & 0.079 & $0.37 \%$ & $\$ 2,281,299,917$ & $0.26 \%$ & $\$ 1,601,763,771$ \\
\hline 1986 & 27.124 & 0.079 & $0.37 \%$ & $\$ 2,230,680,485$ & $0.26 \%$ & $\$ 1,566,222,468$ \\
\hline 1987 & 27.104 & 0.079 & $0.37 \%$ & $\$ 2,181,170,190$ & $0.26 \%$ & $\$ 1,531,459,921$ \\
\hline 1988 & 27.084 & 0.078 & $0.37 \%$ & $\$ 2,132,744,975$ & $0.26 \%$ & $\$ 1,497,459,238$ \\
\hline 1989 & 27.064 & 0.078 & $0.37 \%$ & $\$ 2,085,381,300$ & $0.26 \%$ & $\$ 1,464,203,891$ \\
\hline 1990 & 27.044 & 0.078 & $0.37 \%$ & $\$ 2,039,056,133$ & $0.26 \%$ & $\$ 1,431,677,710$ \\
\hline 1991 & 27.025 & 0.078 & $0.37 \%$ & $\$ 1,993,746,936$ & $0.26 \%$ & $\$ 1,399,864,870$ \\
\hline 1992 & 27.005 & 0.078 & $0.36 \%$ & $\$ 1,949,431,657$ & $0.26 \%$ & $\$ 1,368,749,887$ \\
\hline 1993 & 26.985 & 0.077 & $0.36 \%$ & $\$ 1,906,088,718$ & $0.26 \%$ & $\$ 1,338,317,611$ \\
\hline 1994 & 26.965 & 0.077 & $0.36 \%$ & $\$ 1,863,697,006$ & $0.25 \%$ & $\$ 1,308,553,217$ \\
\hline 1995 & 26.945 & 0.077 & $0.36 \%$ & $\$ 1,822,235,862$ & $0.25 \%$ & $\$ 1,279,442,201$ \\
\hline 1996 & 26.925 & 0.077 & $0.36 \%$ & $\$ 1,781,685,073$ & $0.25 \%$ & $\$ 1,250,970,370$ \\
\hline 1997 & 26.905 & 0.077 & $0.36 \%$ & $\$ 1,742,024,859$ & $0.25 \%$ & $\$ 1,223,123,837$ \\
\hline 1998 & 26.885 & 0.076 & $0.36 \%$ & $\$ 1,703,235,868$ & $0.25 \%$ & $\$ 1,195,889,014$ \\
\hline 1999 & 26.865 & 0.076 & $0.36 \%$ & $\$ 1,665,299,164$ & $0.25 \%$ & $\$ 1,169,252,605$ \\
\hline 2000 & 26.845 & 0.076 & $0.36 \%$ & $\$ 1,628,196,220$ & $0.25 \%$ & $\$ 1,143,201,601$ \\
\hline
\end{tabular}

Notes: Column (1) reports the natural logarithm of totals from the Decennial Census and linearly interpolates inter-censal years. Column (2) provides interpolated estimates of the direct productivity effects of the TVA as described in the text. Column (3) multiplies column (2) by 0.047 , which is the utility elasticity under fixed labor supply, in order to arrive at the proportional impact on worker wages. Column (4) multiplies column (3) by the manufacturing wage bill in order to arrive at a dollar value. Column (5) multiplies column (2) by .033 , which is the utility elasticity when labor supply to the manufacturing sector exhibits a unit elasticity. Column (6) multiplies column (5) by the wage bill in order to arrive at a dollar value. 


\section{Figure A1 - Estimation Sample}

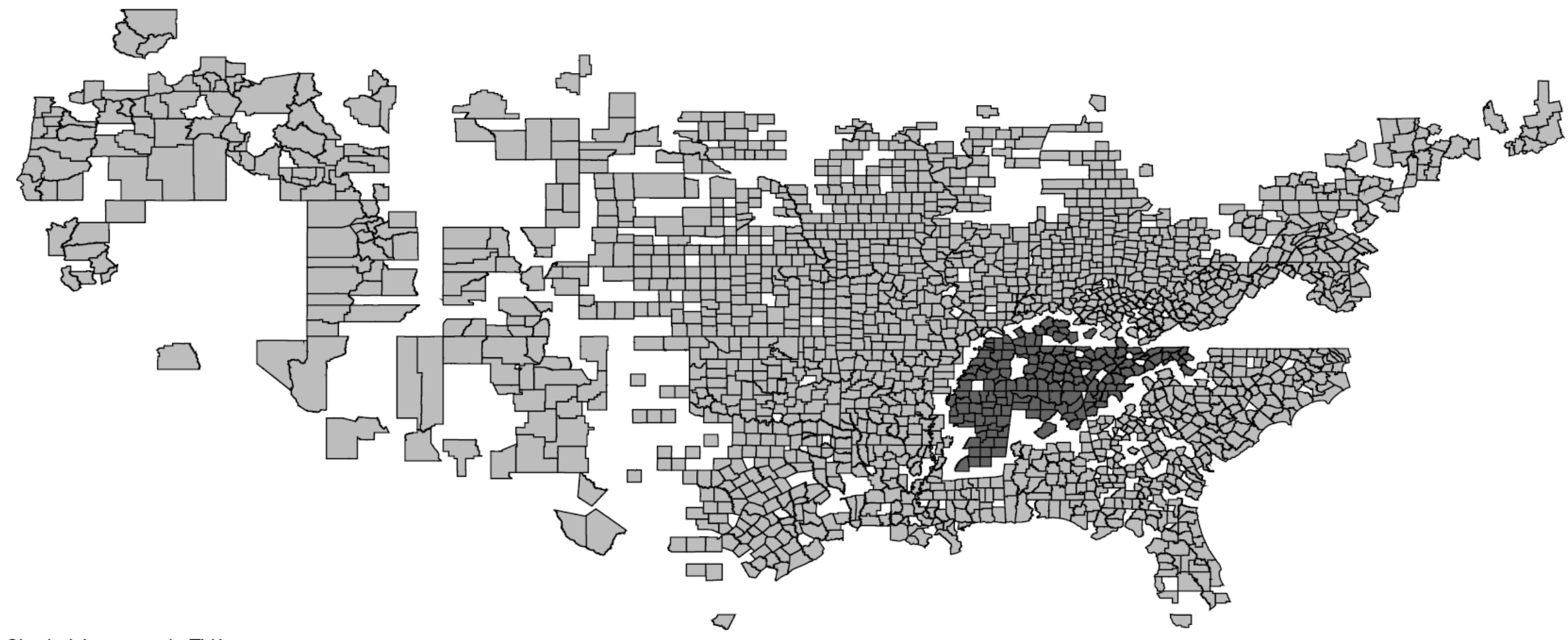

Shaded Areas are in TVA

$\square$

Notes: Map depicts the main estimation sample used in analysis. Counties in Virginia were dropped because of changes in county boundaries. Other non-TVA counties were dropped because of pre-program characteristics putting them in the bottom quartile of estimated propensity scores. Ring of counties adjacent to TVA were also dropped. 
Figure A2: Map of Proposed Authorities

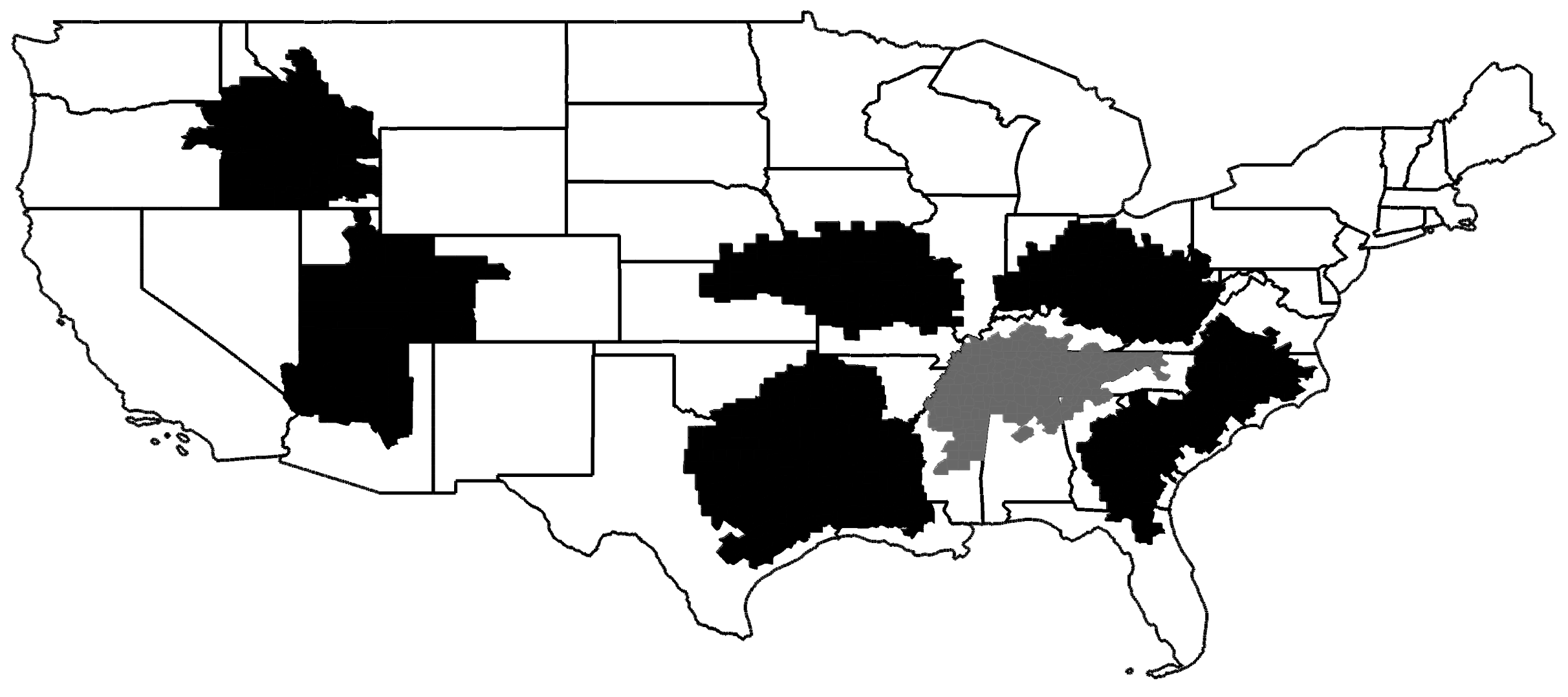

Notes: The map displays in black the six proposed authorities: the Atlantic Seaboard Authority, the Great Lakes-Ohio Valley Authority, the Missouri Valley Authority, the Arkansas Valley Authority, the Columbia Authority, and the Western Authority. The TVA region is displayed in gray. 